\title{
Sensor piezelétrico baseado na tecnologia dos eletretos termo-formados: aprimoramentos dos processos de produção
}

Dissertação de Mestrado apresentada à Escola de Engenharia de São Carlos da Universidade de São Paulo, como parte dos requisitos para obtenção do título de Mestre em Engenharia Elétrica.

Área de Concentração: Processamento de Sinais e Instrumentação.

Orientador: Prof. Tit. Ruy Alberto Corrêa Altafim

São Carlos 



\section{FOLHA DE JULGAMENTO}

Candidato: Licenciado DANIEL RODRIGO FALCONI.

Dissertação defendida e julgada em 12/02/2010 perante a Comissão Julgadora:
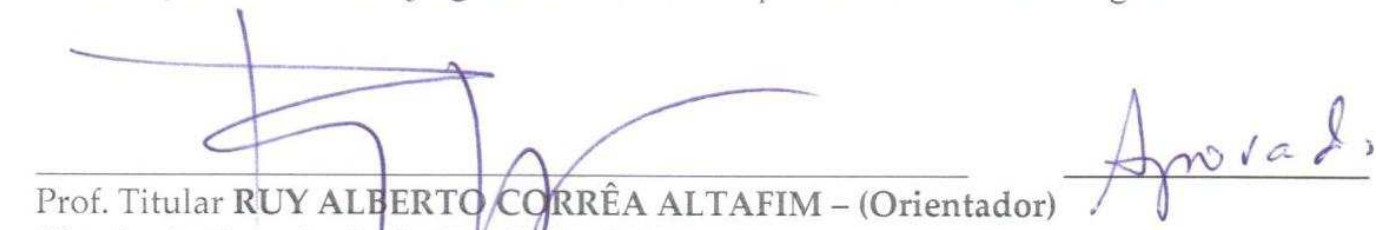

(Escola de Engenharia de São Carlos/USP)
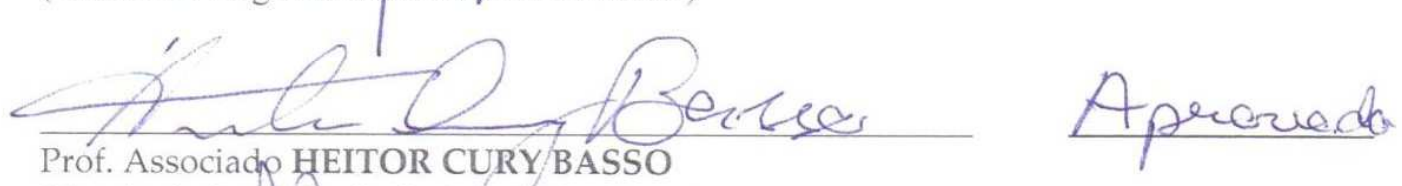

(Escola de Engenharia de Sãc/arlos/USP)

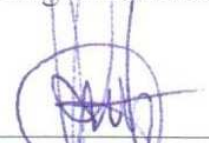

Prof. Associad JO

(Universidade Estadual de Campinas/UNICAMP)
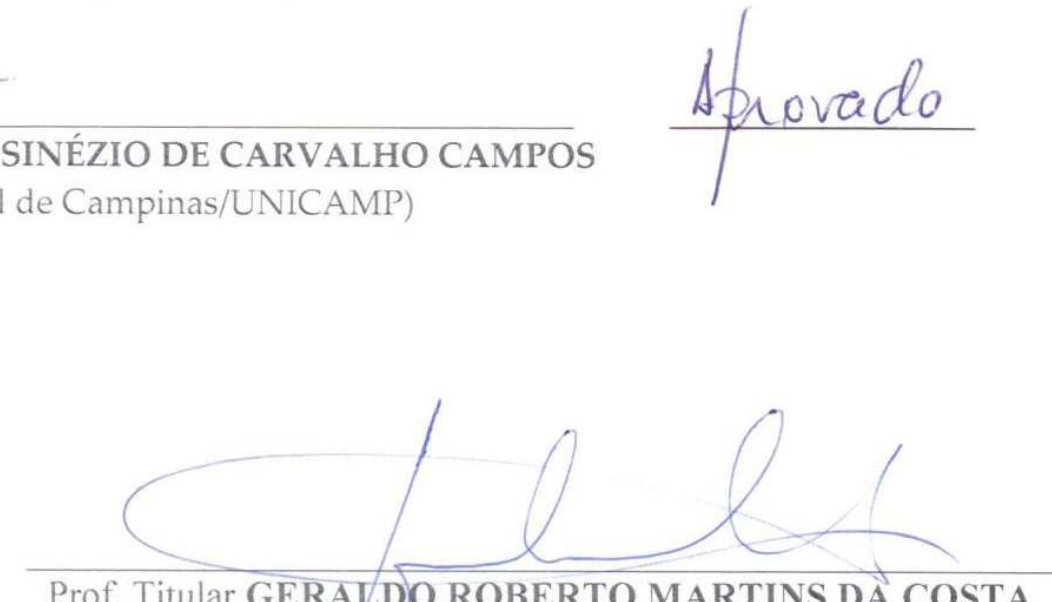

Prof. Titular GERALDO ROBERTO MARTINS DA COSTA

Coordenador do Programa de Pós-Graduação em Engenharia Elétrica e Presidente da Comissão de Pós-Graduação 

Dedico este trabalho a toda minha família, em especial, aos meus pais, Mauro Falconi e Creusa Aparecida Rodrigues Falconi, pelo distinto apoio e incentivo aos estudos que sempre me concederam. 



\section{Agradecimentos}

Ao Prof. Tit. Ruy Alberto Corrêa Altafim que, mediante sua expressiva tutoria contribuiu de forma efetiva, não somente para a conclusão do trabalho, como também para minha formação ética e profissional. Agradeço pela orientação acadêmica e técnica e pelo incentivo e motivação à pesquisa.

Ao aluno de doutorado e amigo Ruy Alberto Pisani Altafim pelas inúmeras discussões e esclarecimentos.

Ao aluno de mestrado Yuri Andrey Olivato Assagra pela constante ajuda no laboratório.

Ao Prof. Dr. Heitor Cury Basso, pela idealização do sistema de medidas desenvolvido neste trabalho.

Aos funcionários do Departamento de Engenharia Elétrica da Escola de Engenharia de São Carlos (SEL/EESC/USP), em especial, ao técnico de manutenção, Rui Bertho, pelo suporte técnico.

À Fundação de Amparo à Pesquisa do Estado de São Paulo (FAPESP), pelo auxílio financeiro concedido no período da realização deste trabalho, na forma de bolsa de estudos (2006/05528-0).

À Coordenação de Aperfeiçoamento de Pessoal de Nível Superior (CAPES), por possibilitar o acesso a inúmeras revistas e periódicos renomados gratuitamente, permitindo o desenvolvimento de um projeto de pesquisa de qualidade superior.

À Universidade de São Paulo (Escola de Engenharia de São Carlos - Departamento de Engenharia Elétrica) que acolheu este trabalho de mestrado, por meio da destinação de espaço físico e apoio administrativo.

E a todas as pessoas que se envolveram de forma direta e/ou indireta no desenvolvimento desta pesquisa. 



\section{Resumo}

FALCONI, D. R. Sensor piezelétrico baseado na tecnologia dos eletretos termo-formados: aprimoramentos dos processos de produção. 99 f. Dissertação (Mestrado em Engenharia Elétrica) - Escola de Engenharia de São Carlos, Universidade de São Paulo, São Carlos, 2010.

Este trabalho descreve dois novos aprimoramentos dos processos para a produção dos eletretos termo-formados, cuja tecnologia é prioritariamente voltada para sensores piezelétricos. Estes sensores constituem-se de dois filmes de Teflon ${ }^{\circledR}$ FEP unidos, contendo entre suas interfaces microbolhas com as superfícies superior e inferior carregadas eletricamente com polaridades opostas, formando grandes dipolos. Esta estrutura permite a alteração dos momentos de dipolo quando solicitada mecânica e eletricamente - o que confere a estrutura uma excelente atividade piezelétrica, com coeficientes piezelétricos atingindo valores superiores a 300 pC/N. No estágio atual, o processo para produção desses sensores é artesanal e produz, geralmente, amostras com deformações em suas bolhas. Contudo, os novos aprimoramentos, aqui apresentados, suprem as deficiências aludidas e possibilitam um maior controle da distribuição, altura e diâmetro das bolhas de ar. Os aprimoramentos do processo foram denominados laminação a quente e adesivo a frio. Basicamente, estes dois processos consistem em quatro etapas: a moldagem do filme de uma das camadas do sensor; a colagem das duas camadas de filmes do sensor; a metalização das superfícies do sensor e o carregamento elétrico, sendo a colagem o ponto crucial e diferente nos dois processos. Ressalta-se que suas principais contribuições relativas aos processos existentes foram a moldagem prévia do filme de uma das camadas e esses novos processos de colagem. Assim, estes aprimoramentos têm permitido um melhor controle das dimensões das bolhas e facilitado sobremaneira sua implementação em escala industrial. Desta forma, vislumbra-se um aumento significativo de aplicações comerciais desses sensores, a exemplo dos sensores de presença, teclados finos, balanças dinâmicas e sensores de pressão. Também como contribuição deste trabalho, coloca-se a implementação do sistema de medidas do coeficiente piezelétrico.

Palavras-Chave: Ferroeletretos, sensor piezelétrico termo-formado, Teflon ${ }^{\circledR}$ FEP, coeficiente piezelétrico. 



\begin{abstract}
FALCONI, D. R. Piezoelectric sensor based on electrets thermoforming technology: improvements on the production processes. 99 1. Dissertation (Master's Degree in Electric Engineering) - Engineering School of São Carlos, University of São Paulo, São Carlos, 2010.

This work describes two improvements on the production of piezoelectric sensors, which are based on thermo-formed electrets technology. These sensors which were previously prepared by fusing and molding two Teflon ${ }^{\circledR}$ FEP films into bubbles structures in a hot-press system, presented piezoelectric coefficients over 300 pC/N after properly electrical charging. However, this production system still presents many technical challenges, most of them concerning the bubble formation. With the improvements, called hot lamination and cold adhesive, a much better control of the distribution, height and diameter of the air bubbles could be obtained. These improvements process can be described into four main stages: the molding of one film; the sticking process of the two films; the metallization of their surfaces followed by electric charging. The sticking processes and the previous molding of the film are crucial and the great contribution of this work. With these contributions not only better sensor could be made but it also facilitated the industrial scale implementation of the sensors. Another expressive contribution of this work was the development of a system to measure the piezoelectric coefficient.
\end{abstract}

Keywords: Ferroelectrets, thermoformed piezoelectric sensor, Teflon ${ }^{\circledR}$ FEP, piezoelectric coefficient. 



\section{Lista de Figuras}

Figura 2.1 Representação esquemática da configuração de cargas elétricas dos eletretos produzidos por Eguchi (a) antes do processo de polarização, (b) logo após a suspensão do campo aplicado e (c) após decorrido pouco tempo.

Figura 2.2 Observação das cargas superficiais nos eletretos de cera de carnaúba em 22, 27 e 35 anos após a polarização. A magnitude da carga é mostrada em função da temperatura de polarização $T_{p}$. $O$ campo elétrico de polarização aplicado foi de $4 \mathrm{MV} / \mathrm{m}$.

Figura 2.3 Esquema da seção transversal de alguns eletretos típicos sem eletrodos ou com eletrodos: (a) eletreto mono polar não-metalizado, (b) eletreto com uma de suas faces metalizada contendo cargas superficiais e espaciais e (c) eletreto com duas faces metalizadas contendo cargas espaciais e dipolares.

Figura 2.4 (a) Diagrama de energia para um polímero. $\mathrm{T}_{\mathrm{e}}$, armadilhas de elétron; $\mathrm{T}_{\mathrm{h}}$, armadilhas de buraco. (b) Densidade de estados energéticos N(E) para um polímero. Estados localizados (armadilhas) estão sombreados; $\mathrm{E}_{\mathrm{c}}$ e $\mathrm{E}_{\mathrm{v}}$ são bordas de mobilidade da banda de condução e de valência, respectivamente.

Figura 2.5 Correntes termicamente estimuladas em circuito aberto para amostras de Teflon ${ }^{\circledR}$ FEP $25 \mu \mathrm{m}$ carregadas com feixes de elétrons das seguintes energias: $3 \mathrm{keV}, 5 \mathrm{keV}, 7 \mathrm{keV}, 10 \mathrm{keV}$.

Figura 2.6 Representação esquemática do método de carregamento térmico. .36

Figura 2.7 Representação esquemática do método de carregamento por feixe de elétrons.

Figura 2.8 Representação esquemática do método para obtenção dos fotoeletretos. .38

Figura 2.9 Representação esquemática do carregamento direto. .38

Figura 2.10 Representação esquemática do método de carregamento por descarga corona.

Figura 2.11 Representação esquemática do método de carregamento por descarga corona com grade (triodo- corona).

Figura 2.12 Sistema de carregamento por efeito impulsivo, onde $R_{1}=72 \Omega, R_{2}=44$ $\Omega, \mathrm{C}_{1}=1,35 \mathrm{mF}, \mathrm{C}_{2}=11 \mathrm{nF}$ e $\mathrm{G}$ é o centelhador.

Figura 2.13 Forma de onda de um carregamento impulsivo, com 1,2 $\mu$ s de frente de onda e $45 \mu$ s de tempo de meia onda. 
Figura 2.14 (a) Efeito piezelétrico direto e (b) inverso.

Figura 2.15 Imagem por microscopia eletrônica da seção transversal de um filme de PP celular de $70 \mu \mathrm{m}$ de espessura.

Figura 2.16 (a) Seção transversal de filme polipropileno celular em microscopia eletrônica. (b) Vista esquemática das cavidades e distribuição de cargas. 48

Figura 2.17 Estrutura capacitiva dos filmes de PP celular. 48

Figura 2.18 Representação da piezeletricidade primária (variação do momento dipolar com a deformação) em eletretos celulares com distribuição espacial de carga (acima) e em eletretos polares (abaixo). Sob compressão, os dipolos orientados e as cavidades carregadas (esquerda) ficam com momentos dipolares menores (direita).

Figura 2.19 Material piezelétrico poroso, com cavidades internas (esquerda) e duas camadas (direita), ambas terminadas por eletrodos

Figura 2.20 Eletreto polimérico poroso com camadas não porosas para proteção da carga depositada e deposição de eletrodos.

Figura 2.21 Esquema de preparação dos filmes de PET celulares por meio de (b) difusão de $\mathrm{CO}_{2}$ numa amostra virgem (a) submetida a uma alta de pressão, (c) tratamento térmico originando microcavidades, (d) estiramento do filme modificando sua estrutural e (e) carregamento elétrico interno por meio de descargas de micro-plasma nas cavidades.

Figura 2.22 Micrografia por escaneamento eletrônico da seção transversal de um filme de i-PP com esferas de vidro de 30 um de diâmetro.

Figura 2.23 Sanduíche multicamada formado por filmes de Teflon ${ }^{\circledR}$ FEP e alumínio. ...... 56

Figura 2.24 Dispositivo para obtenção dos transdutores poliméricos termo-formados........57

Figura 2.25 Detalhe das bolhas de ar entre os filmes poliméricos. ................................... 58

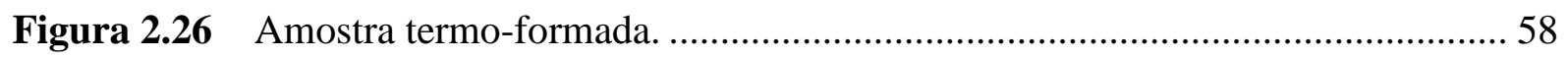

Figura 2.27 (a) Procedimento de preparação do filme celular fluorcarbonado, (b) Imagem obtida por microscopia eletrônica de varredura da seção transversal de um filme de cinco camadas, (c) esquema da seção transversal de um filme de três camadas, com sua distribuição de cargas após metalização e carregamento elétrico.

Figura 2.28 Modelo simplificado da estrutura de um ferroeletreto com duas camadas de dielétrico carregadas.

Figura 3.1 Imagem da prensa hidráulica utilizada no processo de moldagem do filme de Teflon ${ }^{\circledR}$ FEP. 
Figura 3.2 (a) Representação esquemática da etapa de moldagem do filme de Teflon $^{\circledR}$ FEP. (b) Imagem do filme de Teflon ${ }^{\circledR}$ FEP moldado. (c) Representação esquemática da seção transversal do filme moldado.

Figura 3.3 (a) Imagem da máquina laminadora Lassane L-280. (b) Representação esquemática do seu princípio de funcionamento.

Figura 3.4 Representação esquemática da etapa de fusão dos filmes plano e moldado.

Figura 3.5 Representação esquemática da seção transversal de uma amostra produzida pelo processo de laminação a quente.

Figura 3.6 Imagem da vista superior e seção transversal das amostras com bolhas de a) 3,2 $\mathrm{mm}$ de diâmetro e $230 \mu \mathrm{m}$ de altura, b) $3,8 \mathrm{~mm}$ de diâmetro e 280 $\mu \mathrm{m}$ de altura e c) $4,5 \mathrm{~mm}$ de diâmetro e $380 \mu \mathrm{m}$ de altura.

Figura 3.7 Representação esquemática da seção transversal de uma amostra produzida pelo processo adesivo a frio.

Figura 3.8 À esquerda, imagem da furadeira utilizada para gerar furos na fita adesiva dupla face e à direita, representação esquemática do passo de criação de furos na fita adesiva dupla face.

Figura 3.9 Processo adesivo a frio. (a) A matriz com o filme moldado é colocada no suporte guia, (b) a matriz com adesivo é colocada no suporte e pressionada contra o filme moldado, ficando agora com (c) a fita adesiva e sua película protetora (d) que, em seguida, é retirada. O próximo passo é colocar a (e) matriz com filme plano no suporte e (f) pressioná-la contra o filme moldado e com adesivo, originando, assim, (g) (h) uma amostra pelo processo adesivo a frio.

Figura 3.10 Imagem da vista superior e seção transversal das amostras com bolhas de a) $2,5 \mathrm{~mm}$ de diâmetro e $290 \mu \mathrm{m}$ de altura, b) 3,0 $\mathrm{mm}$ de diâmetro e 350 $\mu \mathrm{m}$ de altura e c) $3,5 \mathrm{~mm}$ de diâmetro e $290 \mu \mathrm{m}$ de altura.

Figura 3.11 Circuito utilizado para o carregamento das amostras por tensão impulsiva.

Figura 3.12 Representação esquemática da distribuição de cargas elétricas nas amostras produzidas pelos processos a) de laminação a quente e b) adesivo a frio após o carregamento elétrico.

Figura 4.1 Imagem do sistema de medidas do coeficiente piezelétrico $\mathrm{cp}$. .78

Figura 4.2 Representação esquemática do sistema para medição do coeficiente piezelétrico cp e suas conexões.

Figura 4.3 Forma de onda da tensão elétrica aplicada a bobina pelo gerador de funções Tektronix CFG253 (tensão de pico de 13,2 V e período de $40 \mathrm{~s}$ ). .79 
Figura 4.4 Interface do aplicativo para comunicação com o multímetro digital por meio da porta serial, aquisição e registro dos dados.

Figura 4.5 Gráfico típico da medida de carga elétrica de uma amostra piezelétrica sob solicitação mecânica periódica por meio do sistema desenvolvido neste trabalho.

Figura 4.6 Gráfico da medida de carga elétrica juntamente com sua reta de

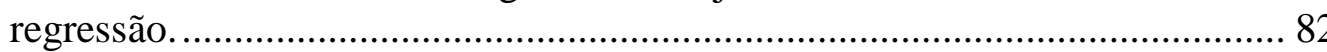

Figura 4.7 Gráfico da medida de carga elétrica com a reta de regressão subtraída........... 82 


\section{Lista de Tabelas}

Tabela 2.1 Distribuição de armadilhas para cargas negativas distribuídas em Teflon ${ }^{\circledR}$

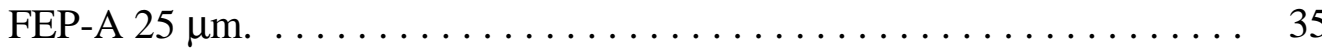

Tabela 2.2 Amostras em camadas rígidas (np) e macias (p) de Teflon ${ }^{\circledR}$ PTFE. . . . . 52

Tabela 4.1 Coeficiente piezelétrico cp das amostras com bolhas de 3,2 $\mathrm{mm}$ de diâmetro e $230 \mu \mathrm{m}$ de altura produzidas pelo processo de laminação a quente e carregadas por três descargas impulsivas com pico de $5,6 \mathrm{kV}$ (desvio padrão dos valores de $\mathrm{cp}$ igual a 4,98). . . . . . . . . . . .

Tabela 4.2 Coeficiente piezelétrico cp das amostras com bolhas de 3,8 $\mathrm{mm}$ de diâmetro e $280 \mu \mathrm{m}$ de altura produzidas pelo processo de laminação a quente e carregadas por três descargas impulsivas com pico de $5,6 \mathrm{kV}$ (desvio padrão dos valores de cp igual a 30,21 ). . . . . . . . . . .

Tabela 4.3 Coeficiente piezelétrico cp das amostras com bolhas de 4,5 $\mathrm{mm}$ de diâmetro e $380 \mu \mathrm{m}$ de altura produzidas pelo processo de laminação a quente e carregadas por três descargas impulsivas com pico de $5,6 \mathrm{kV}$ (desvio padrão dos valores de cp igual a 10,36). . . . . . . . . . . .

Tabela 4.4 Coeficiente piezelétrico cp das amostras com bolhas de 2,5 $\mathrm{mm}$ de diâmetro e $290 \mu \mathrm{m}$ de altura produzidas pelo processo de laminação a quente e carregadas por três descargas impulsivas com pico de $5,6 \mathrm{kV}$ (desvio padrão dos valores de cp igual a 17,37). . . . . . . . . . .

Tabela 4.5 Coeficiente piezelétrico cp das amostras com bolhas de 3,0 $\mathrm{mm}$ de diâmetro e $350 \mu \mathrm{m}$ de altura produzidas pelo processo de laminação a quente e carregadas por três descargas impulsivas com pico de $5,6 \mathrm{kV}$ (desvio padrão dos valores de cp igual a 21,16 ). . . . . . . . . . .

Tabela 4.6 Coeficiente piezelétrico cp das amostras com bolhas de 3,5 $\mathrm{mm}$ de diâmetro e $290 \mu \mathrm{m}$ de altura produzidas pelo processo de laminação a quente e carregadas por três descargas impulsivas com pico de $5,6 \mathrm{kV}$ (desvio padrão dos valores de cp igual a 53,81 ). . . . . . . . . . . . .

Tabela 4.7 Resumo dos valores dos coeficientes piezelétricos médios das amostras produzidas pelos processos laminação a quente e adesivo a frio. 



\title{
Lista de Abreviaturas e Siglas
}

\author{
AF Flúor polímero amorfo \\ $\mathrm{CO}_{2} \quad$ Dióxido de carbono \\ EMFi Filme eletromecânico (electromechanical film) \\ FEP Flúor etileno propileno \\ i-PP Polipropileno isotático \\ $\mathrm{N}_{2} \quad$ Nitrogênio \\ $\mathrm{N}_{2} \mathrm{O} \quad$ Óxido nitroso \\ PS Poliestireno \\ PTFE Politetrafluoretileno \\ PET Politereftalato de etileno \\ PP Polipropileno \\ PVDF Polifluoreto de vinilideno \\ TSC Corrente termicamente estimulada (themally stimulated current)
}





\section{Lista de Símbolos}

b

cp

$\mathrm{d}_{0}$

$\mathrm{d}_{1}$

$\mathrm{E}_{0}$

$\mathrm{E}_{1 \mathrm{a}}$

$E_{1 b}$

$\mathrm{E}_{\mathrm{c}}$

$\mathrm{E}_{\mathrm{v}}$
Permissividade elétrica relativa ou constante dielétrica

Permissividade elétrica do vácuo

Primeiro coeficiente de Towsend

Segundo coeficiente de Towsend

Constante de Boltzman

Frequência de liberação de cargas

Frequência de escape de cargas

Densidade superficial de carga aprisionada nos eletretos

Densidade superficial de carga induzida nos eletrodos

Deformação do espaçamento de ar

Pressão aplicada no sistema de duas camadas de eletretos com um espaçamento de ar entre elas

Variação da densidade de carga elétrica induzida nos eletrodos provocada pela aplicação de uma pressão

Extensão da cavidade

Altura da cavidade

Coeficiente piezelétrico

Espessura da região de ar entre os eletretos

Espessura da camada polimérica

Campo elétrico na região de ar gerado pelas cargas aprisionadas nas camadas poliméricas

Campo elétrico nas camadas poliméricas gerado pelas cargas induzidas nos eletrodos

Campo elétrico na região de ar gerado pelas cargas induzidas nos eletrodos

Borda de mobilidade da banda de condução

Borda de mobilidade da banda de valência 
N(E) Densidade de estados energéticos

$\mathrm{t}$

Tempo

$\mathrm{T}$

Temperatura

$\mathrm{T}_{\mathrm{e}} \quad$ Armadilha de elétron

$\mathrm{T}_{\mathrm{h}} \quad$ Armadilha de buraco

U Energia de ativação dos níveis de aprisionamento

V Tensão elétrica

$\mathrm{V}_{0} \quad$ Tensão elétrica gerada pelas cargas aprisionadas

$\mathrm{V}_{1} \quad$ Tensão elétrica gerada pelas cargas induzidas

Y Constante de elasticidade ou módulo de Young 


\section{Sumário}

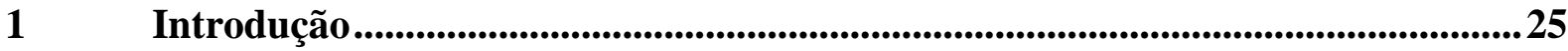

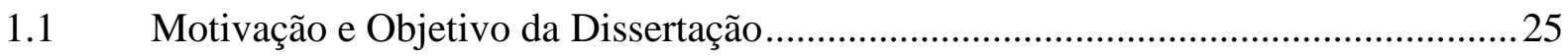

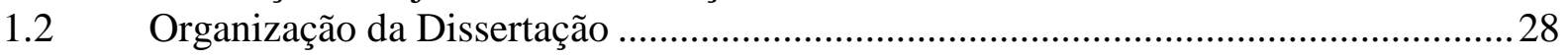

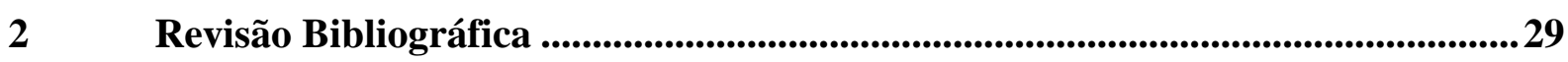

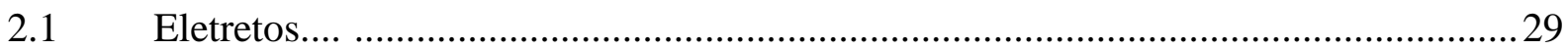

2.2 Processos de Formação de Eletretos ........................................................................... 33

2.2.1 Mecanismo de Aprisionamento de Portadores em Dielétricos Sólidos .......................33

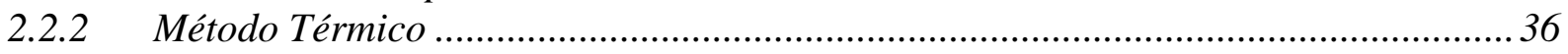

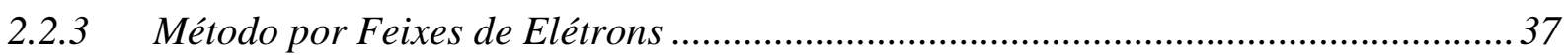

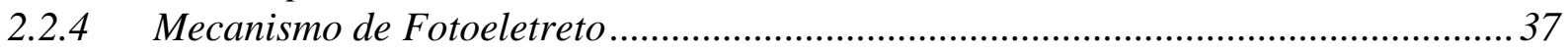

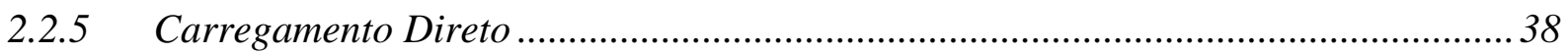

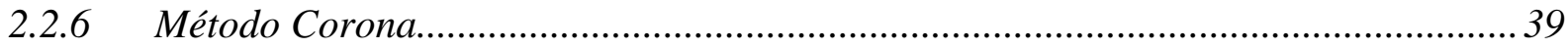

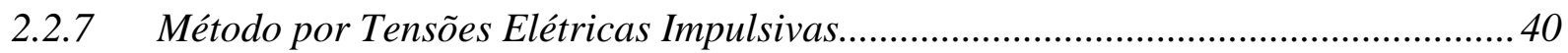

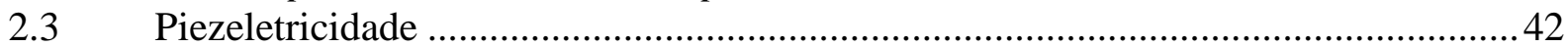

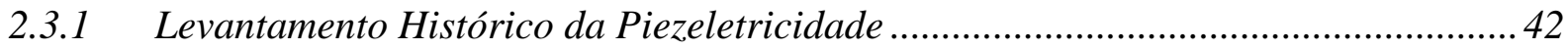

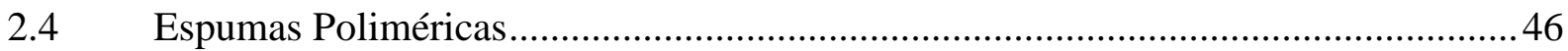

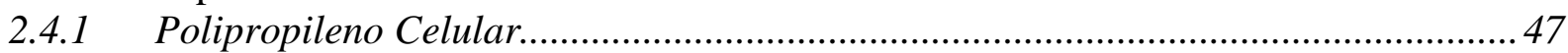

2.4.2 Eletretos Porosos Com Um Único Filme de PTFE .................................................... 50

2.4.3 Sanduíche de Camadas Com Eletretos Porosos de PTFE ..........................................51

2.4.4 Ferroeletretos de Politereftalato de Etileno ................................................................53

2.4.5 Polipropileno Poroso por Adição de Esferas Ocas de Vidro e Estiramento Biaxial. 55

2.5 Ferroeletretos com Estruturas Homogêneas ............................................................56

2.5.1 Transdutores Poliméricos Homogêneos em Multicamadas de Teflon ${ }^{\circledR}$ FEP ...............56

2.5.2 Transdutores de Eletretos Termo-Formados ..............................................................5

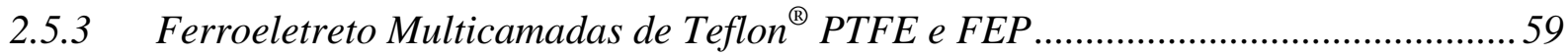

2.6 Coeficiente Piezelétrico dos Ferroeletretos de Duas Camadas Homogêneas .............60

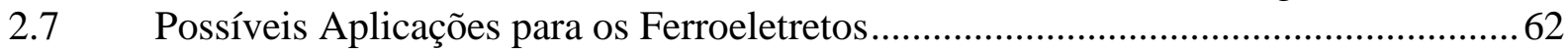

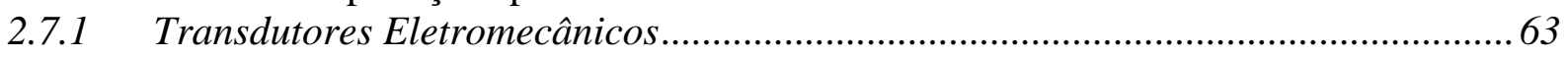

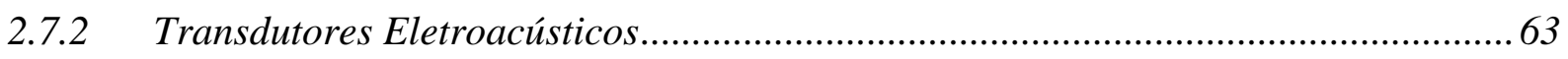

3 Novos Processos de Produção..............................................................................65

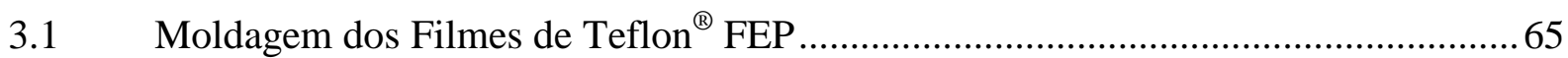

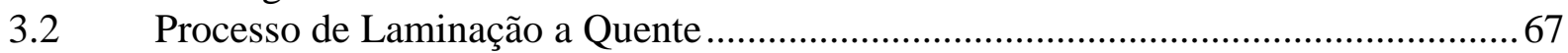

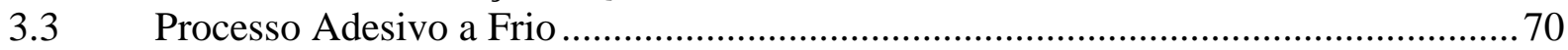

3.4 Carregamento Elétrico por Tensão Impulsiva....................................................... 73

4 Sistema de Medida do Coeficiente Piezelétrico .................................................... 77

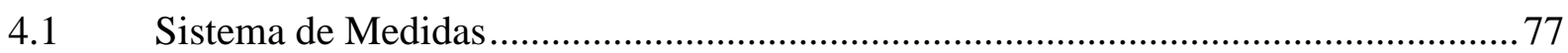

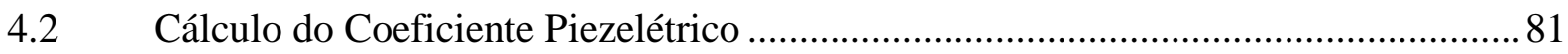

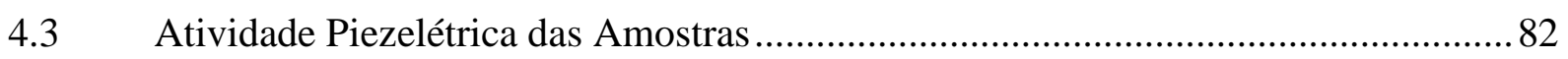

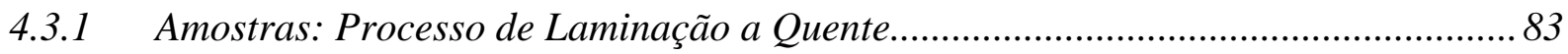

4.3.2 Amostras: Processo Adesivo a Frio ............................................................................. 84

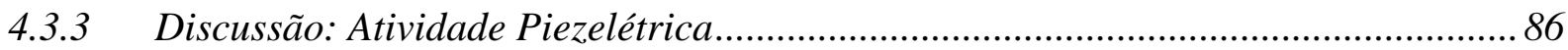

5 Conclusão

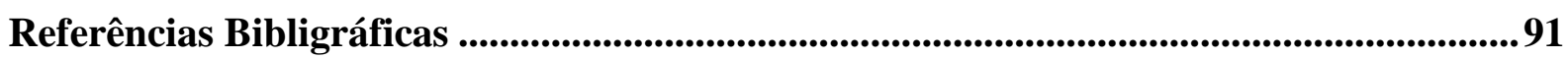





\section{Introdução}

\subsection{Motivação e Objetivo da Dissertação}

O estudo das propriedades de eletreto advem desde a Antiguidade, quando filósofos gregos, em especial Tales de Mileto, Platão, Aristóteles e Plutarco, já relatavam o conhecimento das forças de atração do âmbar atritado. Por volta de 1600, William Gilbert definiu "electrica, quae attrahunt eadem ratione ut electrum" (elétricos que atraem da mesma maneira que o âmbar) e mencionou diversos exemplos de tais materiais (GERHARDMULTHAUPT, 1987).

Durante os três séculos seguintes, cargas elétricas em materiais isolantes (POUNDER, 1977) foram estudadas por inúmeros cientistas. Um deles foi Stephen Gray, quem, em 1732, mencionou a presença de uma "força atrativa perpétua" em vários materiais isolantes e descreveu a produção de "corpos elétricos" de resina, piche, cera de abelha, e enxofre por meio de aquecimento e resfriamento (GRAY, 1732).

A segunda metade do século XVIII acompanhou a introdução do chamado "eletróforo" (portador de eletricidade), que foi independentemente inventado por Johann Carl Wilcke, em 1762, e por Alessandro Volta, em 1771 (GERHARD-MULTHAUPT, 1987). Tal invento possuía o mesmo significado amplo que o termo eletreto possui hoje, reservado aos dielétricos com cargas armazenadas, ou com orientação dipolar. No entanto, este significado mudou com o passar do tempo, visto que alguns fenômenos desta natureza, hoje, são discutidos sob diferentes aspectos, tais como: ferroelétricos, piezelétricos, piroelétricos, distribuição de cargas em dielétricos, orientação molecular, etc. (GERHARD-MULTHAUPT, 2002).

Contribuições importantes também foram feitas por Michael Faraday (1838), quando, ao publicar seus estudos clássicos sobre eletricidade, introduziu o termo "dielétrico" para corpos através dos quais forças elétricas estão atuando e teorizou sobre as propriedades de eletretos, quando se referiu a um "dielétrico que conservava um momento elétrico depois que o campo aplicado externamente tinha sido reduzido a zero". 
Outra valiosa contribuição foi a sugestão dada por Rudolf Kohlrausch em 1854 de que a descarga de uma garrafa de Leyden poderia ser descrita como uma interação de cargas e dipolos (GERHARD-MULTHAUPT, 1987).

Finalmente, em 1885, o cientista inglês Oliver Heaviside denotou o termo "eletreto" e o usou em estrita analogia ao já estabelecido magneto, para designar os materiais dielétricos com uma polarização permanente (GERHARD-MULTHAUPT, 1987).

Entretanto, foi a partir dos trabalhos do físico japonês Mototaro Eguchi, em 1919, que pesquisas sistemáticas com eletretos se iniciaram. Seu primeiro eletreto foi produzido por um método térmico, que consistia na aplicação de um forte campo elétrico a uma mistura fundida de cera de carnaúba e resina em adição de cera de abelha (essencialmente os mesmos materiais utilizados por Gray).

Nas décadas seguintes, eletretos de materiais de cera e várias outras substâncias foram produzidas por técnicas de carregamento diferentes do método térmico de Eguchi. Entre esses métodos, podemos citar: os carregamentos por injeção de elétrons ou íons (GROSS, 1958), iluminação (HILKZER; MALECKI, 1986), descarga corona (CRESWELL; PERLMAN, 1970) e descarga impulsiva (ALTAFIM; GIACOMETTI; JANISZEWSKI, 1992).

Alguns dos mais antigos dispositivos práticos utilizando eletretos são os microfones de eletretos, primeiramente descritos por Nishikawa e Nukijama, em 1928 (SESSLER, 1982). Estes transdutores, assim como os microfones de eletretos discutidos nos anos seguintes (GEMANT, 1935; RUTHERFORD, 1935) e aqueles usados antes e durante a Segunda Guerra Mundial (BRUNO, 1942; GUTMANN, 1948), demonstraram-se insatisfatórios, já que eram constituídos de eletretos de cera, cuja estabilidade elétrica mostrou-se insuficiente sob condições normais de ambiente.

O ritmo das inovações foi acelerado após o advento dos modernos dielétricos poliméricos nas décadas de 1950 e 1960, em particular, após a descoberta da capacidade de aprisionamento de carga de alguns filmes poliméricos. Há, basicamente, dois tipos de materiais poliméricos que são de grande interesse, atualmente: (1) substâncias altamente isolantes, tais como os materiais de Teflon ${ }^{\circledR}$ politetrafluoretileno (PTFE) e seu copolímero flúor etileno propileno (FEP), que têm uma excelente capacidade de retenção de cargas; e (2) substâncias polares, tais como o polifluoreto de vinilideno (PVDF), que exibem dipolos 
permanentes alinhados, resultando em atividades piezelétricas e piroelétricas (SESSLER, 1982).

Em concordância com a extensa vida útil dos novos eletretos poliméricos, foi fabricado, em 1962, o primeiro microfone de eletreto de filme polimérico (SESSLER; WEST, 1962). Com a escolha adequada do material do eletreto (SESSLER; WEST, 1966) e outras melhorias (SESSLER; WEST, 1973), conseguiu-se difundida aceitação comercial.

Mas devido aos pequenos coeficientes piezelétricos, os polímeros carregados foram pouco usados em outras aplicações. Porém, essa situação mudou na década de 1990, com o surgimento dos filmes poliméricos porosos e celulares que apresentam altos coeficientes piezelétricos (LEKKALA; PAAJANEN, 1999). Tais polímeros não apresentam uma estrutura molecular bipolar, mas sim, microcavidades gasosas em sua composição que, além de diminuir a massa dos filmes poliméricos, formam grandes dipolos quando carregadas eletricamente, já que essas cavidades podem ser retratadas como sendo duas camadas superficiais de polaridades opostas (GERHARD-MULTHAUPT, 2002).

No entanto, as microcavidades heterogêneas e aleatórias, derivadas do processo de fabricação dos polímeros porosos e celulares, tornam o carregamento elétrico não homogêneo (QIU et al., 2007a, 2007b).

Procurando encontrar novos materiais que não apresentassem esse inconveniente, Altafim et al. (2003) idealizaram um transdutor piezelétrico composto por uma dupla camada de Teflon ${ }^{\circledR}$ FEP separados por uma fina camada de verniz espargido, obtendo um coeficiente piezelétrico da ordem de $290 \mathrm{pC} / \mathrm{N}$.

Embora esse sensor tenha tido um papel fundamental na mudança do paradigma existente, sua construção artesanal acarretou problemas, tais como a falta de controle da dimensão intersticial entre as paredes do sensor piezelétrico, baixa resistência mecânica durante sua manipulação e perda de sensibilidade com o decorrer do tempo, em função da deformação plástica das gotículas do verniz separador. Com isso, foi idealizado um novo sensor, constituído de microbolhas de ar entre duas folhas de Teflon ${ }^{\circledR}$ FEP através de um processo denominado "termo-formado" (ALTAFIM et al., 2005, 2006), também apresentando um alto coeficiente piezelétrico (superior a $300 \mathrm{pC} / \mathrm{N}$ ).

Os excelentes resultados apresentados pelo novo sensor piezelétrico termo-formado (ALTAFIM et al., 2006) permitem aventar a possibilidade de desenvolver protótipos e procedimentos para sua produção em escala industrial e, consequentemente, ampliar sua gama 
de aplicações comerciais. Cita-se, dentre as possíveis aplicações, a de sensores de presença, teclados finos, balanças dinâmicas e sensores de pressão em ambientes contendo óleos isolantes, similares a tanques de transformadores.

Antes de se apresentar como produto final e ser comercializado, o sensor piezelétrico de Teflon ${ }^{\circledR}$ FEP termo-formado necessita de um processo repetitivo, tanto no mercado interno quanto no externo. Neste contexto, este trabalho apresenta dois novos processos para a produção dos sensores piezelétricos poliméricos baseados na tecnologia dos eletretos termoformados.

\subsection{Organização da Dissertação}

Este trabalho está organizado em cinco capítulos. Além da introdução, a sequência é descrita a seguir.

No Capítulo 2, são tratados os conceitos e fundamentos relativos aos eletretos, bem como sua evolução no emprego de transdutores eletromecânicos, em especial, o aspecto piezelétrico.

Os aprimoramentos dos processos de produção idealizados para a fabricação dos sensores piezelétricos baseados na tecnologia dos eletretos termo-formados são descritos no Capítulo 3.

Um sistema de medidas da piezeletricidade encontra-se descrito no Capítulo 4, que traz, também, os resultados das medições das amostras.

A conclusão desta dissertação de mestrado e as propostas para a continuidade deste estudo em trabalhos futuros são apresentadas no Capítulo 5.

Finalizando este trabalho, encontram-se as referências bibliográficas. 


\section{Revisão Bibliográfica}

\subsection{Eletretos}

Numa definição clássica, o termo eletreto é designado às substâncias dielétricas eletrizadas quase permanentemente. O termo "quase permanente" significa que a constante de tempo característica para o decaimento das cargas elétricas é maior que o período de tempo em que estudos são realizados com o eletreto (SESSLER, 1998).

Os estudos sistemáticos sobre eletretos foram iniciados por Mototaro Eguchi, em 1919. Em seu primeiro trabalho (EGUCHI, 1919), ele ainda usava o termo eletróforo; somente mais tarde (EGUCHI, 1920, 1923, 1925) passou a usar a palavra eletreto, originada de Heaviside. Seu primeiro eletreto foi produzido por um método térmico. Eguchi fundiu partes iguais de cera de carnaúba e resina a cerca de $130{ }^{\circ} \mathrm{C}$, com ou sem certa quantidade de cera de abelha (essencialmente os mesmos materiais utilizados por Gray), e a deixou solidificar sob um forte campo elétrico, de aproximadamente 1,5 MV/m (FUKADA, 2000).

Com esse experimento, Eguchi constatou a existência de dois tipos de cargas elétricas. Logo após a preparação desses eletretos, ele encontrou que suas superfícies apresentavam cargas de polaridade oposta a dos eletrodos formadores adjacentes. Mas estes tipos de cargas mostraram ser de natureza temporária e desapareciam gradualmente em um curto intervalo de tempo, dentro de um ou dois dias. Após o decaimento completo destas cargas, outras de sinais opostas cresceram gradualmente até saturar em alguns dias, ou seja, ocorreu a inversão da polarização e as superfícies do eletreto passaram a apresentar polaridades iguais aos dos eletrodos adjacentes. As cargas com polaridades iguais aos do eletrodo adjacente foram posteriormente nomeadas homocargas, por Andrew Gemant (1935), e as de sinais opostas, foram nomeadas heterocargas. A permanência das heterocargas mostrou excelente estabilidade temporal, não se detectando qualquer decaimento sensível mesmo após muitos anos do preparo das amostras (EGUCHI, 1925). Um disco desse eletreto, $20 \mathrm{~cm}$ de diâmetro e $1 \mathrm{~cm}$ de espessura, está preservado no Museu de Ciências em Tóquio. 
Suas cargas superficiais permanecem mesmo 45 anos após sua preparação e foi observado ser aproximadamente um sétimo das cargas originais (FUKADA, 2000). Apesar da observação dessa inversão de polaridade, naquele momento não foi encontrada explicação para a origem dessas cargas.

Em 1944 Bernhard Gross, enquanto desenvolvia as idéias de Edwin Plimpton Adams (1927) e Andrew Gemant (1935), publicou suas hipóteses relativas à origem de polarização permanente como um resultado de dois processos: a orientação de dipolos moleculares e de cargas espaciais (responsáveis pela origem das heterogargas) e a injeção de cargas elétricas a partir dos eletrodos (responsável pela origem das homocargas), como sugerido por Faraday um século antes (HILCZER; MALECKI, 1986).

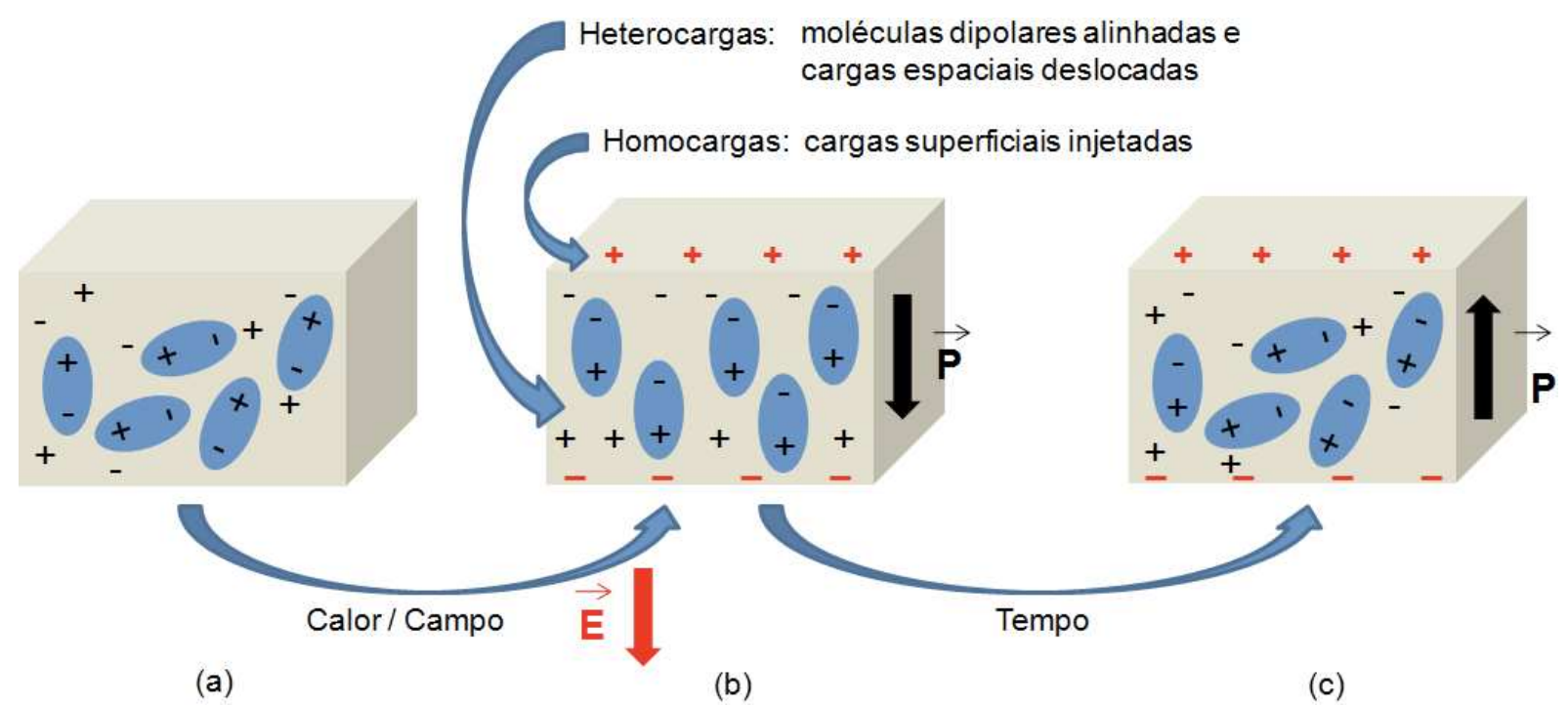

Figura 2.1 Representação esquemática da configuração de cargas elétricas dos eletretos produzidos por Eguchi (a) antes do processo de polarização, (b) logo após a suspensão do campo aplicado e (c) após decorrido pouco tempo.

A teoria precisa e consistente de Gross explicou os fatos experimentais de forma extremamente bem sucedida e foi uma importante contribuição para o estudo de eletretos. Para explicar a inversão de polarização observada no experimento de Eguchi, Gross teoriza que a aplicação de campo elétrico provoca o alinhamento de moléculas dipolares e o deslocamento de cargas espaciais (cargas aprisionadas no interior do material) do dielétrico. Além disso, nas superfícies do dielétrico são injetadas cargas elétricas (cargas superficiais) de mesmo sinal dos eletrodos formadores adjacentes. Logo após a suspensão do campo elétrico, devido a uma maior contribuição dos campos elétricos advindos das moléculas dipolares e das cargas espaciais deslocadas em relação aos das cargas injetadas, a direção e o sentido da 
polarização resultante $\vec{P}$ são os mesmos do campo elétrico aplicado $\vec{E}$, conforme mostrado na Figura 2.1b. No entanto, devido ao relaxamento dos dipolos moleculares e ao movimento das cargas espaciais, a magnitude de $\vec{P}$ decresce gradualmente. Depois de $\vec{P}$ tornar-se zero, $\vec{P}$ cresce gradualmente em sentido oposto a $\vec{E}$, quando as contribuições dos campos das cargas espaciais passam a sobrepor aos dos dipolos moleculares e das cargas espaciais, conforme mostrado na Figura 2.1c. Portanto, a inversão de polarização observada no experimento de Eguchi é atribuída a natureza temporária das heterocargas (dipolos moleculares e cargas espaciais) e a predominante contribuição das homocargas (cargas superficiais injetadas).

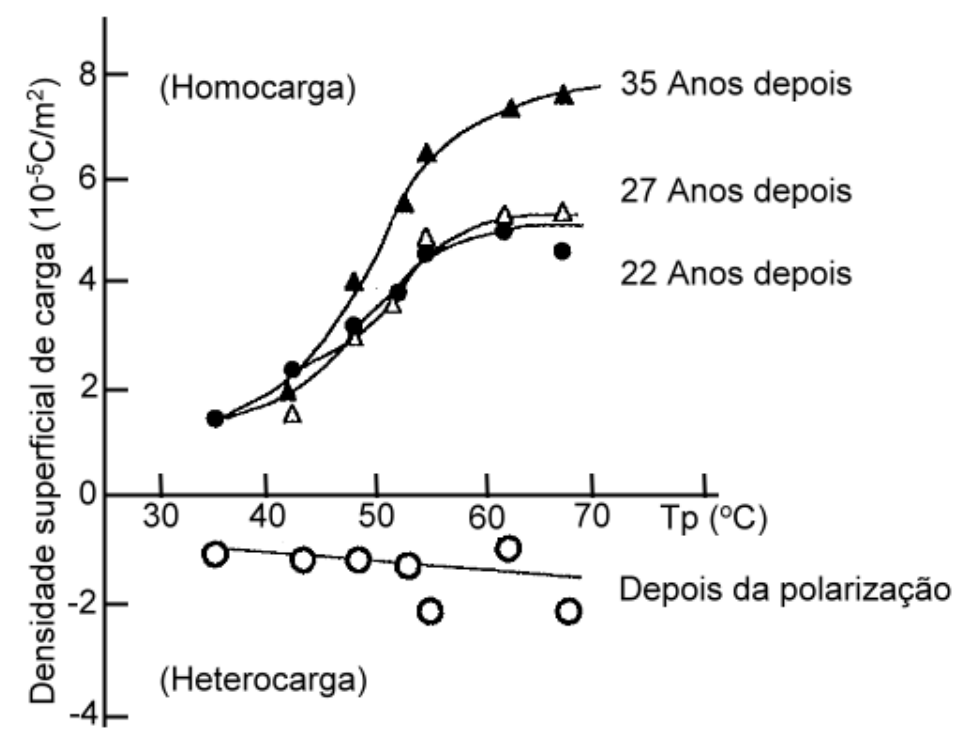

Figura 2.2 Observação das cargas superficiais nos eletretos de cera de carnaúba em 22, 27 e 35 anos após a polarização. A magnitude da carga é mostrada em função da temperatura de polarização $T_{p}$. O campo elétrico de polarização aplicado foi de $4 \mathrm{MV} / \mathrm{m}$ (FUKADA, 2000).

Por volta de 1951, Sumoto preparou diversos eletretos de cera de carnaúba. Ele envolveu-os com folhas de metal e armazenou-os em dessecadores. Takamatsu realizou medidas de suas cargas superficiais em 22, 27, e 35 anos após sua preparação. Os resultados são mostrados na Figura 2.2. As cargas medidas são traçadas de encontro à temperatura de polarização. Imediatamente depois da polarização dos eletretos, as cargas de superfície eram negativas, indicando as heterocargas. Entretanto, após mais de 22 anos, cargas positivas foram observadas, indicando as homocargas. A quantidade de homocargas cresce com o aumento da temperatura de polarização. Outro exemplo da excelente estabilidade de homocargas injetadas é apresentado pelos filmes de Teflon FEP, que são instalados em microfones de eletretos nos milhões de aparelhos telefônicos (FUKADA, 2000). 
Assim, numa definição moderna, o termo eletreto inclui materiais dielétricos que apresentam moléculas dipolares alinhadas, portadores de cargas elétricas deslocadas ou ainda cargas aprisionadas nas proximidades das duas superfícies do dielétrico.

Enquanto os eletretos clássicos eram feitos de placas espessas de cera de carnaúba ou substâncias similares, pesquisas recentes sobre eletretos estão sendo realizadas com filmes finos de materiais poliméricos, tais como os materiais de Teflon ${ }^{\circledR}$ FEP e PTFE, PVDF e filmes celulares e porosos de PP. Eletretos típicos em uso atual são feitos de filmes com espessura entre $10 \mu \mathrm{m}$ e $100 \mu \mathrm{m}$, de poucos $\mathrm{cm}^{2}$ de área, geralmente cobertos em uma ou ambas as superfícies com camadas de metal evaporado. As polarizações atuais podem produzir eletretos com densidades de carga entre $10^{-8}$ e $10^{-6} \mathrm{C} / \mathrm{cm}^{2}$, sendo que em materiais de Teflon $^{\circledR}$ e de PP predominam injeções de cargas, que são aprisionadas em armadilhas energéticas profundas e superficiais, e no PVDF predomina a polarização por orientação dipolar, com cargas injetadas em menor proporção.

Exemplos de alguns eletretos metalizados e não metalizados são mostrados na Figura 2.3. Um eletreto não coberto por eletrodos de metal produz um campo eletrostático externo devido a suas cargas não compensadas e à polarização, fenômeno análogo ao de um magneto permanente, cujo campo magnético é gerado apenas por dipolos magnéticos. Esta analogia tem sido muito importante e de uso comum para o melhor entendimento dos eletretos. Enquanto as amostras não metalizadas e as metalizadas em um lado geralmente exibem campos elétricos internos e externos, os campos das amostras metalizadas nas duas faces estão completamente contidos dentro do dielétrico.

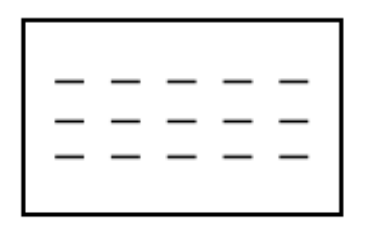

(a)

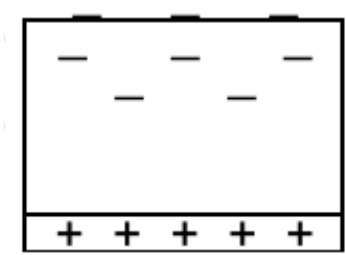

(b)

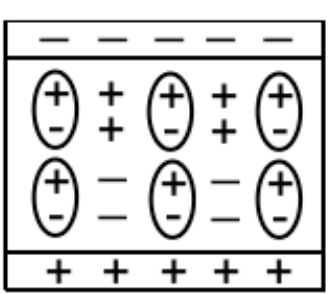

(c)

Figura 2.3 Esquema da seção transversal de alguns eletretos típicos sem eletrodos ou com eletrodos: (a) eletreto mono polar não-metalizado, (b) eletreto com uma de suas faces metalizada contendo cargas superficiais e espaciais e (c) eletreto com duas faces metalizadas contendo cargas espaciais e dipolares. 


\subsection{Processos de Formação de Eletretos}

A formação de eletretos, que significa carregamento ou polarização de um dielétrico, pode ser alcançada por uma variedade de métodos. Estes métodos dependem da constante de ruptura do gás próximo à superfície para ser carregado, da injeção de portadores de cargas elétricas pelos eletrodos ou por feixes de partículas, ou da separação de cargas induzidas por um campo elétrico ou alinhamento de dipolos no dielétrico. O processo de formação é frequentemente limitado pelo fenômeno de ruptura interna ou externa que dependem, respectivamente, da permissividade elétrica e da lei de Paschen; em outros casos, a formação é limitada pela saturação da quantidade de armadilhas ou moléculas polarizáveis no material.

Algumas das técnicas de formação mais estudadas nas últimas décadas foram: a térmica, injeção de cargas por feixe de elétrons, métodos fotoelétricos, carregamento direto, corona e por descarga impulsiva. Antes da discussão sobre estes métodos, que será feita nas seções seguintes, o processo de aprisionamento de cargas nos dielétricos sólidos será discutido.

\subsubsection{Mecanismo de Aprisionamento de Portadores em Dielétricos Sólidos}

Dois processos - polarização molecular em um campo elétrico e aprisionamento de carga - determinam as propriedades de eletreto dos dielétricos. Nesta seção, será descrito resumidamente o mecanismo de aprisionamento de portadores em dielétricos sólidos, principal mecanismo de formação dos eletretos termo-formados, bem como dos eletretos poliméricos porosos e celulares. Sendo assim, neste trabalho não será abordado o alinhamento de moléculas polares.

A retenção quase-permanente de cargas reais em eletretos poliméricos ocorre devido à presença de estados de aprisionamento capazes de deter portadores de carga durante um longo período de tempo. Em 1972, Bauser sugeriu um modelo para o aprisionamento de cargas em polímeros baseado num modelo de banda de energia modificado (Figura 2.4a). De acordo com este modelo, as armadilhas são estados localizados que pertencem a determinadas moléculas ou grupos moleculares. Sendo os polímeros amorfos e/ou semicristalinos, os níveis de energia, que são afetados por seu ambiente local, são diferentes em distintas regiões moleculares do material. Assim, a profundidade das armadilhas é distribuída de acordo com a distribuição dessas regiões. 


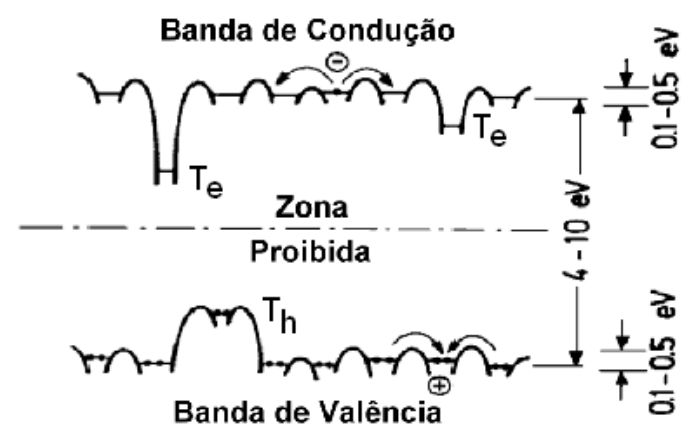

(a)

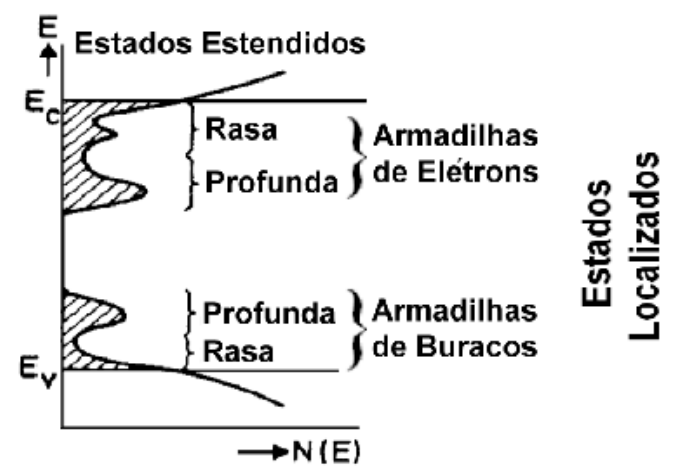

(b)

Figura 2.4 (a) Diagrama de energia para um polímero. $T_{e}$, armadilhas de elétron; $T_{h}$, armadilhas de buraco. (b) Densidade de estados energéticos $N(E)$ para um polímero. Estados localizados (armadilhas) estão sombreados; $E_{c}$ e $E_{v}$ são bordas de mobilidade da banda de condução e de valência, respectivamente (SESSLER, 1982).

Além destes estados localizados (armadilhas), há estados não localizados, geralmente referidos como estados estendidos, que são situados energeticamente próximos à parte inferior da banda de condução e da parte superior da banda de valência (Figura 2.4b). Estes últimos são separados dos estados localizados pela chamada borda de mobilidade, em que a mobilidade de portador diminui diversas ordens de grandeza. Em tais estados, os portadores movem-se pelo salto quântico. O aprisionamento de carga em estados estendidos é, geralmente, insignificante em materiais de eletreto. Os estados estendidos, no entanto, são responsáveis pelo transporte de carga (SESSLER, 1982).

O aprisionamento de carga em polímeros pode ocorrer em armadilhas distribuídas na superfície e no volume do eletreto. Enquanto é facilmente possível distinguir entre estas categorias, é difícil avaliar a origem molecular das armadilhas. As armadilhas superficiais podem ser originadas devido a impurezas químicas, defeitos superficiais específicos, cadeias quebradas, moléculas absorvidas ou diferenças na ordem de curto alcance de superfície e volume. Por outro lado, as armadilhas de volume apresentam três níveis estruturais de aprisionamento (SESSLER, 1982). Os níveis primários são sítios atômicos nas cadeias moleculares, os níveis secundários estão entre grupos de átomos em moléculas vizinhas, e os níveis terciários são as regiões cristalinas ou interfaces cristalino-amorfas.

Para o Teflon ${ }^{\circledR}$ FEP a localização espacial e a temperatura de ativação térmica de suas armadilhas superficiais e volumétricas têm sido determinadas por medições de descarga termicamente estimulada (TSC - thermally stimulated current) (VON SEGGERN, 1979). Foram encontradas temperaturas de liberação de cargas de $155^{\circ} \mathrm{C}$ e $200{ }^{\circ} \mathrm{C}$ para armadilhas de superfície e de volume, respectivamente, e $170{ }^{\circ} \mathrm{C}$ para um aprisionamento intermediário. 
Também foi detectado um nível de aprisionamento mais raso, ativo sob certas condições, onde as armadilhas mais profundas estão ocupadas, com descarregamento ocorrendo a $95{ }^{\circ} \mathrm{C}$. Finalmente, informações sobre a distribuição espacial das armadilhas entre $155^{\circ} \mathrm{C}$ e $200{ }^{\circ} \mathrm{C}$ foram obtidas por meio de TSC em circuito aberto para amostras carregadas por feixes de elétrons retratados na Figura 2.5. Os resultados destas investigações, mostrados na Tabela 2.1, sugerem uma extensão das camadas superficiais para uma profundidade de, aproximadamente, $2 \mu \mathrm{m}$ (VON SEGGERN, 1979).

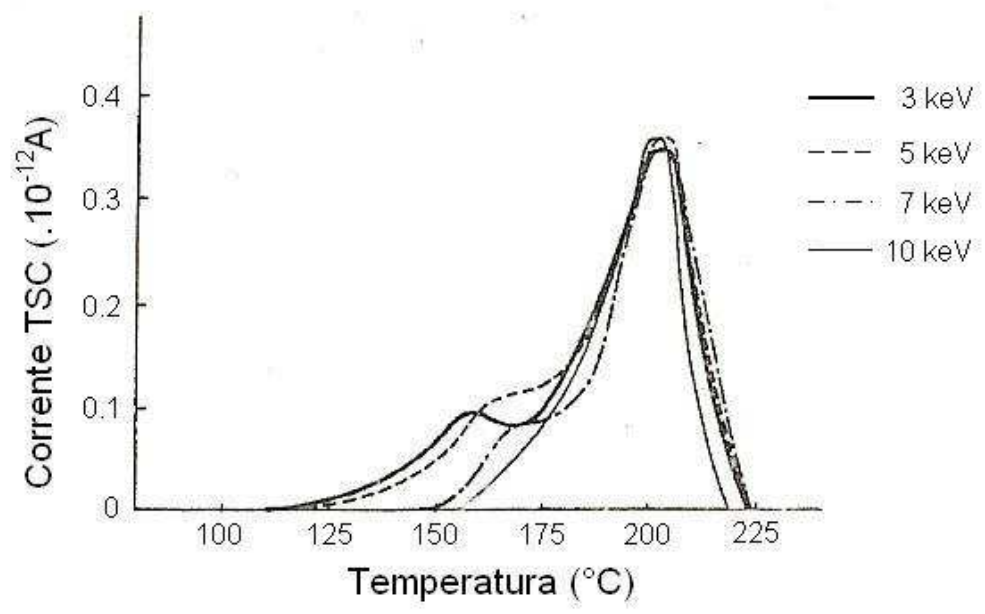

Figura 2.5 Correntes termicamente estimuladas em circuito aberto para amostras de Teflon ${ }^{\circledR}$ FEP $25 \mu$ m carregadas com feixes de elétrons das seguintes energias: $3 \mathrm{keV}, 5 \mathrm{keV}, 7 \mathrm{keV}, 10 \mathrm{keV}$ (VON SEGGERN, 1979).

Tabela 2.1 Distribuição de armadilhas para cargas negativas distribuídas em Teflon ${ }^{\circledR}$ FEP-A 25 m (VON SEGGERN, 1979).

\begin{tabular}{|c|c|l|}
\hline $\begin{array}{c}\text { Temperatura } \\
\text { de pico }\left({ }^{\circ} \mathrm{C}\right)\end{array}$ & $\begin{array}{c}\text { Localização relativa à } \\
\text { superfície carregada }(\mu \mathrm{m})\end{array}$ & \multicolumn{1}{|c|}{ Tipo de armadilha } \\
\hline 95 & $0-25$ & Armadilha energeticamente mais rasa \\
155 & $0-0.5$ & Armadilha de superfície \\
170 & $0.5-1.8$ & Armadilha próxima a superfície \\
200 & $1.8-25$ & Armadilha de volume \\
\hline
\end{tabular}

Os valores das energias de ativação dos níveis de aprisionamento de vários polímeros também foram obtidos por TSC e outras técnicas. Valores típicos para essas energias são 1,9 $\mathrm{eV}$ para Teflon ${ }^{\circledR} \mathrm{FEP}, 1,8-2,2 \mathrm{eV}$ para Mylar, 1,5 eV para polietileno (PE) e 1,2 eV para poliimida. Armadilhas desta profundidade aprisionam cargas por um longo período de tempo, alcançando uma frequência de liberação de cargas 


$$
v=v_{0} e^{(-U / \kappa T)}
$$

onde $v_{0}$ é a frequência de escape, $U$ é a energia de ativação dos níveis de aprisionamento, $\kappa$ é a constante de Boltzman e $T$ é a temperatura. À temperatura ambiente a frequência de liberação de cargas pode atingir valores de $10^{-4}$ a $10^{-22} \mathrm{~s}^{-1}$, assumindo uma frequência de escape $v_{0}$ igual a $10^{13} \mathrm{~s}^{-1}$ (SESSLER, 1982).

Densidades de armadilhas em polímeros têm sido inferidas a partir da máxima densidade de carga armazenada. Em alguns filmes poliméricos, tais como o Teflon ${ }^{\circledR}$ FEP 25 $\mu \mathrm{m}$, armadilhas de superfície são capazes de armazenar mais cargas que armadilhas de volume e o carregamento de tais materiais geralmente produzirá cargas superficiais (uma exceção é o carregamento de feixes de elétrons que resulta em uma carga volumétrica) (SESSLER, 1982).

Esta pequena introdução teórica fornece elementos conceituais que facilitam o entendimento dos principais mecanismos de formação de eletretos com excesso de cargas, descritos nos itens seguintes.

\subsubsection{Método Térmico}

Técnicas de formação térmica consistem na aplicação de um campo elétrico ao polímero em uma elevada temperatura e subsequente resfriamento, enquanto o campo ainda está sendo aplicado (EGUCHI, 1919). Tais métodos podem ser usados em amostras tendo eletrodos inicialmente depositados sobre o dielétrico ou em amostras separadas dos eletrodos por um espaçamento de ar ou outro gás (SESSLER, 1982).

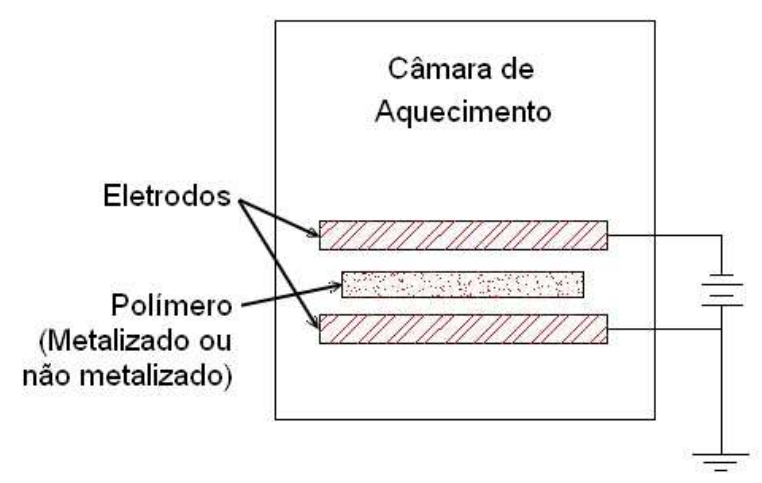

Figura 2.6 Representação esquemática do método de carregamento térmico. 
Dependendo da geometria, da configuração dos eletrodos, da intensidade do campo aplicado, da temperatura e de parâmetros intrínsecos do material, podem ocorrer uma série de fenômenos. Na presença de espaçamentos de ar, processos de ruptura podem ocorrer no gás, resultando em deposição de cargas sobre as superfícies do polímero. Quando eletrodos depositados são usados, cargas podem ser injetadas pelos eletrodos. Finalmente, dipolos podem ser alinhados ou cargas podem ser separadas no dielétrico. Sob resfriamento, todos os movimentos de cargas são congelados (SESSLER, 1982).

\subsubsection{Método por Feixes de Elétrons}

Este método consiste da injeção de elétrons de determinada energia, de acordo com o polímero (SESSLER, 1982). Se o alcance dos elétrons é menor que a espessura do dielétrico, o carregamento é causado diretamente pelo aprisionamento dos portadores injetados. $\mathrm{O}$ método de feixes de elétrons foi usado por Bernhard Gross, em 1958, para carregar placas espessas de materiais dielétricos e, mais tarde, em 1970, foi adaptado por Sessler e West para o carregamento de filmes poliméricos.

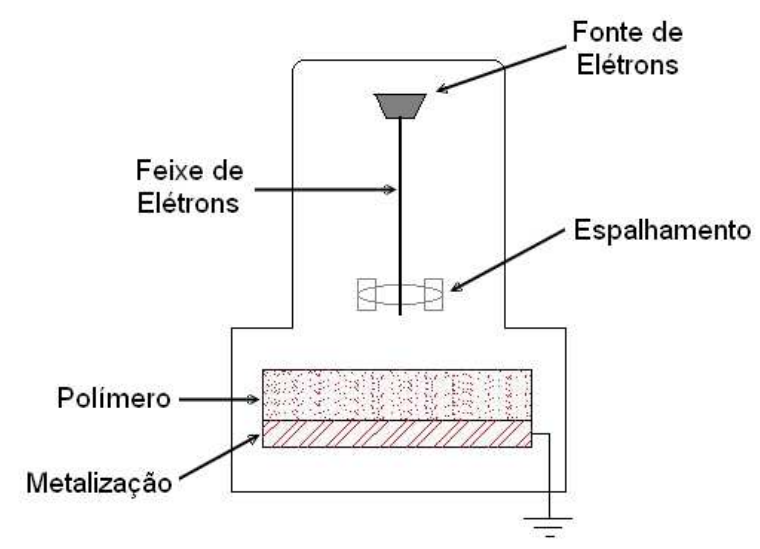

Figura 2.7 Representação esquemática do método de carregamento por feixe de elétrons.

\subsubsection{Mecanismo de Fotoeletreto}

Os materiais fotocondutores ao serem irradiados com luz ultravioleta ou luz visível sob um campo elétrico e cobertos com um ou dois eletrodos transparentes, geram uma polarização depois de removido o campo e de terminada a irradiação, criando-se um fotoeletreto. Este efeito é atribuído à geração de portadores pela luz, deslocamento de cargas pelo campo elétrico, e eventual aprisionamento. No entanto, para isso, é necessário que a luz irradiada possua energia suficiente para remover os elétrons de sua banda de valência criando 
pares elétrons-lacunas. Assim, esses portadores livres podem mover-se, sob a ação do campo elétrico, para uma das extremidades do material (HILKZER; MALECKI, 1986).

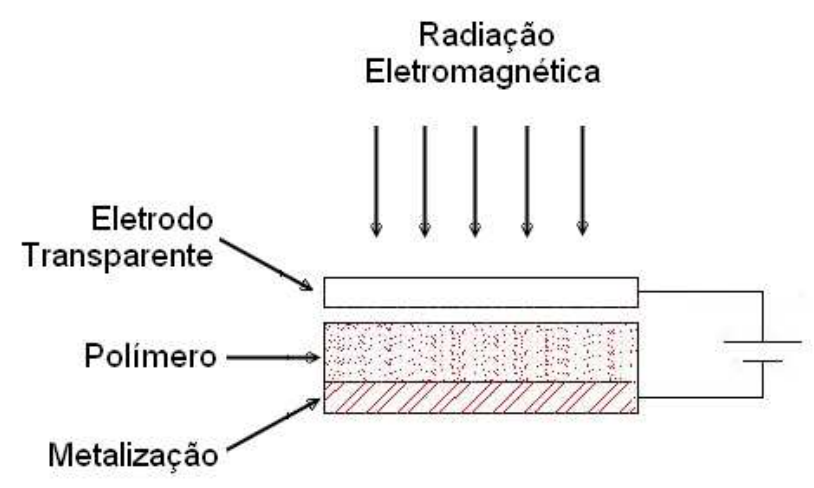

Figura 2.8 Representação esquemática do método para obtenção dos fotoeletretos.

\subsubsection{Carregamento Direto}

Ao ser aplicado aos eletrodos de uma configuração mostrada na Figura 2.9 um campo elétrico suficientemente forte (a partir de, aproximadamente, $1 \mathrm{kV} / \mathrm{cm}$ ), ocorre uma migração de cargas elétricas do eletrodo para o dielétrico. Para garantir tanto o contato dos eletrodos com o dielétrico quanto uma distribuição homogênea das cargas, é necessário que o material possua eletrodos depositados. Caso o dielétrico não possua eletrodos depositados, possivelmente existirão espaçamentos de ar entre o eletrodo e o dielétrico e, assim, a transferência de cargas se dará também através de descargas elétricas no ar. Ocorrida a transferência de cargas e retirado o campo elétrico, ficará um campo elétrico remanescente no material com características elétricas estáveis, ou seja, ocorreu a criação de um eletreto.

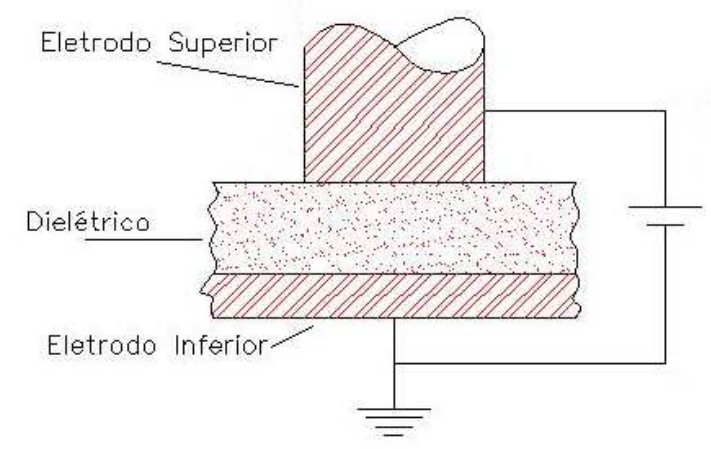

Figura 2.9 Representação esquemática do carregamento direto.

A intensidade máxima do campo que pode ser aplicado está limitada à ocorrência da ruptura interna do dielétrico, relacionada intimamente à rigidez dielétrica do material. No caso 
dos polímeros, como a rigidez dielétrica é elevada - da ordem de $10^{6} \mathrm{~V} / \mathrm{cm}$ (para o Teflon ${ }^{\circledR}$ FEP é da ordem de $2,2 \times 10^{6} \mathrm{~V} / \mathrm{cm}$ ) -, a ruptura interna dificilmente ocorre. No entanto, o mesmo não acontece com a ruptura externa, também conhecida como ruptura reversa de Paschen, que acontece muito mais frequentemente por ser função da geometria do eletrodo, da composição do gás e da pressão.

\subsubsection{Método Corona}

O método corona depende da deposição de carga sobre um polímero por meio de uma descarga corona (Figura 2.10). A descarga é gerada pela aplicação de uma tensão de alguns quilovolts entre um eletrodo em forma de agulha (eletrodo-ponta) e um eletrodo plano localizado embaixo da amostra (CRESWELL; PERLMAN, 1970).

Se o eletrodo-ponta apresenta polaridade negativa, como geralmente ocorre no carregamento do Teflon ${ }^{\circledR}$ FEP, os portadores negativos fluem para o dielétrico. No ar, à pressão atmosférica, os íons $\mathrm{CO}_{3}^{-}$são os principais portadores (SHAHIN, 1968, 1969). Devido à sua pequena energia térmica, esses íons são depositados na superfície do material, e supõe-se que suas cargas são transferidas para as armadilhas superficiais do material. A penetração de cargas no material depende da polaridade, de sua densidade e das características do próprio material dielétrico. No Teflon ${ }^{\circledR}$ FEP, por exemplo, as cargas negativas penetram muito pouco para densidade de cargas em torno de $10^{-8} \mathrm{C}_{\mathrm{cm}}$, enquanto as cargas positivas penetram substancialmente no material (SAWA; LEE; IEDA, 1975; MORENO; GROSS, 1976).

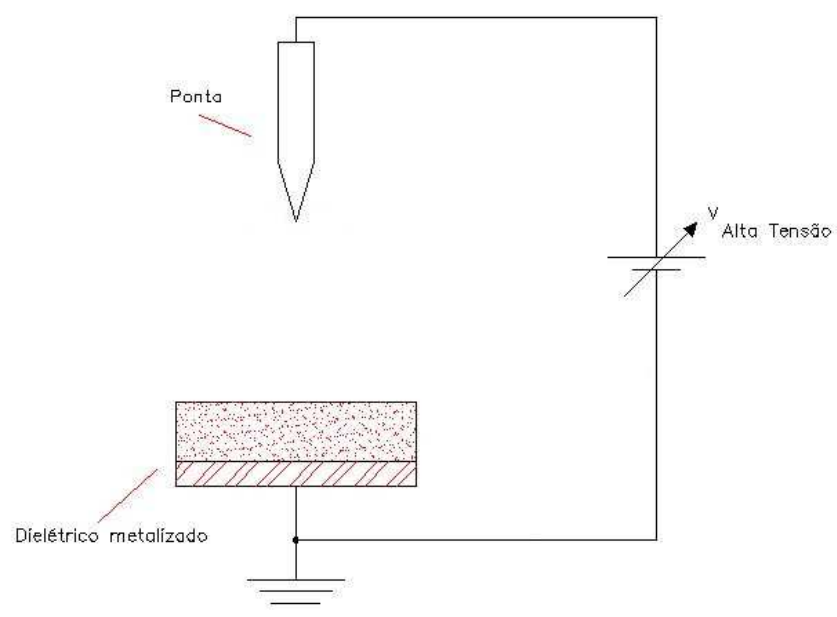

Figura 2.10 Representação esquemática do método de carregamento por descarga corona. 
Este método apresenta alguns inconvenientes, sendo o maior deles a não uniformidade da distribuição de cargas (MORENO; GROSS, 1976). Por isso, um dispositivo auxiliar foi arranjado, contribuindo para uma distribuição homogênea das cargas injetadas no material (MURPHY, 1972).

A Figura 2.11 apresenta as alterações feitas na configuração primitiva, com a implementação de uma grade metálica também submetida à tensão controlada, de algumas centenas de volts. Desta forma, a distribuição de carga na placa a ser carregada passa a ser uniforme e facilmente controlada (MURPHY, 1972).

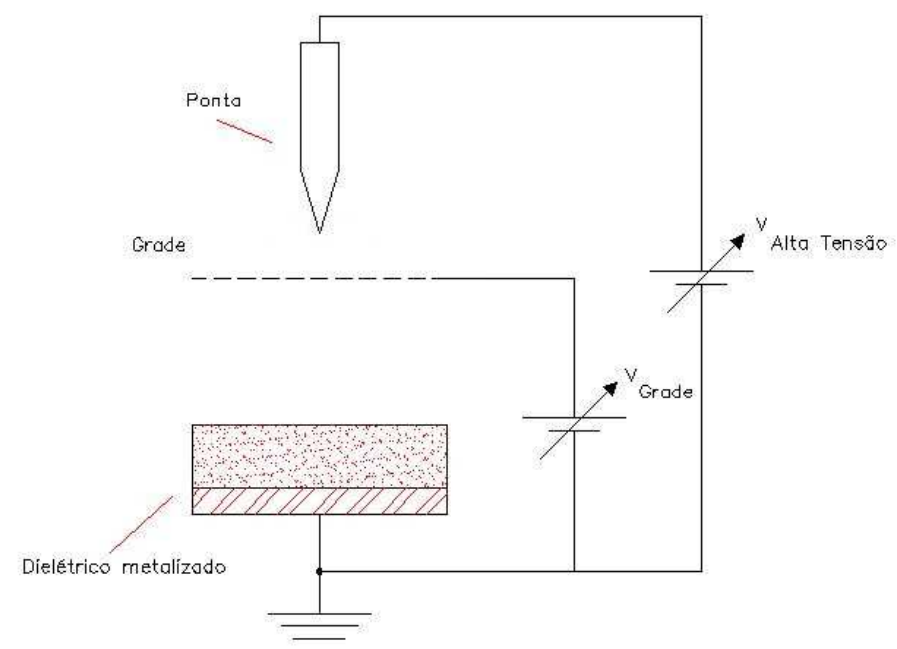

Figura 2.11 Representação esquemática do método de carregamento por descarga corona com grade (triodocorona).

Para o carregamento corona também é necessário tempo bastante prolongado e temperaturas elevadas, motivo pelo qual outros métodos foram apresentados com algumas vantagens.

\subsubsection{Método por Tensões Elétricas Impulsivas}

O processo de formação de eletretos por tensões impulsivas foi desenvolvido por Altafim e colaboradores em 1992 e modelado em 1998 (ALTAFIM; GIACOMETTI; JANISZEWSKI, 1992; ALTAFIM; LEAL FERREIRA; GIACOMETTI, 1998). Esse método de carregamento consiste na aplicação de uma onda de tensão impulsiva, com um pico elevado, diretamente sobre o filme polimérico. Gerhard-Multhaupt et al. (2002) e Altafim et al. $(2003,2005,2006)$ utilizam este processo impulsivo, com grande eficiência, para também carregar polímeros celulares e porosos e obter materiais com altos coeficientes piezelétricos. 
A configuração básica do carregador por impulso e a forma de onda são mostradas nas Figuras 2.12 e 2.13, respectivamente.

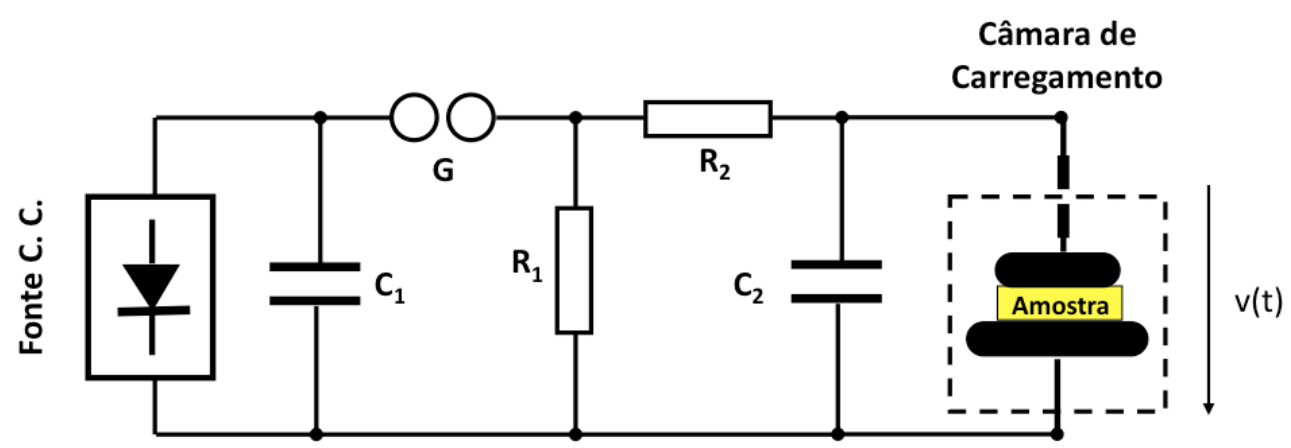

Figura 2.12 Sistema de carregamento por efeito impulsivo, onde $R_{1}=72 \Omega, R_{2}=44 \Omega, C_{1}=1,35 \mathrm{mF}, C_{2}=11$ $n F$ e $G$ é o centelhador.

Um pico de tensão negativa de curta duração é aplicado sobre um filme polimérico que induz o aprisionamento de cargas elétricas na superfície do filme, formando termoeletretos em um curto espaço de tempo. Como pode ser observada na Figura 2.13, uma das vantagens do carregamento impulsivo, com relação ao carregamento por descarga corona, é o curto tempo para ser realizado, da ordem de micro segundos.

A tensão a que o filme dielétrico é submetido é dada segundo a equação abaixo.

$$
V(t)=V_{0}\left(e^{-\alpha_{1} \cdot t}-e^{-\alpha_{2} \cdot t}\right)
$$

O tempo de frente e de cauda da onda de impulso é determinado pelas constantes de Towsend, constantes de tempo $\alpha_{1}$ e $\alpha_{2}$. Manipulando-se tais parâmetros, é possível observar formas de ondas com frentes de $1,2 \mu$ s e tempos de meia onda iguais a $45 \mu \mathrm{s}$. O tempo de onda é medido desde o início da onda impulsiva, até o tempo em que esta decai à metade do valor de pico.

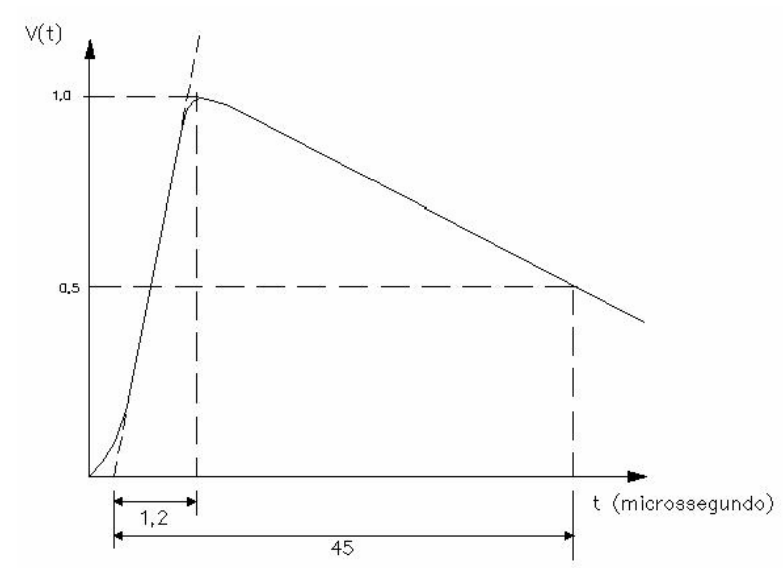

Figura 2.13 Forma de onda de um carregamento impulsivo, com 1,2 $\mu$ s de frente de onda e $45 \mu$ s de tempo de meia onda. 


\subsection{Piezeletricidade}

A palavra piezeletricidade literalmente significa "eletricidade por meio de pressão"; sendo o prefixo piezo derivado da palavra grega piezein - "pressionar". Uma definição clássica de piezeletricidade é a geração de uma polarização elétrica produzida pela imposição de tensão mecânica, sendo a polarização proporcional à deformação. A produção de uma polarização elétrica por meio de uma tensão mecânica é chamada de efeito piezelétrico direto. O efeito inverso, uma deformação mecânica provocada por meio de um campo elétrico de polarização também existe.

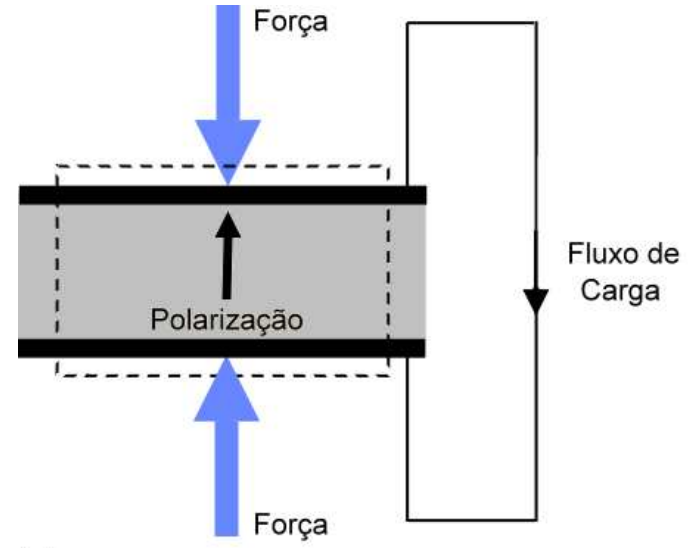

(a)

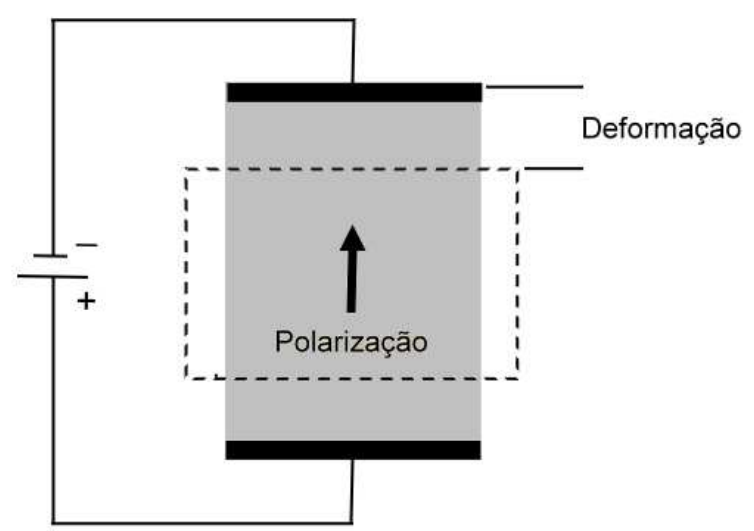

(b)

Figura 2.14 (a) Efeito piezelétrico direto e (b) inverso.

Em alguns materiais, a polarização elétrica é produzida, simplesmente, aplicando uma tensão mecânica ao longo de certo eixo. Outros tipos de deformação, tais como dobras, cisalhamento ou torção também produzem polarização em determinados materiais. Em alguns casos, diversos efeitos existem simultaneamente. Inversamente, a aplicação de campos elétricos de polarização pode causar a um material uma deformação longitudinal ou cisalhamento, e sob certas condições, também podem ser produzidos dobramento, torção, e flexão.

\subsubsection{Levantamento Histórico da Piezeletricidade}

As primeiras suposições de que eletricidade também poderia ser produzida por pressão foram levantadas por Coulomb entre 1780 e 1790, conduzindo, posteriormente, aos experimentos de Haüy, sem resultados conclusivos, prevendo a produção de cargas em uma borracha sob tensão mecânica. No século seguinte, em 1819, Antoine César Becquerel descobriu o efeito piezelétrico em alguns cristais, detectando um potencial elétrico quando 
estes eram submetidos a pressões mecânicas, atribuindo tal comportamento a certas diferenças constantes e presentes no interior da estrutura cristalina do material (BALLATO, 1996).

A descoberta efetiva da piezeletricidade se deu pelos irmãos Jacques e Pierre Curie, em 1880, a partir de uma curiosidade científica, observando o aparecimento de cargas superficiais em alguns materiais de estrutura cristalina, quando estes eram mecanicamente solicitados (BOTTOM, 1968).

Em 1881, Wilhelm Gottlieb Hankel sugeriu o nome "piezeletricidade", que foi aceito por todos. Também em 1881, Lippmann, com bases termodinâmicas, afirmou que o efeito inverso também deveria existir, ou seja, a imposição de cargas elétricas superficiais induz deformações mecânicas. Ainda neste mesmo ano, os irmãos Curie confirmaram a afirmação de Lippmann, e anunciaram que os coeficientes piezelétricos para ambos os efeitos, direto e inverso, eram idênticos (BALLATO, 1996).

William Thomson, conhecido por Lorde Kelvin, desenvolveu, em 1893, um modelo atômico para descrever o efeito piezelétrico. No ano seguinte, em 1894, o tratamento formal da piezeletricidade avançou substancialmente com os trabalhos de Pierre-Maurice-Marie Duhem e Frederich Pockels. Ainda no mesmo ano, o fenômeno da piezeletricidade alcançou a sua maturidade com artigos de Woldemar Voigt, que tratou os coeficientes piezelétricos relacionando-os com a presença de tensores mecânicos (BALLATO, 1996).

Durante a Primeira Guerra Mundial, no período de 1914-1918, Langevin utilizou transdutores piezelétricos na detecção de submarinos, tornando-se, mais tarde, o pai do sonar e da disciplina de Ultrassônica. Mais à frente, em 1920, Max Born publicou o primeiro cálculo teórico para o coeficiente piezelétrico da esfalerita ou $\beta-\mathrm{ZnS}$ (beta sulfeto de zinco), uma rocha mineral (BALLATO, 1996).

Durante a década de 1950, foram realizados os primeiros estudos sobre a piezeletricidade em polímeros polares e de origem biológica, como a celulose e o colágeno, bem como nos de origem sintética, a exemplo das poliamidas e dos ácidos poli lácticos (FUKADA, 2000). Bazhenov, em 1950, observou o efeito piezelétrico na madeira, atribuindoo às macromoléculas de celulose presentes em sua composição. Em 1953, Yasuda descobriu a piezeletricidade em ossos, ao observar que produzem eletricidade quando deformados por flexão. As primeiras demonstrações de dispositivos eletromecânicos empregando polímeros de origem biológica foram conduzidas por Fukada, em 1959, empregando tendão, osso e cartilagem de baleia em cápsulas de agulhas para toca-discos no lugar daquelas 
comercialmente utilizadas e formadas com o sal de Rochelle (tartarato de sódio e potássio) (FUKADA, 2000).

Kawai, em 1969, descobriu piezeletricidade em filmes alongados e polarizados de PVDF. A estrutura química das moléculas de PVDF resulta em dipolos que são alinhados na direção normal à superfície do filme, depois de ser carregado e originar uma polarização residual. Vários dispositivos eletromecânicos empregando o PVDF e seus copolímeros foram desenvolvidos a partir de 1970. Valores elevados para constantes piezelétricas em polímeros, $d_{31}=20 \mathrm{pC} / \mathrm{N}$ e $d_{33}=30 \mathrm{pC} / \mathrm{N}$, motivaram aplicações práticas em sensores de pressão e transdutores ultrassônicos à base deste material polimérico. Transdutores eletroacústicos ultrassônicos empregando filmes alongados e polarizados de PVDF foram produzidos, inicialmente, em 1972 e 1973. Fones de ouvido, hidrofones e alto-falantes, empregando o PVDF, foram bastante comercializados em 1975.

Fundamentados na elasticidade linear, Kacprzyk et al. (1995) demonstraram a ocorrência de uma piezeletricidade aparente devido à simples justaposição de dois materiais com propriedades elásticas diferentes. Com as deduções e experiências realizadas, foi introduzido um novo sistema constituído de camadas alternadas de filmes de Teflon ${ }^{\circledR}$ PTFE poroso e mais maleável (desenvolvido na China pela Shangai Plastics Institute), com o mesmo material, porém, não-poroso e menos maleável (fabricado na Rússia pela Plastpolymer e na Inglaterra pela Goodfellow). Originava-se, assim, um dispositivo híbrido constituído de um filme poroso, contendo micro-orifícios, envolvido por camadas externas de filmes não-porosos. Como sua deformação não é uniforme sob pressão mecânica ou imposição de calor, suas camadas carregadas são deslocadas relativamente aos eletrodos mesmo mecanismo de funcionamento do microfone de eletreto -, levando a uma resposta elétrica semelhante aos efeitos piezelétrico e piroelétrico e exibindo, assim, propriedades que justificavam as atividades eletromecânicas para um transdutor de eletretos dotado de uma piezeletricidade aparente, alcançando valores de até 30 pC/N (GERHARD-MULTHAUPT et al., 1999).

Com base no princípio de funcionamento do microfone de eletreto, muitos pesquisadores iniciaram a busca pelo desenvolvimento de filmes poliméricos que contivessem cavidades ou orifícios distribuídos em seu interior, como uma alternativa de dispor minúsculos microfones de eletreto em um único material, dentro de uma estrutura heterogênea. Com isso, foi desenvolvido na Finlândia, em 1998 - por pesquisadores da Universidade de Tecnologia de Tampere -, um filme de PP contendo cavidades celulares (ou 
microbolhas) no seu interior e finas camadas externas lisas e homogêneas do mesmo material (LEKKALA; PAAJANEN, 1999), por meio de um processo envolvendo aeração e extrusão. Após seu carregamento, as superfícies inferiores e superiores das cavidades apresentam cargas de polaridades opostas, dispondo, assim, micro-dipolos elétricos e, dessa forma, obtendo uma sensibilidade piezelétrica acima de 600 pC/N.

Assim inicia-se a busca pelo desenvolvimento de processos para a implementação de cavidades, interessantes pelas propriedades ferroelétricas, piroelétricas e piezelétricas.

Recentemente, foi introduzido o conceito de "ferroeletreto" para eletretos não polares contendo em seu interior cavidades, cujas superfícies inferiores e superiores são carregadas com polaridades opostas de cargas, exibindo, assim, um comportamento piezelétrico, piroelétrico e ferroelétrico, similar ao apresentado, por exemplo, pelos eletretos polares de PVDF (BAUER et al., 2004).

Em 2005, Wegener et al. desenvolveram um filme de politereftalato de etileno (PET), com estrutura semelhante aos filmes de PP celulares desenvolvidos na Finlândia, por meio de difusão de gás dióxido de carbono numa amostra virgem, seguido de um tratamento térmico e estiramento do filme, obtendo um coeficiente piezelétrico de aproximadamente 15 pC/N após carregamento elétrico.

Outra abordagem para a criação de cavidades é o adicionamento de partículas junto ao polímero no início do processo de extrusão do filme, seguido de estiramento. Em 2006, foi investigada a influência de esferas ocas de vidro de diferentes tamanhos na morfologia das cavidades originadas durante o estiramento de filmes de polipropileno isotático (i-PP) contendo tais partículas. Estas partículas atuam como concentradores de stress durante o processo de estiramento, e as cavidades alongadas são iniciadas como uma consequência da concentração de stress local. Neste caso, o coeficiente piezelétrico atingiu valores de até 170 $\mathrm{pC} / \mathrm{N}$, dependendo da concentração e do diâmetro das esferas adicionadas (BEHRENDT et al., 2006).

Em 2008, um novo eletreto celular foi desenvolvido a partir da fusão de microesferas de determinados tipos de polímeros contendo certos tipos de gases (isobutano ou isopropano). Além de criar pontos de contato entre as esferas, o aquecimento também provocou sua expansão, originando, assim, uma nova espuma que alcançou um coeficiente piezelétrico de 330 pC/N (WINDMILL et al., 2008).

Os resultados das pesquisas com transdutores eletromecânicos constituídos de filmes 
de eletretos porosos e celulares motivaram Altafim et al. (2003, 2005, 2006) no desenvolvimento de dispositivos similares. Seu primeiro dispositivo é constituído por duas camadas de Teflon ${ }^{\circledR}$ FEP unidas pela aspersão de verniz pulverizado, como um adesivo, sobre a superfície interior de cada película, obtendo, assim, um coeficiente piezelétrico da ordem de 300 pC/N (ALTAFIM et al., 2003). Dessa forma, surge uma nova abordagem para a produção de ferroeletretos; ferroeletretos de filmes homogêneos. E o segundo dispositivo elaborado por Altafim et al. constitui-se de dois filmes de Teflon ${ }^{\circledR}$ FEP envolvendo microbolhas de ar homogêneas, construído por meio do processo denominado termo-formado, resultando em ferroeletretos com coeficiente piezelétrico de 500 pC/N (ALTAFIM et al., 2005, 2006).

De forma similar, Zhang, Hillenbrand e Sessler (2006, 2007) desenvolveram um ferroeletreto, também constituído de bolhas distribuídas uniformemente, pressionando uma grade metálica aquecida contra uma estrutura de três ou mais camadas de PTFE e FEP, organizadas em uma sequência alternada, sendo as medidas da atividade piezelétrica apontando valores entre 1000 e 2200 pC/N, dependendo da quantidade de camadas.

Diante dessa diversidade de técnicas para a fabricação de ferroeletretos, serão discutidas nas seções que se seguem as metodologias empregadas tanto para a produção de ferroeletretos celulares e porosos, quanto para a produção de ferroeletretos a partir de estruturas homogêneas.

\subsection{Espumas Poliméricas}

Os polímeros celulares, ou espumas poliméricas, são comuns no nosso dia-a-dia. Eles são usados como isolantes térmicos, como embalagens, como isolador acústico, justificado por seu baixo peso e por suas boas propriedades mecânicas (LINDNER et al., 2004); recentemente, emergiram como uma nova classe de materiais para aplicação em dispositivos eletromecânicos (GERHARD-MULTHAUPT, 2002).

O processo de produção dos filmes porosos e celulares combina procedimentos de aeração em fusão, seguida de extrusão sob resfriamento. Assim, são produzidas microcavidades no material com dimensões não homogêneas, determinadas por um conjunto de condições específicas, tais como: temperatura de fusão, velocidade de agitação da massa fundida, pressão do ar insuflado na solução, diâmetro do tubo na extrusão, temperatura de resfriamento, além de eventuais interferências que possam ocorrer. A influência de todas estas 
variáveis acaba contribuindo para que o processo industrial, assim descrito, seja controlado estatisticamente na linha de produção (GERHARD-MULTHAUPT, 2002).

\subsubsection{Polipropileno Celular}

O polímero formado por filmes com espumas de i-PP orientado biaxialmente (paredes entre as cavidades) é altamente cristalino e também anisotrópico, com cavidades em forma de lentes ou discos, com diâmetros da ordem de $10 \mu \mathrm{m}$ e espessura de $1 \mu \mathrm{m}$ (SAVOLAINEN, 1990). A maioria destes filmes de PP celular possui camadas externas coextrudadas de PP liso, isto é, não esponjoso, o que contribui no polimento da superfície, na uniformidade da espessura e na aderência aos eletrodos (PAAJANEN; LEKKALA; KIRJAVAINEN, 2000).

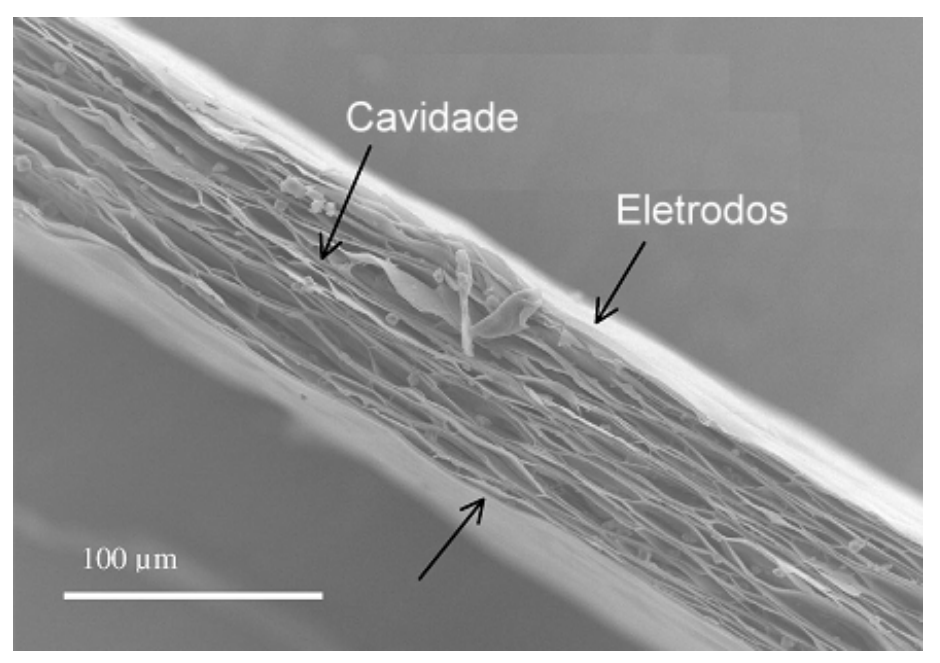

Figura 2.15 Imagem por microscopia eletrônica da seção transversal de um filme de PP celular de 70 um de espessura (PAAJANEN; VÄLIMÄKI; LEKKALA, 2000).

O PP celular é, geralmente, carregado por efeito corona (sem grade de controle em alta tensão), com uma tensão superior a $20 \mathrm{kV}$ (PAAJANEN; LEKKALA; KIRJAVAINEN, 2000; VAN TURNHOUT et al., 1999), e as camadas superficiais de cargas produzem campos elétricos intensos que são levados à ruptura interna nas cavidades do material (CRICHTON; KARLSSON; PEDERSEN, 1989; MCALLISTER, 1992, MCALLISTER, 1997). Após a ruptura elétrica, cada cavidade do material tem sua parte superior e inferior carregada com polaridades respectivamente opostas (Figura 2.16b) às polaridades dos eletrodos adjacentes (VAN TURNHOUT et al., 1999).

O papel da ruptura elétrica interna na obtenção da carga interna e na correspondente resposta piezelétrica foi confirmado por experiências em diversas amostras de PP celular 
fabricadas com cavidades formadas pela aeração com diferentes gases. O ar foi substituído por outros gases de moléculas menores, entre elas, o nitrogênio $\left(\mathrm{N}_{2}\right)$ e o gás hilariante (óxido nitroso, $\mathrm{N}_{2} \mathrm{O}$ ), injetados sob ciclos de pressão acima da atmosférica, alternando com o vácuo. Estes gases com moléculas pequenas se difundem mais facilmente pelas paredes do polímero entre as cavidades e oferecem maior resistência à ruptura elétrica interna, permitindo níveis mais altos de carga no interior das cavidades, com coeficientes piezelétricos maiores, de até 790 pC/N (PAAJANEN; WEGENER; GERHARD-MULTHAUPT, 2001a, 2001b).

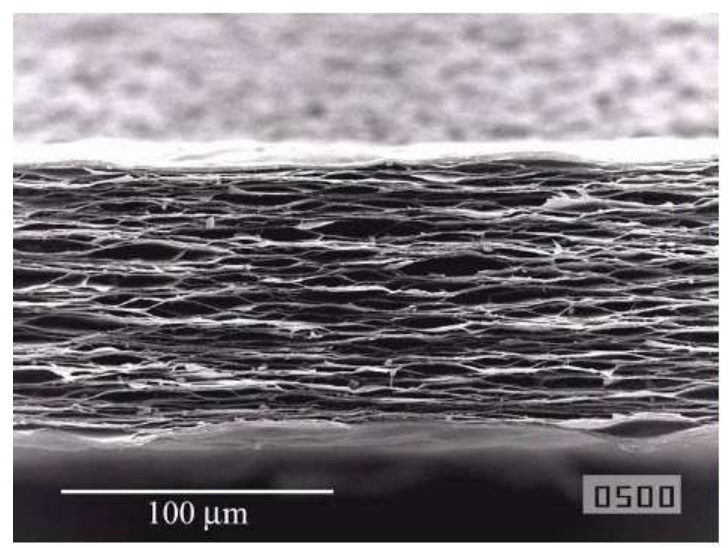

(a)

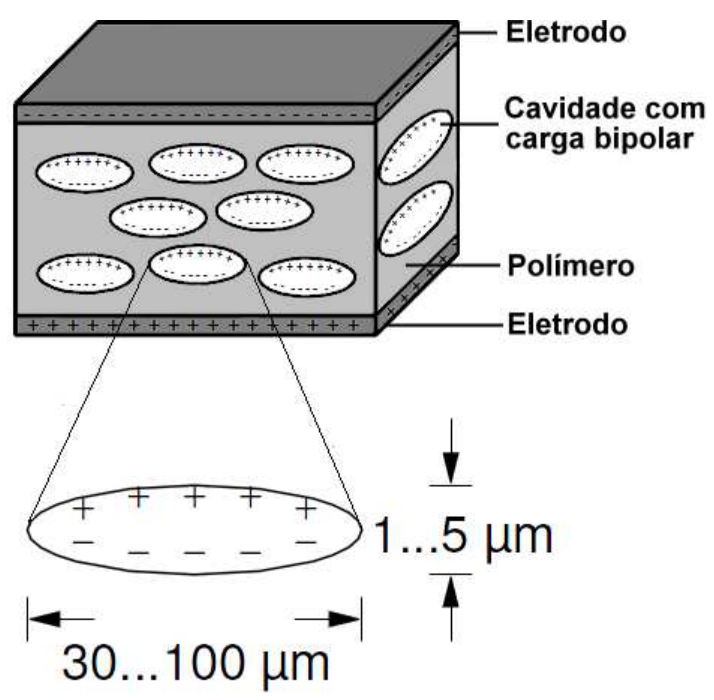

(b)

Figura 2.16 (a) Seção transversal de filme polipropileno celular em microscopia eletrônica (PAAJANEN; WEGENER; GERHARD-MULTHAUPT, 2001b). (b) Vista esquemática das cavidades e distribuição de cargas.

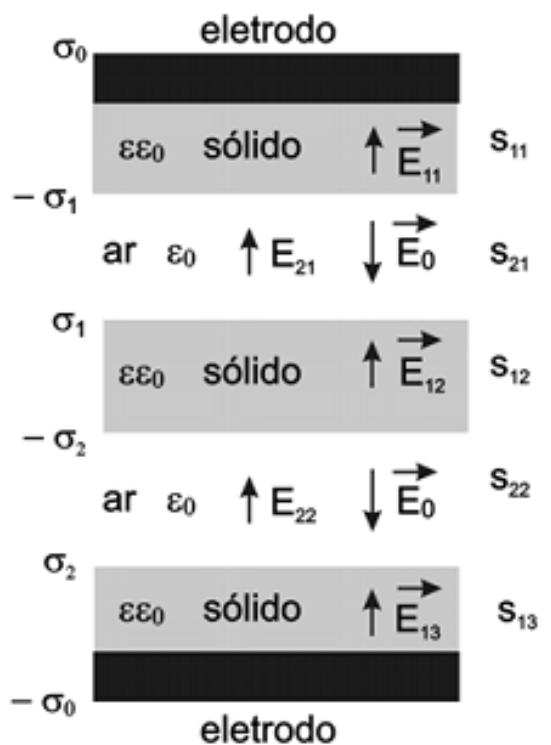

Figura 2.17 Estrutura capacitiva dos filmes de PP celular (SESSLER; HILLENBRAND, 1999a, 1999b; HILLENBRAND; SESSLER, 2000). 
Estes espaçamentos vazios e alongados, com estas dimensões e as camadas envolventes, transmitem a ideia de capacitores planos (Figura 2.17) associados, em série, entre os eletrodos, dispondo, finalmente, estes arranjos seriais em paralelo (SESSLER; HILLENBRAND, 1999a, 1999b; HILLENBRAND; SESSLER, 2000).

Existe uma relação biunívoca entre os dipolos formados pelas cavidades carregadas, internamente, num eletreto celular, e as variações nas suas espessuras - consequentemente, em seus momentos dipolares, quando o filme de PP celular sofre deformações sob solicitação elétrica ou mecânica. Conforme mostrado na Figura 2.18, este comportamento pode ser considerado piezeletricidade primária, em analogia aos materiais piezelétricos polares. A piezeletricidade observada nos eletretos de filmes de PP celulares opera, praticamente, no chamado modo espessura $\left(d_{33}\right)$, em que suas grandes variações são, comparativamente, maiores do que no comprimento do material celular quando sob solicitações mecânicas ou elétricas.
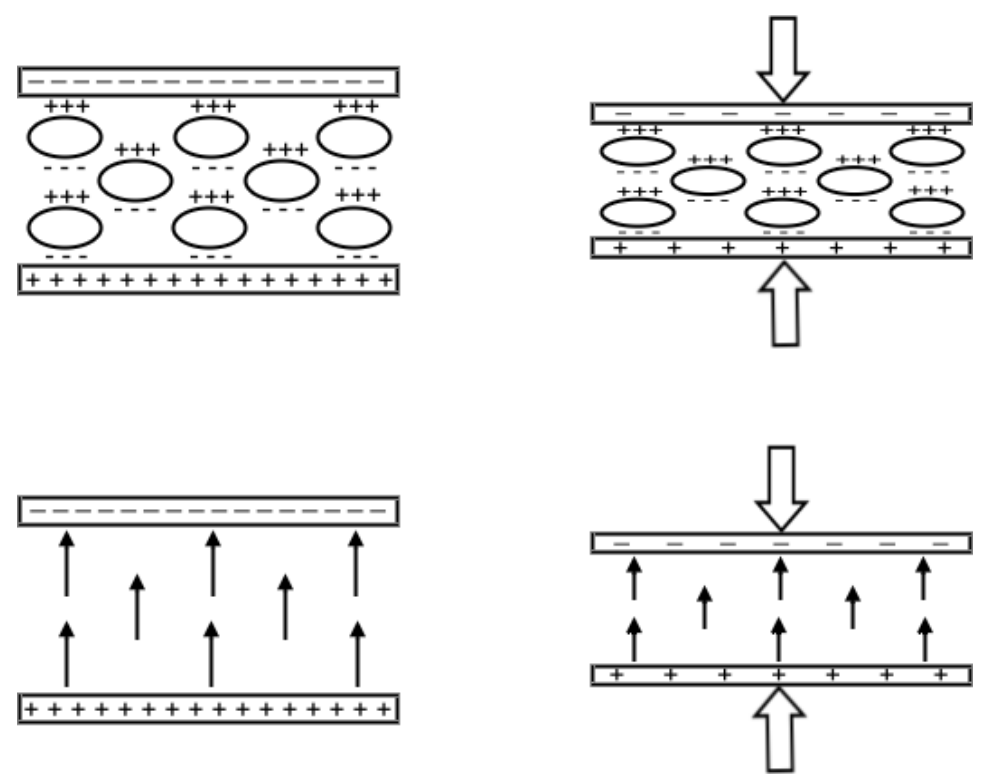

Figura 2.18 Representação da piezeletricidade primária (variação do momento dipolar com a deformação) em eletretos celulares com distribuição espacial de carga (acima) e em eletretos polares (abaixo). Sob compressão, os dipolos orientados e as cavidades carregadas (esquerda) ficam com momentos dipolares menores (direita)(GERHARD-MULTHAUPT, 2002).

Quanto à estabilidade térmica, os eletretos de PP perdem uma quantidade significativa de suas cargas em temperaturas bem abaixo de $100{ }^{\circ} \mathrm{C}$ (YANG, 1993). Experimentos com TSC em circuito aberto mostraram que o envelhecimento térmico pode melhorar a estabilidade da carga (VAN TURNHOUT et al., 1999); porém, não há boa retenção de cargas, mesmo a temperaturas de $100{ }^{\circ} \mathrm{C}$. Medidas de TSC sob curto circuito (PAAJANEN; LEKKALA; KIRJAVAINEN, 2000; PAAJANEN; LEKKALA; VÄLIMÄKI, 
2001) e de decaimento no tempo da resposta piezelétrica em temperaturas elevadas levaram à conclusão de que os eletretos fabricados com esponja de PP não podem ser utilizados ou armazenados em temperaturas superiores a 60-70 ${ }^{\circ} \mathrm{C}$ (SESSLER; HILLENBRAND, 1999a; HILLENBRAND; SESSLER, 1999).

Com relação às suas vantagens, este material apresenta uma grande maleabilidade devido às microcavidades presentes internamente, aliadas a uma forte carga elétrica retida e permanente, imprimindo maior sensibilidade às respostas das ações de forças exercidas numa direção normal à sua superfície. Além disso, este material, desenvolvido e conhecido como filme eletromecânico (EMFi - electromechanical film), é fino e fácil de ser cortado em qualquer forma e tamanho, podendo, assim, ser utilizado em inúmeras aplicações, destacandose pela sua portabilidade e, também, pela sua versatilidade (GERHARD-MULTHAUPT, 2002).

\subsubsection{Eletretos Porosos Com Um Único Filme de PTFE}

A alta estabilidade de carga superficial dos filmes de PTFE poroso, em particular, a temperaturas elevadas, foi confirmada em experimentos repetidos (XIA et al., 1999; XIA; WEDEL; DANZ, 1999) e independentes (PAAJANEN; VÄLIMÄKI; LEKKALA, 1999; SCHWÖDIAUER et al. 2000). Subsequentemente, foram investigadas as propriedades piezelétricas de eletretos com um único filme e múltiplas camadas de filmes de PTFE porosos. Para um único filme, foi encontrado um alto coeficiente piezelétrico (KÜNSTLER et al., 2000), mas o efeito decresce pela metade quando filmes não porosos de PTFE, sem cargas, são inseridos entre as camadas porosas e carregadas de PTFE e os eletrodos (GERHARD-MULTHAUPT et al., 2000; WEINHOLD et al. 2000). Além do mais, os eletrodos metalizados por pulverização direta sobre o PTFE poroso tornaram-se inviáveis, uma vez que não se pode evitar um contato elétrico (curto-circuito) entre os eletrodos através dos poros abertos do fluoropolímero (GERHARD-MULTHAUPT, 2002).

Estes filmes, com poros abertos e camada única, foram analisados com um e dois eletrodos de metal, confirmando que grande parte do efeito piezelétrico, neste caso, origina-se da variação nas cavidades de ar entre o eletreto poroso e o(s) eletrodo(s) (GERHARDMULTHAUPT et al., 2000). Como este efeito depende de condições não tão bem definidas, tais como a rugosidade do eletrodo, a planaridade do eletreto e a história da amostra, ele não pode ser controlado nem reproduzido com precisão, portanto, não é adequado para a maioria das aplicações (GERHARD-MULTHAUPT, 2002). 
Seria desejável contornar os problemas encontrados empregando-se filmes celulares de fluoropolímeros com uma estrutura com cavidades similar ao PP, adicionada do aumento da estabilidade de carga do PTFE. Este objetivo é difícil de ser atingido, visto que os fuoropolímeros são mais difíceis de serem manipulados e processados que a maioria dos polímeros de hidrocarbonetos. A fadiga mecânica do PTFE exclui este homopolímero de aplicações envolvendo muitos ciclos de solicitação ou com grandes cargas estáticas (GERHARD-MULTHAUPT, 2002).

\subsubsection{Sanduíche de Camadas Com Eletretos Porosos de PTFE}

Os eletretos com poros abertos de filme de PTFE foram - de um modo prático, porém incômodo - empregados como transdutores piezelétricos incorporados em camadas, como num sanduíche (KÜNSTLER et al., 2000; GERHARD-MULTHAUPT et al., 1999). A concepção básica, conforme mostrada na Figura 2.19, à esquerda, segue ou a estrutura da maioria dos filmes celulares de PP - com suas camadas mais externas não porosas e um núcleo interno poroso formado por um volume carregado (PAAJANEN; LEKKALA; KIRJAVAINEN, 2000) -, ou, à direita, como sanduíches de dupla camada, uma mais e outra menos maleável, com uma distribuição superficial de carga entre elas (KACPRZYK; MOTYL, 1994; KACPRZYK; DOBRUCKI; GAJEWSKI, 1997).

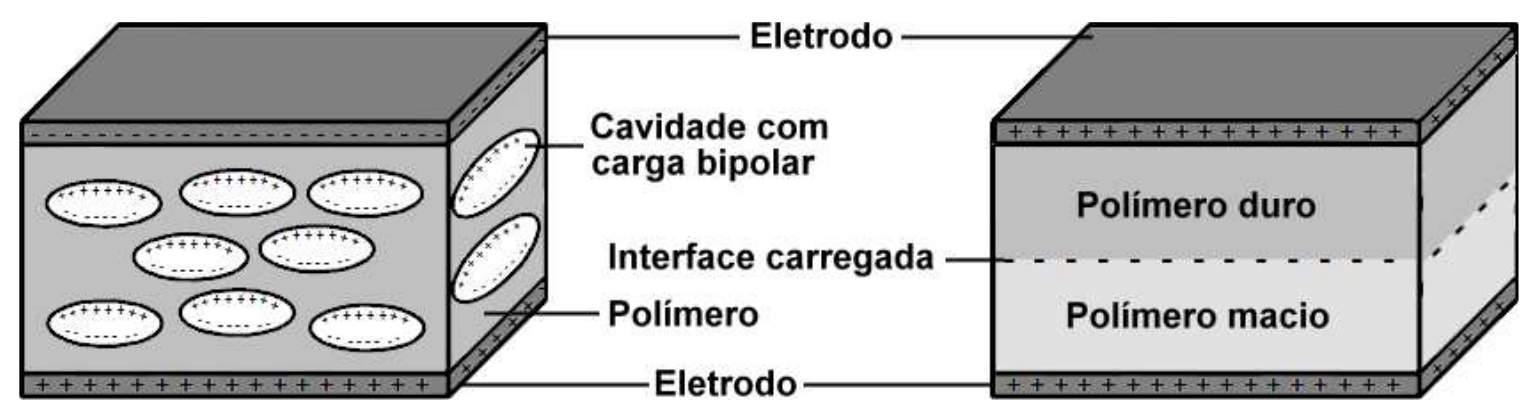

Figura 2.19 Material piezelétrico poroso, com cavidades internas (esquerda) e duas camadas (direita), ambas terminadas por eletrodos (GERHARD-MULTHAUPT, 2002).

Um estudo com várias amostras em arranjos de duas, três e quatro camadas (Tabela 2.2) - com cargas superficiais entre os filmes porosos e não porosos de PTFE - mostrou que a resposta piezelétrica de tais transdutores de eletreto é (GERHARD-MULTHAUPT et al., 1999; GERHARD-MULTHAUPT et al., 2000): 
1. aproximadamente, a metade, quando a camada maleável é dobrada,

2. mais do que dobrada, quando ambas as camadas já possuem as superfícies carregadas antes da montagem do sanduíche, e

3. dobrada, quando dois sanduíches de dupla camada são montados face a face com seus eletrodos em contato, resultando em um transdutor encapsulado e eletricamente muito bem blindado.

Tabela 2.2 Amostras em camadas rígidas e macias de Teflon ${ }^{\circledR}$ PTFE (GERHARD-MULTHAUPT et al., 1999).

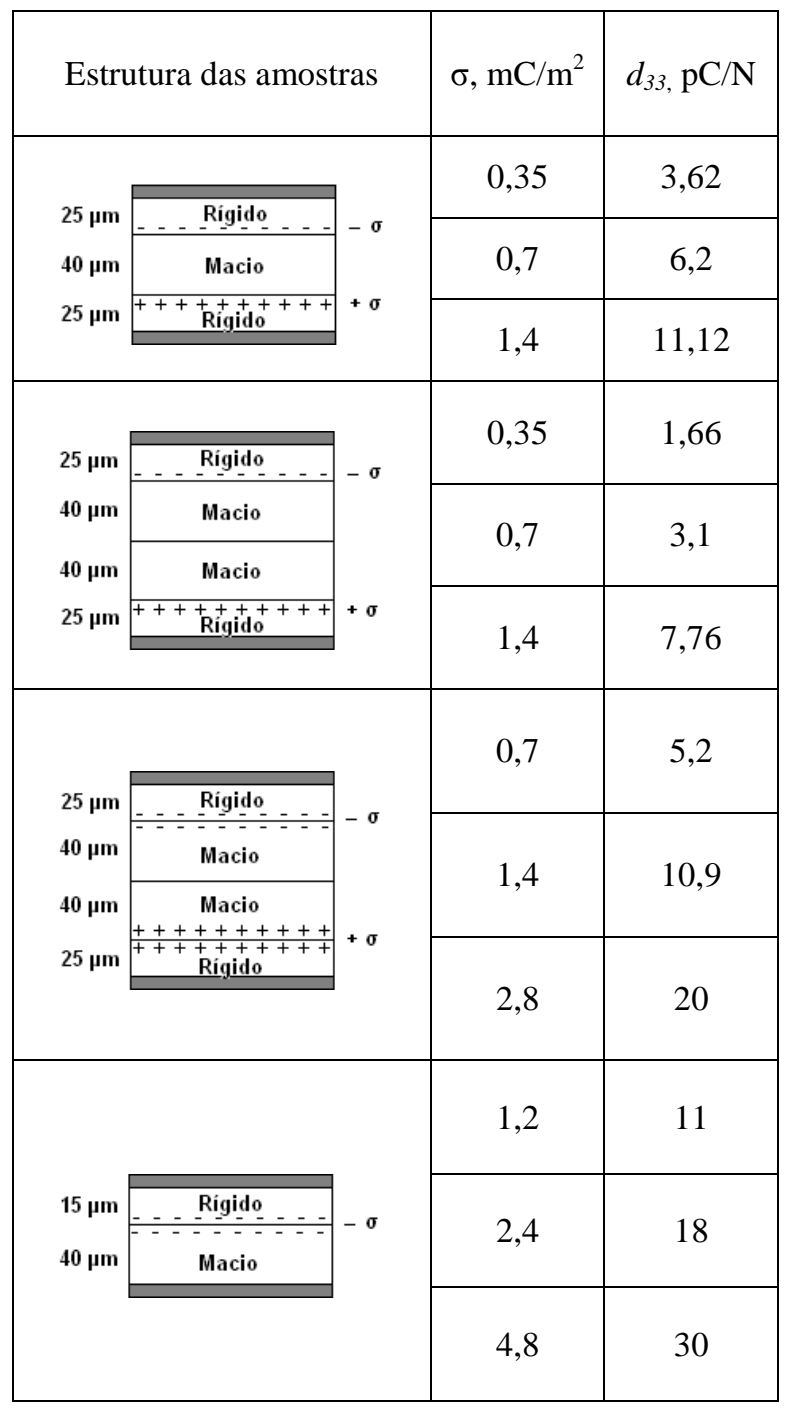

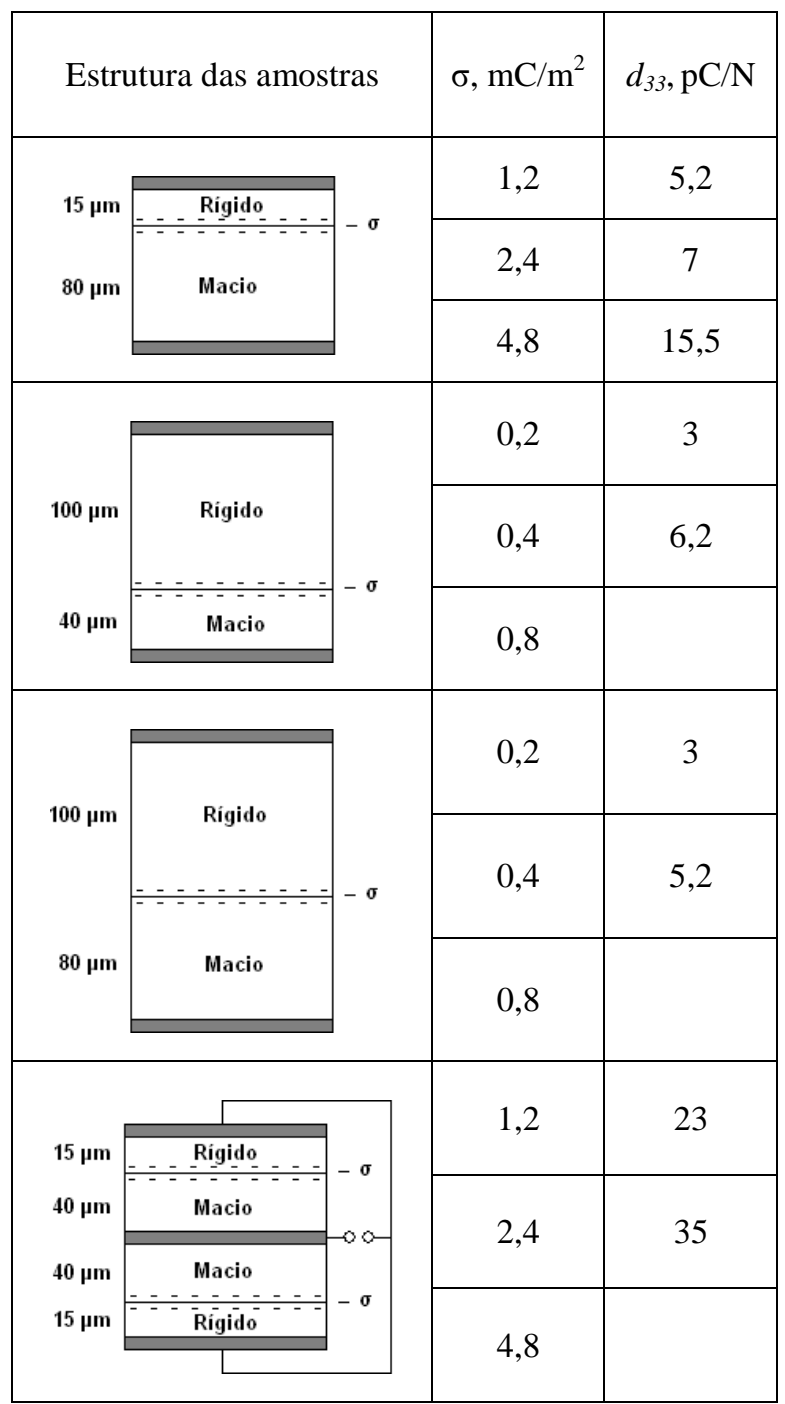


Também foram desenvolvidos filmes com eletretos poliméricos rígidos de perfluor ciclobuteno e combinados com filmes de PTFE porosos (SCHWÖDIAUER et al. 1999a, 1999b), como eletretos, em sanduíches de camadas maleáveis e não maleáveis, fornecendo altíssimas respostas piezelétricas (SCHWÖDIAUER et al. 2000; NEUGESCHWANDTNER et al. 2000).

$\mathrm{Na}$ prática, eletretos de PTFE porosos foram estudados em condições específicas, com uma cobertura em um ou em ambos os lados (GERHARD-MULTHAUPT, 2002), pelo simples espalhamento de uma solução de um flúor polímero amorfo (AF), ou com a aplicação desta solução por spin-coating (espalhamento da solução em rotação seguido de evaporação controlada para espalhamento uniforme). Na Figura 2.20, ilustra-se um sanduíche de eletreto polimérico poroso entre dois filmes poliméricos não porosos altamente isolantes, conectados por eletrodos nas suas superfícies externas.

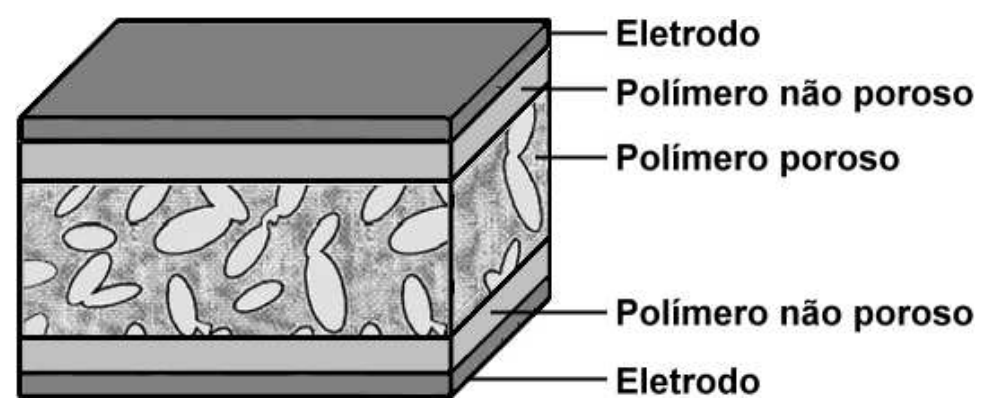

Figura 2.20 Eletreto polimérico poroso com camadas não porosas para proteção da carga depositada e deposição de eletrodos (GERHARD-MULTHAUPT, 2002).

O carregamento por corona, seguido da metalização da cobertura, ainda produziu coeficientes piezelétricos razoáveis, de modo que se supôs uma separação da carga interna no sistema de camadas encapsuladas do flúor polímero (GERHARD-MULTHAUPT, 2002). Os coeficientes piezelétricos observados, no entanto, não são competitivos, e a estabilidade térmica da cobertura de AF é limitada pela sua temperatura de transição vítrea - em torno de $160{ }^{\circ} \mathrm{C}$ (GERHARD-MULTHAUPT, 2002). Filmes de sanduíche de eletreto de PTFE poroso com boa qualidade foram obtidos quando cobertos por spin-coating com poliestireno (PS), ou com um adesivo de PET (WEGENER et al. 2001).

\subsubsection{Ferroeletretos de Politereftalato de Etileno}

A Figura 2.21 resume o processo de preparação da espuma de PET desenvolvida por Wegener et al. (2005), que é formada por meio de difusão, em alta pressão, de dióxido de 
carbono $\left(\mathrm{CO}_{2}\right)$ em uma amostra virgem não porosa, seguida de um tratamento térmico em uma banheira com água aquecida, fazendo com que o $\mathrm{CO}_{2}$ difuso no material sofra expansão e, assim, origine microcavidades.

No entanto, este primeiro passo conduziu a formação de cavidades quase esféricas. É sabido, de pesquisas sobre filmes de PP celulares e de simulações numéricas, que cavidades na forma de lentes com razão a/b dos seus raios (a: extensão da cavidade, b: altura da cavidade) entre 2 e 6 fornecem melhores atividades piezelétricas (TUNCER; WEGENER, 2004; WEGENER et al., 2004). Cavidades quase esféricas com uma razão a/b dos seus raios menores que 1.5 , geralmente são muito duros para permitir deformações e, dessa forma, não mostram uma piezeletricidade significante. Por isso, foi realizado um segundo passo, no qual é feito, primeiramente, um estiramento na direção $x$ e, depois, um estiramento na direção $y$, alcançando, assim, razões a/b superiores a 4.

Por fim, a espuma foi submetida ao carregamento elétrico por meio de descarga corona ponta-plano com uma tensão de $-25 \mathrm{kV}$ por $30 \mathrm{~s}$. Essa espuma de PET porosa carregada eletricamente apresentou um coeficiente piezelétrico de aproximadamente $15 \mathrm{pC} / \mathrm{N}$.

a)

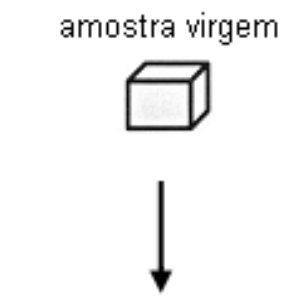

b) tratamento com $\mathrm{CO}_{2}$
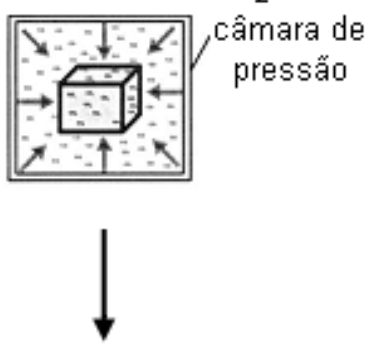

c) tratamento térmico

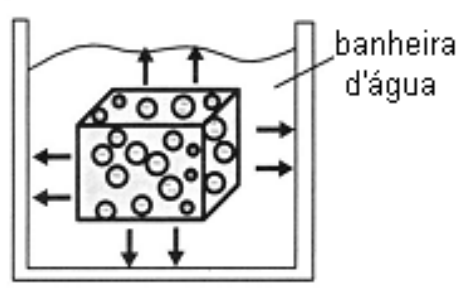

e) carregamento
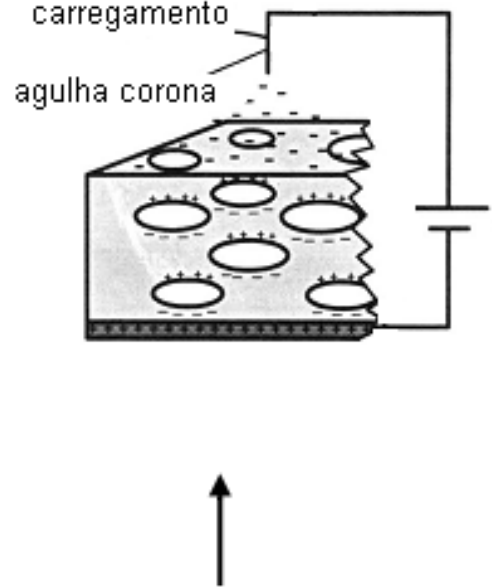

d) estiramento

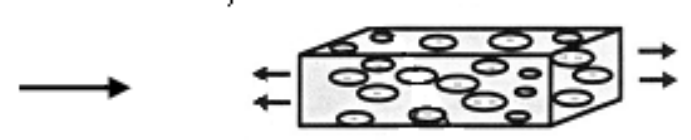

Figura 2.21 Esquema de preparação dos filmes de PET celulares por meio de (b) difusão de $\mathrm{CO}_{2}$ numa amostra virgem (a) submetida a uma alta de pressão, (c) tratamento térmico originando microcavidades, (d) estiramento do filme modificando sua estrutural e (e) carregamento elétrico interno por meio de descargas de micro-plasma nas cavidades (WEGENER et al., 2005). 


\subsubsection{Polipropileno Poroso por Adição de Esferas Ocas de Vidro e Estiramento Biaxial}

Como exemplo da técnica de adição de partículas para a produção de espumas polimérica cita-se a produção de PP poroso, proposto por Behrendt et al. em 2006, a partir da adição de esferas ocas de vidro no início do processo extrusão do filme seguido de estiramento biaxial.

Nesse processo, i-PP em pó e esferas ocas de vidro de diferentes diâmetros e em diferentes concentrações foram misturados a temperatura ambiente e deixados secar por um dia a $120^{\circ} \mathrm{C}$. Uma extrusora, operando numa faixa de aquecimento entre 200 e $230{ }^{\circ} \mathrm{C}$, então alimentada por essa mistura, produziu filmes de aproximadamente $0,3 \mathrm{~mm}$ de espessura. Em seguida, uma pilha com 12 folhas desse filme, pré-aquecida por 3 minutos a uma temperatura de $260{ }^{\circ} \mathrm{C}$, foi pressionada por uma força de $15 \mathrm{kN}$ durante 4 minutos, nesta mesma temperatura, e, após esse tempo, foi deixada resfriar a temperatura ambiente, originando um novo filme com 0,9 mm de espessura. Depois disso, foi realizado o estiramento biaxial desse novo filme. Nesse processo de estiramento, as esferas de vidro atuam como concentradores de stress e as cavidades alongadas são iniciadas como uma consequência da concentração de stress local. Por fim, o novo filme celular (Figura 2.22) foi submetido ao carregamento elétrico por meio de descarga corona, com uma tensão de $32 \mathrm{kV}$ por $60 \mathrm{~s}$, e suas superfícies foram metalizadas.

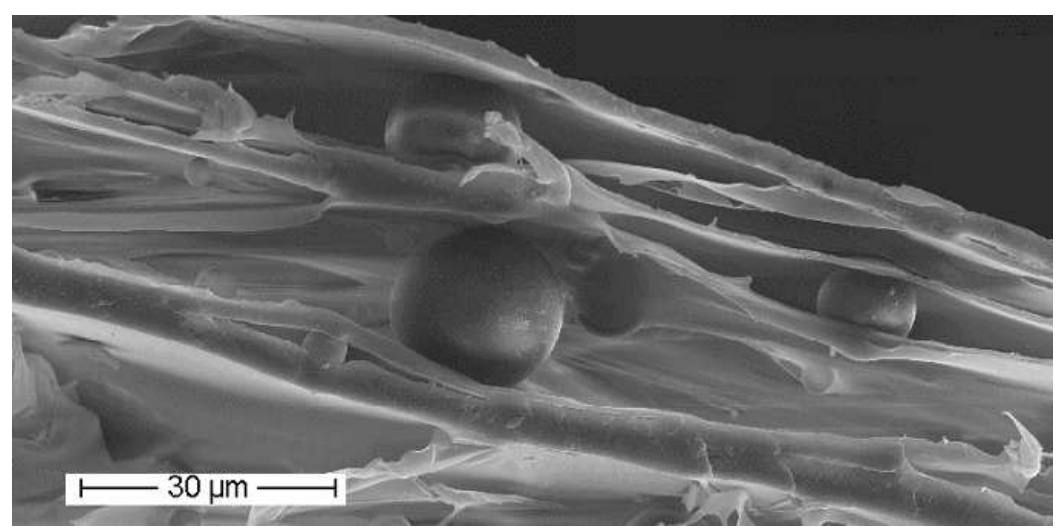

Figura 2.22 Micrografia por escaneamento eletrônico da seção transversal de um filme de i-PP com esferas de vidro de $30 \mu \mathrm{m}$ de diâmetro (BEHRENDT et al., 2006).

Usando o procedimento descrito acima, diferentes tipos de esferas ocas de vidro com diâmetros médios diferentes foram misturados com a i-PP em diferentes escalas de concentração. A influência da cavidade formada foi então estudada com relação às propriedades piezelétricas desses filmes. Assim, foi observado que os filmes estirados com 
esferas maiores alcançaram maiores atividades piezelétricas comparados aos filmes com esferas menores, pois esferas maiores resultam em cavidades maiores - o que conduz a uma maior maciez e, portanto, um maior coeficiente piezelétrico. Os filmes estirados com esferas de 30 e $40 \mu \mathrm{m}$ de diâmetro obtiveram coeficiente piezelétrico, respectivamente, de 98 pC/N e $170 \mathrm{pC} / \mathrm{N}$.

\subsection{Ferroeletretos com Estruturas Homogêneas}

\subsubsection{Transdutores Poliméricos Homogêneos em Multicamadas de Teflon ${ }^{\circledR}$ FEP}

O primeiro dispositivo construído pela equipe de Altafim (2003) era constituído por duas camadas circulares de Teflon ${ }^{\circledR}$ FEP empilhadas, cada uma com 2,5 cm de diâmetro e 75 $\mu \mathrm{m}$ de espessura, terminadas por duas folhas laminadas em alumínio, como eletrodos de contato, conforme a ilustração na Figura 2.23. Os filmes poliméricos foram unidos pela aspersão de verniz pulverizado, como um adesivo, sobre a superfície interior de cada película.

A irregularidade deixada pela aspersão do verniz acabou resultando na formação de cavidades microscópicas de ar, que deixava uma espessura média de $10 \mu \mathrm{m}$ entre os filmes poliméricos, conferindo, assim, uma geometria semelhante àquela dos filmes celulares industrialmente produzidos. O mesmo verniz também foi utilizado para colar as folhas de alumínio, como eletrodos, nas películas de Teflon ${ }^{\circledR}$ FEP. O dispositivo foi, então, montado e carregado por um impulso negativo em alta tensão.

No entanto, esta técnica resultou em amostras com baixa resistência mecânica devido à característica antiaderente do Teflon ${ }^{\circledR}$ FEP.
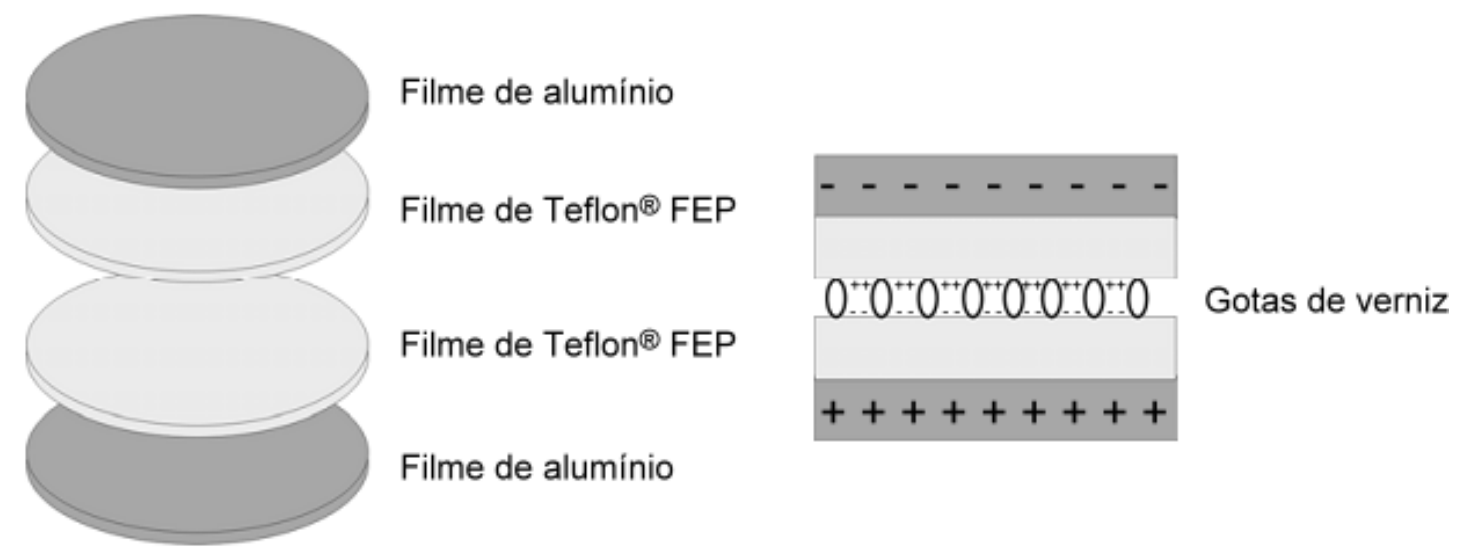

Figura 2.23 Sanduiche multicamada formado por filmes de Teflon ${ }^{\circledR}$ FEP e alumínio (ALTAFIM, et al. 2003). 


\subsubsection{Transdutores de Eletretos Termo-Formados}

Os problemas apresentados quanto à aspersão do verniz entre os dois filmes de Teflon $^{\circledR}$ FEP foram observados e, dois anos depois, novas mudanças foram propostas por Altafim e colaboradores. Em lugar do verniz sob aspersão, o elemento de separação entre as camadas poliméricas foi substituído por micro células obtidas com bolhas de ar distribuídas na interface entre as películas; assim, a condutividade elétrica e a ocorrência de descargas internas nas camadas de ar - observadas na versão anterior deste dispositivo - eram minimizadas.

Como uma alternativa melhorada, desenvolveu-se mais um transdutor eletromecânico com eletretos em filmes poliméricos de Teflon ${ }^{\circledR} \mathrm{FEP}$, não poroso e não celular. Este dispositivo foi produzido com a utilização de eletrodos metálicos aquecidos independentemente e uma bomba a vácuo para formar múltiplas bolhas de ar em um dos filmes de Teflon $^{\circledR}$ FEP. A Figura 2.24 mostra uma representação esquemática desse mecanismo (ALTAFIM et al., 2005).

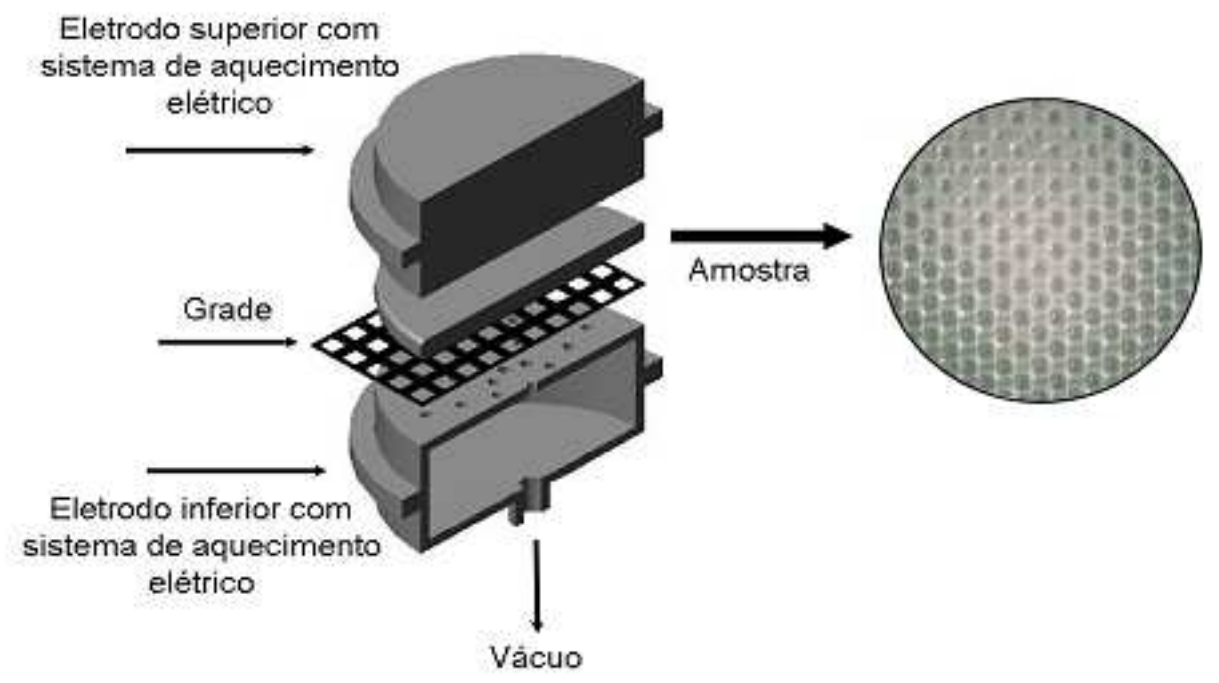

Figura 2.24 Dispositivo para obtenção dos transdutores poliméricos termo-formados (ALTAFIM et al., 2006).

Este arranjo possui uma placa metálica superior móvel pivotante e outra fixa a uma base inferior, ambas com uma resistência elétrica, para o aquecimento controlado, numa temperatura inferior ao ponto de fusão das películas. Sobre a base inferior, é colocada uma espécie de máscara metálica que configura a geometria das bolhas de ar que serão formadas.

Esta máscara é formada por uma grade reticulada ou por uma chapa perfurada, por meio da qual todas as bolhas serão formadas de maneira homogênea. Esta base fixa e inferior 
possui uma comunicação hermética com uma bomba de vácuo, que provoca o estiramento da película inferior quando aquecida.

Estando as duas placas aquecidas, coloca-se uma película sobre a máscara aquecida, que será, posteriormente, submetida a um vácuo que provoca o estiramento do filme nos locais marcados pela máscara, concebendo forma às bolhas. Em seguida, a outra película é posta sobre a primeira e ambas são prensadas entre as duas placas aquecidas, o suficiente para uni-las por uma espécie de solda. A Figura 2.25 mostra um transdutor produzido em laboratório por este processo, com os detalhes das microbolhas de ar formadas entre os dois filmes poliméricos de Teflon ${ }^{\circledR}$ FEP, que serão, assim, carregados para formar os eletretos (ALTAFIM et al., 2005).

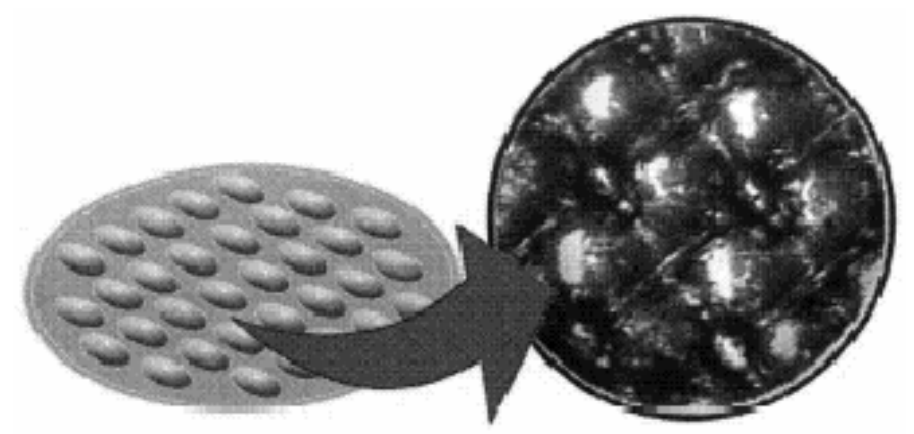

Figura 2.25 Detalhe das bolhas de ar entre os filmes poliméricos (ALTAFIM et al., 2005).

Este transdutor de eletretos com bolhas de ar termo-formadas e, então, denominados de eletretos termo-formados é, portanto, obtido pela união térmica de duas películas poliméricas, com microbolhas de ar, pronto para ser submetido ao processo de carregamento elétrico. Depois do carregamento interno por uma alta tensão impulsiva, essa estrutura contendo bolhas exibiu atividades piezelétricas bastante altas, com coeficientes superiores a 500 pC/N (ALTAFIM et al., 2006).

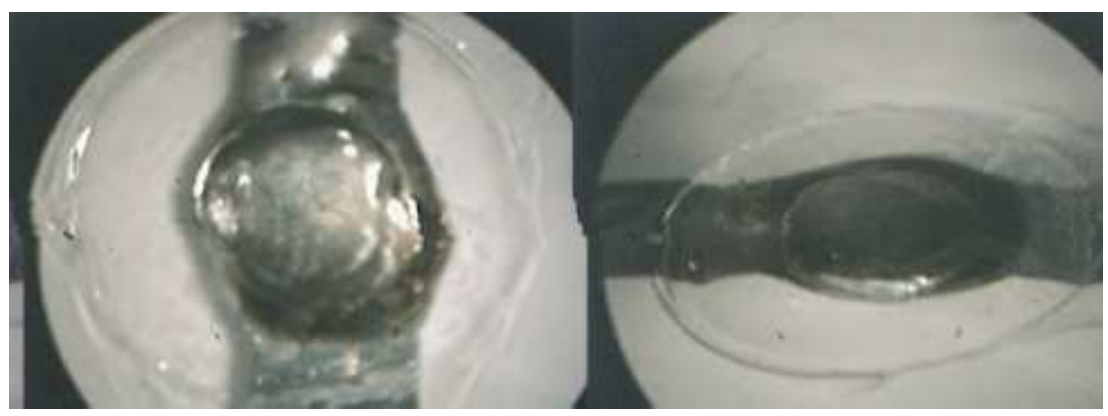

Figura 2.26 Amostra termo-formada (PISANI ALTAFIM, 2006). 
No entanto, esse processo de produção de amostras, geralmente, produz amostras com deformações (PISANI ALTAFIM, 2006), ou seja, com bolhas de diferentes tamanhos, como pode ser visto na Figura 2.26.

\subsubsection{Ferroeletreto Multicamadas de Teflon ${ }^{\circledR}$ PTFE e FEP}

O ferroeletreto proposto por Zhang, Hillenbrand e Sessler (2006) consiste de camadas alternadas de PTFE e FEP com cavidades nas suas interfaces. O procedimento para fabricação desses filmes é similar ao introduzido por Altafim et al. (2005), diferindo-se no uso de uma pilha alternada de camadas de PTFE e FEP.

(a)

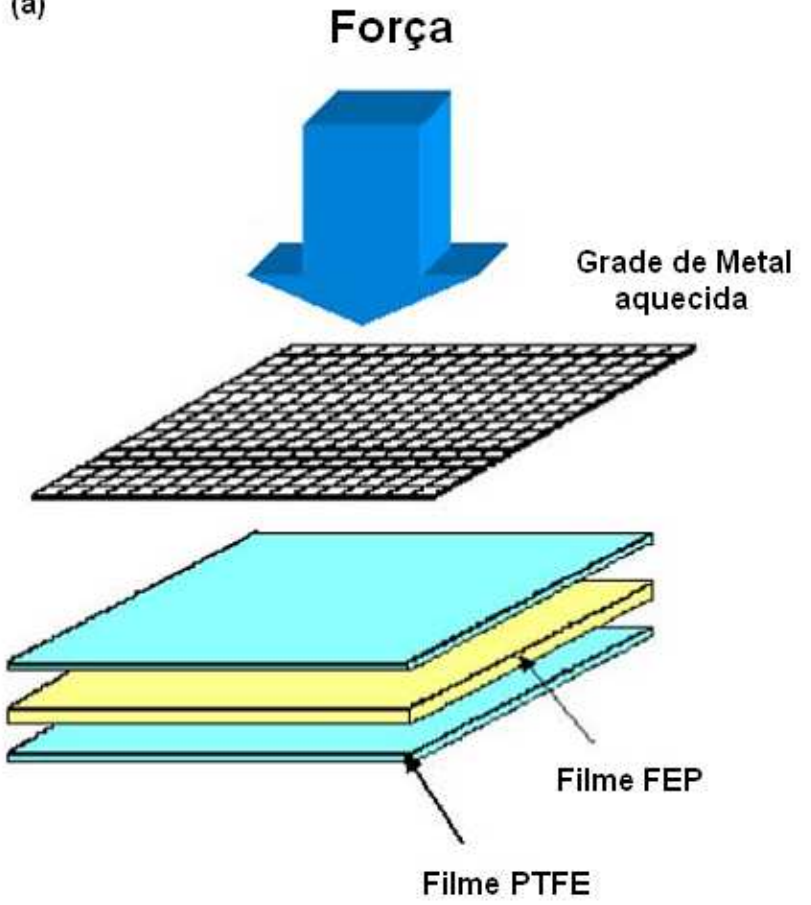

(b)

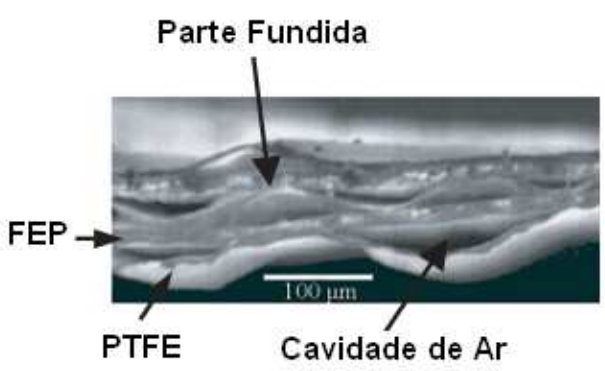

(c)

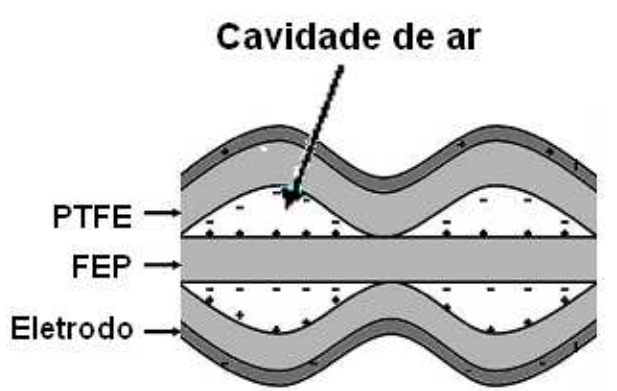

Figura 2.27 (a) Procedimento de preparação do filme celular fluorcarbonado (ZHANG; HILLENBRAND; SESSLER, 2006), (b) Imagem obtida por microscopia eletrônica de varredura da seção transversal de um filme de cinco camadas (ZHANG; HILLENBRAND; SESSLER, 2007), (c) esquema da seção transversal de um filme de três camadas, com sua distribuição de cargas após metalização e carregamento elétrico (ZHANG; HILLENBRAND; SESSLER, 2007).

O procedimento de preparação é ilustrado na Figura 2.27. Os filmes são preparados pela fusão a elevada temperatura de três ou mais camadas de PTFE e FEP, dispostas em uma sequência alternada, sendo sempre o PTFE o filme de revestimento. Uma grade de metal é pressionada contra a pilha de filmes, com uma forca de aproximadamente $20 \mathrm{~N}$, aquecida a uma temperatura de $280{ }^{\circ} \mathrm{C}$, por um período de uma hora. Por fim, a pilha é resfriada lentamente e a grade de metal é, então, retirada. Assim, são formadas bolhas de ar na interface 
dos filmes. Após o carregamento do filme, foi constatado um coeficiente piezelétrico acima de $1000 \mathrm{pC} / \mathrm{N}$; uma estabilidade térmica foi verificada após submeter o filme a um ambiente aquecido a $90^{\circ} \mathrm{C}$ por 4 dias, com um coeficiente piezelétrico de, aproximadamente, $400 \mathrm{pC} / \mathrm{N}$.

\subsection{Coeficiente Piezelétrico dos Ferroeletretos de Duas Camadas Homogêneas}

No processo de polarização dos ferroeletretos, os macro-dipolos ficam alinhados na mesma direção do campo elétrico aplicado, devido às cargas aprisionadas nas superfícies internas das cavidades (BAUER et al., 2003; LINDNER et al., 2004). Com isso, a atividade piezelétrica apresenta-se mais pronunciada por meio de uma excitação, seja ela mecânica ou elétrica, nessa mesma direção. Assim, em analogia à matriz de coeficientes piezelétricos empregado nas medidas em cristais e cerâmicas (WEINHOLD et al., 2000; BAUER et al., 2003; ZHANG et al., 2005), muitos autores adotaram o coeficiente piezelétrico $d_{33}$ como principal parâmetro de medida do efeito piezelétrico nos ferroeletretos, que aqui é denominado simplesmente $c p$ (coeficiente piezelétrico).

O princípio de funcionamento desses novos transdutores é similar ao funcionamento dos bem conhecidos microfones de eletretos, na medida em que uma variação na espessura das cavidades de ar dos ferroeletretos provoca uma variação das cargas elétricas induzidas nos eletrodos. Assim, com a força aplicada ao ferroeletreto e o valor da correspondente carga induzida, podemos obter o valor de $c p$. Para a sua descrição matemática, definimos um modelo simplificado, adaptado de Sessler e Hillenbrand (1999a, 1999b), para dois filmes dielétricos separados por um espaçamento de ar (Figura 2.28), análogo a dois filmes homogêneos com bolhas entre eles.

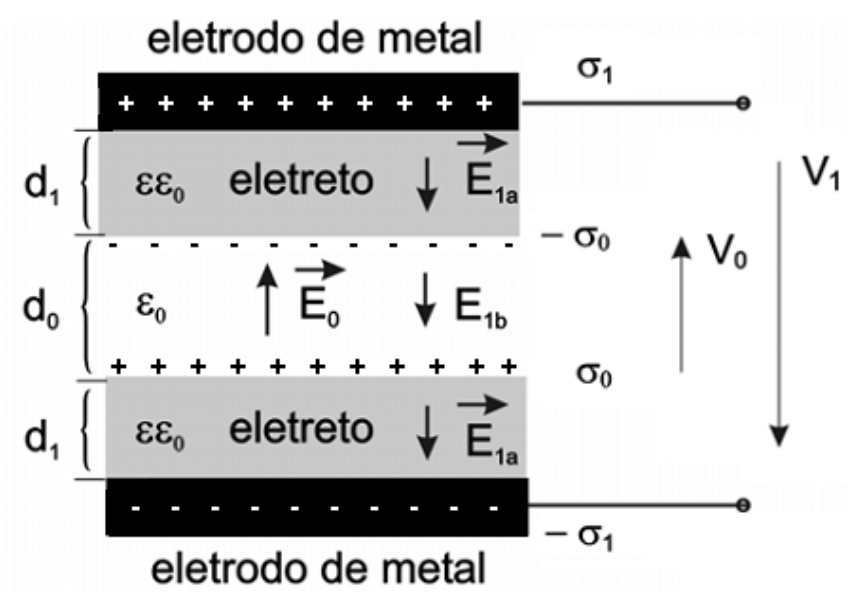

Figura 2.28 Modelo simplificado da estrutura de um ferroeletreto com duas camadas de dielétrico carregadas. 
Nesse modelamento, $\varepsilon_{0}$ representa a permissividade do vácuo, $d_{0}$ a espessura da camada de ar, $d_{l}$ a espessura das camadas do material eletricamente carregadas (supondo espessuras iguais para os dois filmes) com uma magnitude de densidade de carga superficial $\sigma_{0}$ (também supondo-se iguais à densidade de cargas aprisionadas nas superfícies internas) e permissividade relativa $\varepsilon$, e $\sigma_{l}$ a magnitude da densidade de cargas induzidas nos eletrodos.

Sendo as espessuras envolvidas muito menores que as dimensões laterais e paralelas dos eletrodos, permitem-nos desprezar os efeitos de borda causados pelo espalhamento das linhas de campo. Dessa forma, pela lei de Gauss, as cargas aprisionadas nas camadas poliméricas geram um campo elétrico uniforme $E_{0}$ na região de ar dado por

$$
E_{0}=\frac{\sigma_{0}}{\varepsilon_{0}}
$$

Essas mesmas cargas aprisionadas nas armadilhas energéticas do material induzem cargas elétricas de densidade superficial $\sigma_{1}$ com polaridades opostas em cada eletrodo metálico que, por sua vez, geram um campo elétrico $E_{l a}$ ao longo da espessura em cada filme e $E_{l b}$ na região de ar entre elas, também uniformes, dado por

$$
\begin{gathered}
E_{1 a}=\frac{\sigma_{1}}{\varepsilon \varepsilon_{0}} \\
E_{1 b}=\frac{\sigma_{1}}{\varepsilon_{0}}
\end{gathered}
$$

Entre os eletrodos de metal, surge uma diferença de potencial $V_{0}$ decorrente do campo elétrico $E_{0}$ gerado pelas cargas aprisionadas no dielétrico, que é dado por

$$
V_{0}=\frac{\sigma_{0}}{\varepsilon_{0}} d_{0}
$$

Por outro lado, as cargas induzidas nos eletrodos também criam campos elétricos que por sua vez determinam uma diferença de potencial negativa $V_{l}$ dado por

$$
V_{1}=-\left(2 \frac{\sigma_{1}}{\varepsilon \varepsilon_{0}} d_{1}+\frac{\sigma_{1}}{\varepsilon_{0}} d_{0}\right)
$$

Supondo uma diferença de potencial entre os eletrodos igual a zero, pela lei de Kirchhoff das tensões, temos que

$$
V_{0}+V_{1}=0
$$




$$
\frac{\sigma_{0}}{\varepsilon_{0}} d_{0}-\left(2 \frac{\sigma_{1}}{\varepsilon \varepsilon_{0}} d_{1}+\frac{\sigma_{1}}{\varepsilon_{0}} d_{0}\right)=0
$$

e, assim, a densidade superficial de cargas induzidas nos eletrodos $\sigma_{l}$ pode ser calculada por

$$
\sigma_{1}=\frac{d_{0} \sigma_{0} \varepsilon}{2 d_{1}+\varepsilon d_{0}}
$$

Quando uma força é aplicada no sistema, supondo incompressibilidade das camadas de dielétricos, essa força provoca uma deformação na bolha de ar, de modo que o espaçamento de ar $d_{0}$ entre os filmes de dielétricos sofra uma deformação $\Delta d_{0}$, provocando, consequentemente, uma variação da densidade de carga induzida nos eletrodos, que, para pequenas deformações, pode ser controlada pela primeira derivada da série de Taylor

$$
\frac{\partial \sigma_{1}}{\partial d_{0}}=\frac{2 d_{1} \sigma_{0} \varepsilon}{\left(2 d_{1}+\varepsilon d_{0}\right)^{2}}
$$

e supondo linearidade entre a carga induzida nos eletrodos e a deformação provocada pela força aplicada, temos que

$$
\frac{\partial \sigma_{1}}{\partial d_{0}}=\frac{\Delta \sigma_{1}}{\Delta d_{0}}=\frac{2 d_{1} \sigma_{0} \varepsilon}{\left(2 d_{1}+\varepsilon d_{0}\right)^{2}}
$$

No caso quase estático (bem abaixo de qualquer ressonância), uma relação de deformação pode ser obtida pela lei de Hooke

$$
\Delta p=Y \frac{\Delta d_{0}}{d}
$$

onde $d=d_{0}+2 d_{1}$ (espessura inicial do sistema), $\Delta p$ é a pressão aplicada no sistema e $Y$ é a constante de elasticidade de Young para o sistema.

O coeficiente piezelétrico $c p$ pode, então, ser calculado por

$$
c p=\frac{\Delta \sigma_{1}}{\Delta p}=\frac{\varepsilon d}{Y} \frac{2 d_{1} \sigma_{0}}{\left(2 d_{1}+\varepsilon d_{0}\right)^{2}}
$$

\subsection{Possíveis Aplicações para os Ferroeletretos}

Em meio às discussões, muitas aplicações eletromecânicas e eletroacústicas podem ser apresentadas, com algumas aplicações com eletretos celulares ou porosos de distribuição espacial de cargas. Por exemplo, um conversor termoelétrico de energia foi proposto, a partir 
de considerações teóricas das variações das capacitâncias termicamente induzidas (GERHARD-MULTHAUPT, 2002). Aplicações em filtros de membranas de eletretos flúor poliméricos com poros abertos e carregados também foram consideradas e investigadas (GERHARD-MULTHAUPT, 2002).

\subsubsection{Transdutores Eletromecânicos}

A pequena massa, a alta flexibilidade e uma forma praticamente arbitrária indicam os eletretos de esponjas poliméricas como sensores em aplicações biomédicas, tais como: sensores de movimentos respiratórios em animais de laboratório ou detectores para a monitoração de respiração humana inseridos entre o paciente e o leito, aplicações diversas para medidas de força dinâmica nas atividades esportivas, além de outras aplicações que utilizem estes transdutores, como, teclados sensitivos, sensores de impacto, detectores de movimentos subterrâneos, etc. (GERHARD-MULTHAUPT, 2002).

\subsubsection{Transdutores Eletroacústicos}

Um alto-falante foi proposto, construído e testado para médias e altas frequências (BAKMAN; KARJALAINEN, 1990). Também foram construídos alto-falantes planos, utilizando tensões de controle de, somente, $100 \mathrm{~V}$ para níveis máximos de pressão sonora ligeiramente superiores a $100 \mathrm{~dB}$, porém, com respostas insuficientes a baixas frequências de áudio (GERHARD-MULTHAUPT, 2002).

Painéis com alto-falantes planos podem ativar o controle de som em todos os tipos de compartimentos, tais como: salas, automóveis, trens, ônibus, aviões, barcos, etc. (GERHARD-MULTHAUPT, 2002). A ideia de um ambiente acústico inteligente (adaptativo) pode tornar-se viável (GERHARD-MULTHAUPT, 2002) com o desenvolvimento de eletretos de esponja polimérica termicamente estáveis e de alta sensibilidade piezelétrica. Estudos sobre efeitos piezelétricos lineares e não lineares, diretos e inversos em eletretos de esponja polimérica (KRESSMANN, 2001a, 2001b), tornam-se muito úteis para a implementação destas e de outras aplicações como transdutores.

Também são investigadas aplicações em microfones, em particular, como arranjos de sensores para áreas grandes, com uma única camada de eletreto com eletrodos moldados nela (GERHARD-MULTHAUPT, 2002). Foram propostos, ainda, transdutores para pontos ultrassônicos no ar e na água (GERHARD-MULTHAUPT, 2002). Medidas em tais 
transdutores também foram utilizadas para caracterizar as respostas piezelétricas diretas e inversas nos eletretos poliméricos porosos e celulares (KRESSMANN, 2001b; GERHARDMULTHAUPT et al., 2000). 


\section{Novos Processos de Produção}

O processo de produção de eletretos termo-formados, desenvolvido por Altafim et al. (2005), apresenta, algumas vezes, deformações nas bolhas, pela ausência de controle do processo e também não permite que seja feita uma produção em larga escala. Estes fatores têm contribuído para que sejam desenvolvidas pesquisas para novos aprimoramentos nesse processo. Nesse contexto, este trabalho descreve dois novos aprimoramentos do processo para a produção dos eletretos termo-formados. Um dos processos é denominado laminação a quente e o outro, processo adesivo a frio. Estes novos aprimoramentos visam suprir as deficiências aludidas e promover um maior controle da distribuição, altura e diâmetro das bolhas de ar. Com amostras que possuam essas características, tornar-se-á possível uma melhor compreensão da correlação existente entre as dimensões das bolhas e o efeito piezelétrico resultante e, consequentemente, permitindo o projeto de transdutores piezelétricos - conforme sua aplicação - e ampliando sua gama de aplicações comerciais.

Basicamente, os dois processos consistem em quatro etapas: a moldagem do filme de uma das camadas do sensor; a colagem das duas camadas de filmes do sensor; a metalização das superfícies do sensor e o carregamento elétrico. O processo de colagem é o ponto crucial e diferente dos dois processos. Estas quatro etapas encontram-se mais bem descritas nos itens subsequentes.

\subsection{Moldagem dos Filmes de Teflon ${ }^{\circledR}$ FEP}

Em filmes de eletretos, com finalidades piezelétricas, é de suma importância que haja bolhas gasosas ou uma separação de ar, ou outro gás, formando, assim, os ferroeletretos. $\mathrm{Na}$ abordagem de Altafim et al. (2005), para a criação de cavidades nos eletretos termo-formados, denominado, neste capítulo, Processo I, as cavidades foram originadas por uma bomba a vácuo e eletrodos metálicos previamente aquecidos. Já o ferroeletreto, desenvolvido por Zhang, Hillenbrand e Sessler (2006), agora denominado Processo II - que fez uso desta 
mesma abordagem -, utiliza uma grade de metal aquecida previamente, pressionando-a contra uma pilha de filmes, para a formação das cavidades.

Estudando estes dois processos, foi observado que, no Processo I, a bomba a vácuo não possibilita uma formação homogênea das bolhas de ar e também dificulta o controle da altura das bolhas formadas; o Processo II despende um tempo muito longo para a formação das cavidades - a grade de metal é pressionada contra a pilha de filmes por um período de uma hora (ZHANG; HILLENBRAND; SESSLER, 2006). Além disso, os ferroeletretos originados pelo Processo II também não apresentam uma homogeneidade quanto à altura das cavidades, como pode ser visto na Figura 2.27(b).

Buscando aprimorar e sistematizar o processo de formação das bolhas, os novos processos aqui desenvolvidos realizam a moldagem do filme de Teflon ${ }^{\circledR}$ FEP num estágio que antecede a colagem das camadas de filmes, tanto no processo de laminação a quente como no processo adesivo a frio.

A moldagem prévia do filme é realizada, como mostrado na Figura 3.1 e Figura 3.2, com uma prensa hidráulica que aplica uma força ao conjunto composto pelo filme colocado entre uma barra plana de borracha e uma matriz de metal. Desta forma, o filme fica moldado com formato de bolhas - ilustrado na Figura 3.2(b). A borracha utilizada neste trabalho possui constante de elasticidade igual a 7,3 MPa.

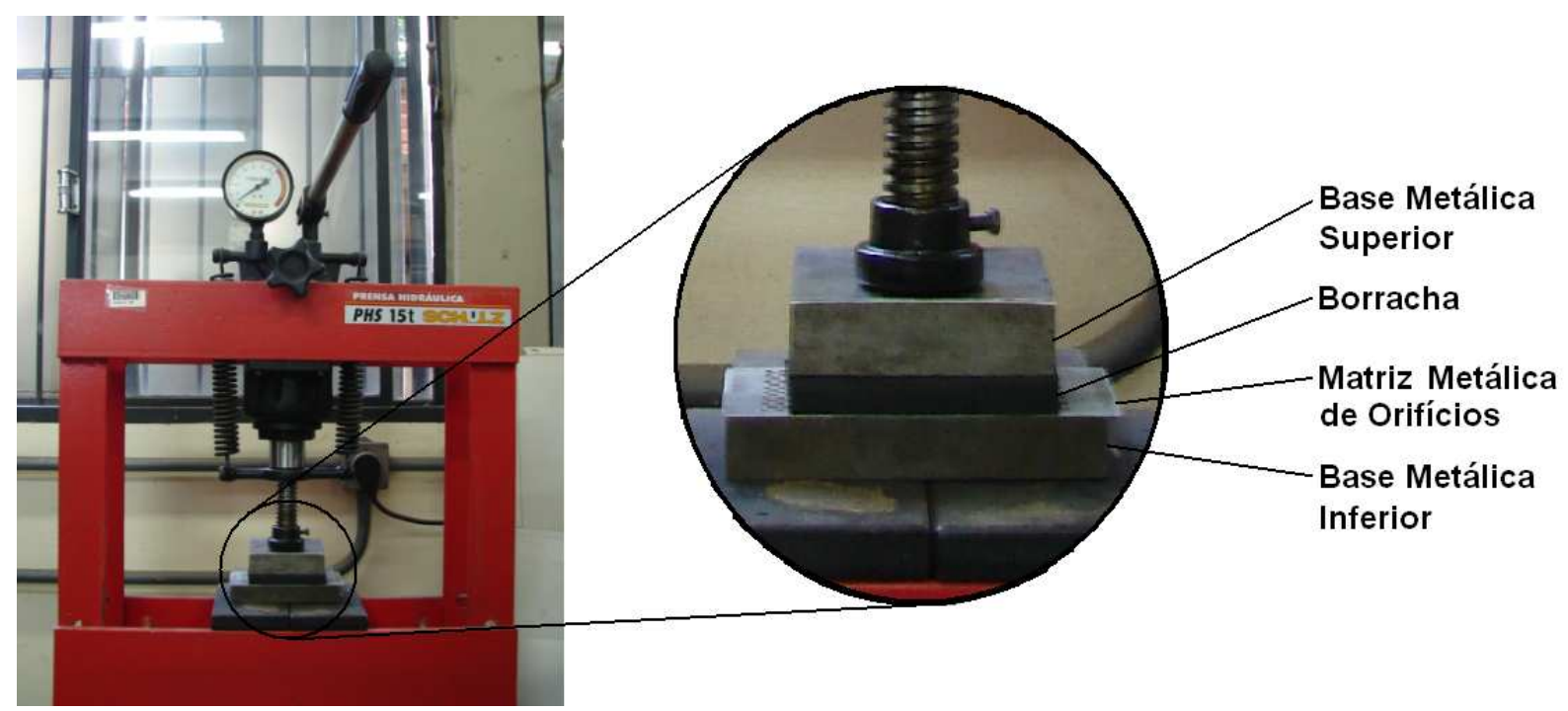

Figura 3.1 Imagem da prensa hidráulica utilizada no processo de moldagem do filme de Teflon ${ }^{\circledR}$ FEP.

No processo de prensagem, empregou-se uma prensa hidráulica modelo SCHULZ PHS 15t ICO Comercial S.A., cujo controle é realizado manualmente. Os filmes de Teflon 
$\mathrm{FEP}^{\circledR}$ com $50 \mu \mathrm{m}$ de espessura foram moldados em matrizes metálicas contendo orifícios de diferentes diâmetros distribuídos hexagonalmente. A força empregada para a moldagem do filme variou com o diâmetro dos orifícios da matriz e a altura da cavidade, e foi determinada empiricamente para cada uma das matrizes. Para a produção das amostras deste trabalho a pressão empregada foi de $944,7 \mathrm{kPa}$.

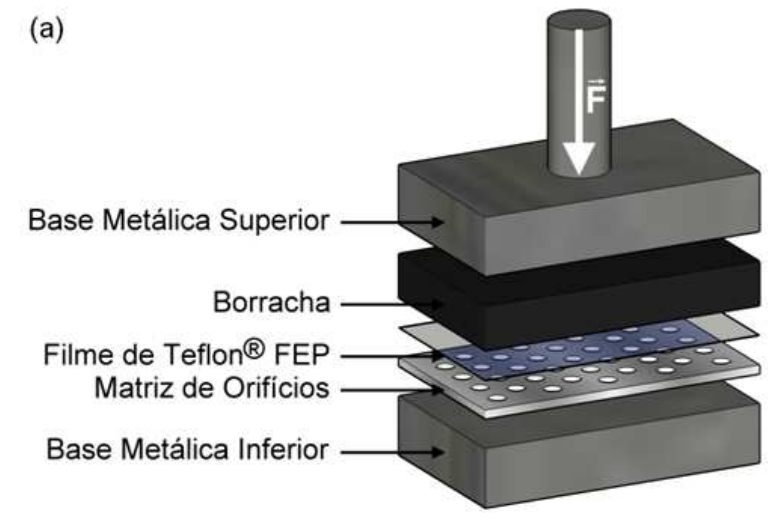

(b)

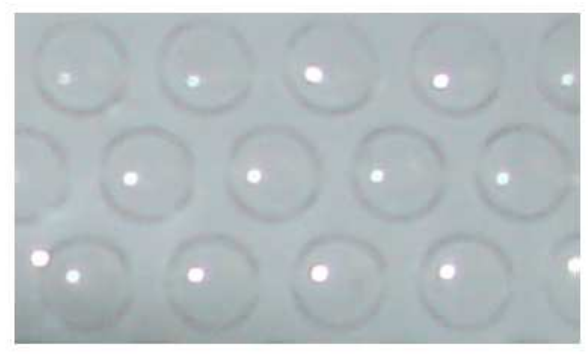

(c)

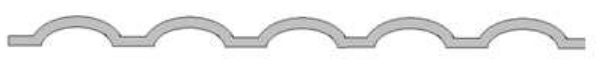

Figura 3.2 (a) Representação esquemática da etapa de moldagem do filme de Teflon ${ }^{\circledR}$ FEP. (b) Imagem do filme de Teflon ${ }^{\circledast}$ FEP moldado. (c) Representação esquemática da seção transversal do filme moldado.

Com este sistema de moldagem pode-se controlar o diâmetro e distribuição do relevo por meio da escolha da matriz de orifícios, e pode-se controlar também a altura desse relevo por meio da força aplicada pela prensa hidráulica.

\subsection{Processo de Laminação a Quente}

A etapa seguinte, neste novo aprimoramento do processo de produção dos eletretos termo-formados - processo por laminação a quente -, consiste na união do filme de Teflon ${ }^{\circledR}$ FEP moldado (originado pelo procedimento descrito na seção anterior) com outro filme de Teflon ${ }^{\circledR}$ FEP, este, por sua vez, plano, ou seja, que não apresente qualquer relevo.

Agora, considerando a etapa de soldagem dos Processos I e II, constata-se que, no Processo I, a estrutura de placas metálicas aquecidas geralmente provoca deformações estruturais na amostra resultante (PISANI ALTAFIM, 2006) e, pelo Processo II, é necessário um longo tempo para produzir pontos de colagem entre as camadas de filmes. No aprimoramento aqui ilustrado - os procedimentos de fusão dos filmes -, diferente dos realizados pelos Processos I e II, empregou-se a mesma ideia do processo de laminação a quente, desenvolvido por Pisani Altafim et al. (2009) na formação dos ferroeletretos de canais tubulares. Por meio deste 
processo, um conjunto composto por uma camada de filme plano, uma camada de filme moldado e uma matriz metálica é passado através de uma máquina laminadora. Como máquina laminadora, usou-se o modelo L-280, fabricado por Lassane Plásticos LTDA. Tratase de um equipamento comercial, dedicado à plastificação de documentos, composto, basicamente, por duas placas metálicas de dimensões 26 x $5 \mathrm{~cm}$, aquecidas independentemente e dispostas paralelamente, e dois pares de cilindros de borracha, um na entrada do equipamento e o outro na saída, que giram com uma velocidade linear de $1 \mathrm{~cm} / \mathrm{s}$. Para sua aplicação normal, o modelo da laminadora foi projetado para atingir, no máximo, uma temperatura de $180{ }^{\circ} \mathrm{C}$. Como essa temperatura não é suficiente para realizar a fusão entre os dois filmes de Teflon ${ }^{\circledR}$ FEP, foi embutido um controlador digital de temperatura, fabricado pela Full Gauge Controls, modelo MT-511RJ, que permite que o aquecimento das placas metálicas atinja temperaturas superiores a $400{ }^{\circ} \mathrm{C}$. Uma imagem da laminadora e uma representação do seu princípio de funcionamento são mostradas na Figura 3.3.

(a)

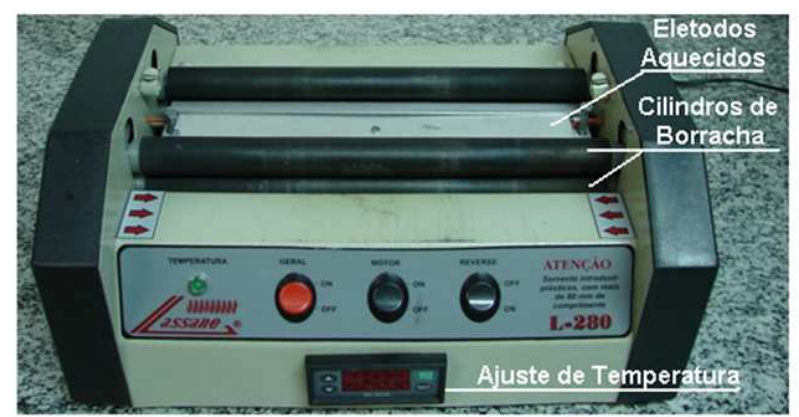

(b)

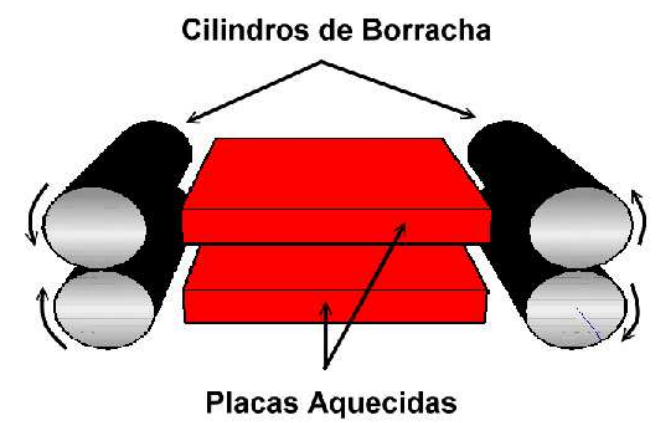

Figura 3.3 (a) Imagem da máquina laminadora Lassane L-280. (b) Representação esquemática do seu princípio de funcionamento.

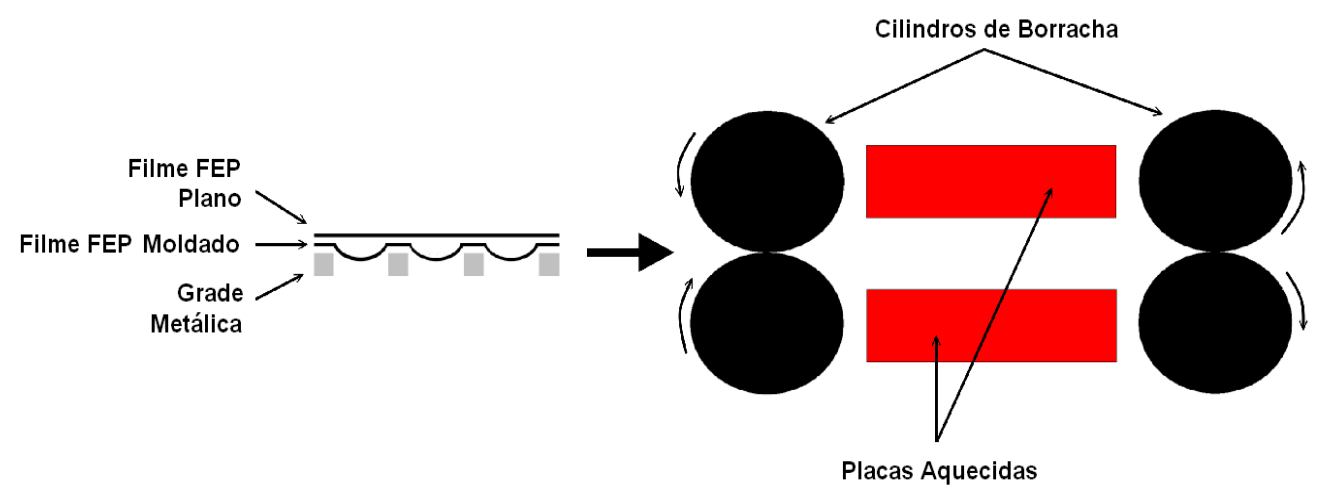

Figura 3.4 Representação esquemática da etapa de fusão dos filmes plano e moldado. 
Antes da etapa de fusão, o filme plano e o moldado são dispostos um sobre o outro e sobre uma matriz de orifícios, conforme mostrado na Figura 3.4. O conjunto, assim montado, é inserido nos cilindros de entrada, que giram, tracionam e arrastam no sentido das placas metálicas aquecidas. O conjunto, ao ser aquecido com uma temperatura superior à temperatura de fusão dos filmes, cola-os apenas nas extremidades das bolhas, como ilustra a representação esquemática da Figura 3.4.

O par de cilindros localizados na saída da laminadora, além de ter a função de arraste, também auxilia na soldagem dos filmes por meio da pressão que aplica sobre o conjunto filmes-matriz. A temperatura para colagem efetiva entre as camadas de filmes moldado e plano depende da matriz; para as matrizes de aço inox e com espessura de $1 \mathrm{~mm}$, as temperaturas variam de $300^{\circ} \mathrm{C}$ a $330{ }^{\circ} \mathrm{C}$.

No processo de laminação a quente, após a colagem, é realizada a metalização e, por último, as amostras são submetidas ao carregamento elétrico por tensão impulsiva. A metalização consiste na deposição de uma camada de alumínio, numa área específica de cada superfície da amostra, por meio de evaporação de alumínio em ambiente a vácuo. Estão, assim, formados os eletrodos, neste caso, com superfície circular de $16 \mathrm{~mm}$ de diâmetro.

A última etapa deste processo de formação consiste no carregamento elétrico, que se encontra ilustrado na seção 3.4. Na figura 3.5, podemos visualizar uma imagem da vista superior de uma amostra metalizada e uma representação esquemática de sua seção transversal após a etapa de carregamento elétrico.

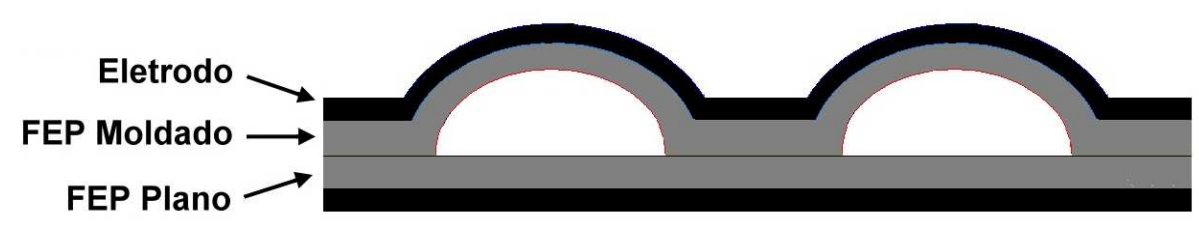

Figura 3.5 Representação esquemática da seção transversal de uma amostra produzida pelo processo de laminação a quente.

Neste trabalho, foram feitas amostras com três diâmetros diferentes de bolhas: 3,2 $\mathrm{mm}, 3,8 \mathrm{~mm}$ e 4,5 $\mathrm{mm}$. Uma imagem de cada uma, juntamente com a seção transversal de uma de suas bolhas, são mostradas na Figura 3.6. 


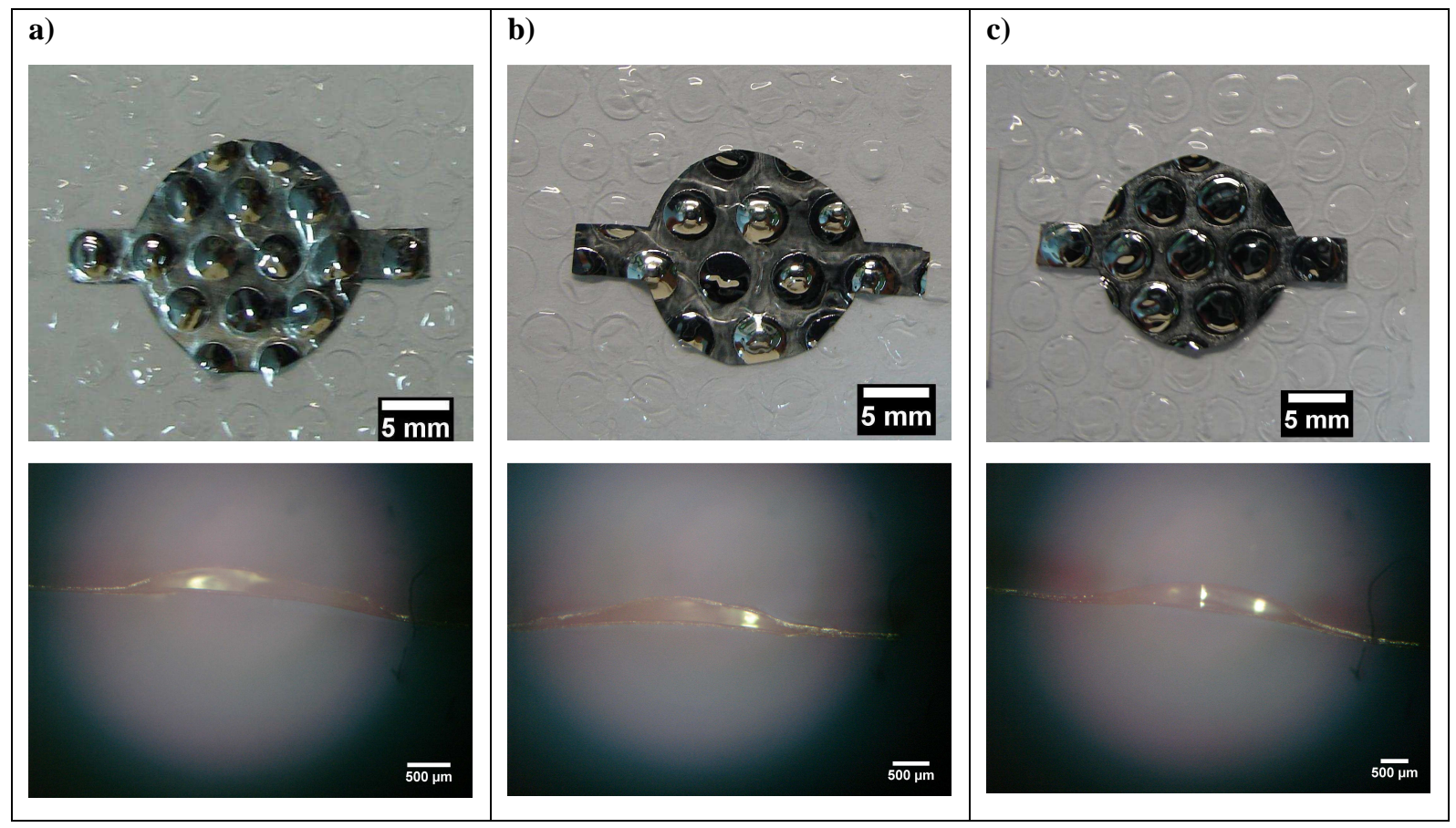

Figura 3.6 Imagem da vista superior e seção transversal das amostras com bolhas de a) 3,2 mm de diâmetro e $230 \mu \mathrm{m}$ de altura, b) 3,8 $\mathrm{mm}$ de diâmetro e $280 \mu \mathrm{m}$ de altura e c) 4,5 mm de diâmetro e 380 um de altura.

\subsection{Processo Adesivo a Frio}

Desde o processo desenvolvido por Altafim et al. (2003), tem-se buscado produtos que promovam uma colagem efetiva dos filmes de Teflon ${ }^{\circledR}$ FEP. No entanto, com resultados ainda insatisfatórios. Contudo, durante a pesquisa bibliográfica deste trabalho, verificou-se que fitas adesivas já foram usadas para colagem de folha de alumínio a um filme de PP celular (KRESSMANN, 2001) e para a colagem entre filmes de PTFE porosos e não porosos (GERHARD-MULTHAUPT, 2002). Isso incentivou a realização de testes com fitas adesivas disponíveis comercialmente.

Duas marcas de fitas adesivas dupla face foram testadas: as fabricadas por Adelbras Indústria e Comércio de Adesivos Ltda e as fabricadas por 3M do Brasil Ltda (linha Scotch ${ }^{\circledR}$ ). Ambas promoveram uma excelente aderência nos filmes de Teflon ${ }^{\circledR}$ FEP.

Com a utilização de fita adesiva dupla face foi então desenvolvido o processo aqui denominado adesivo a frio para a produção de sensores piezelétricos baseado na técnica de cavidades entre dois filmes de eletreto. O princípio básico de preparação de amostras por meio desse processo é a união entre uma camada de filme de Teflon ${ }^{\circledR}$ FEP previamente moldado, conforme descrito na Seção 3.1, a outra camada do mesmo filme, mas este não 
contendo relevo algum (Figura 3.7), por meio de uma camada adesiva. A preparação de amostras em laboratório por meio desse processo é descrita, em detalhes, a seguir.

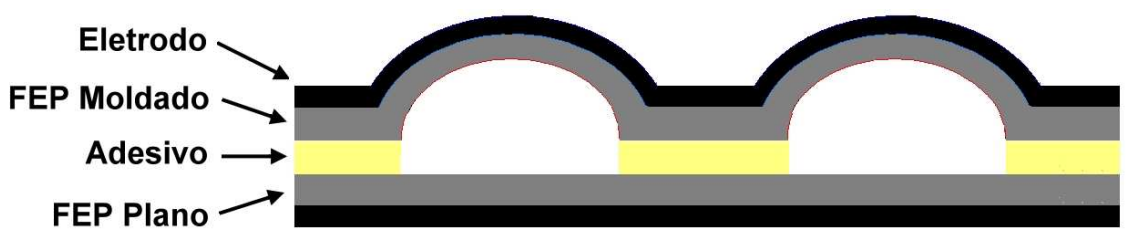

Figura 3.7 Representação esquemática da seção transversal de uma amostra produzida pelo processo adesivo a frio.

Neste processo, a metalização das superfícies do filme, a mesma já descrita na Seção 3.2 para a laminação a quente, é realizada antes da etapa de colagem. Isto porque o alto vácuo da câmara provoca um colapso das bolhas de ar.

A colagem do processo adesivo a frio pode ser dividida em três passos: criação de furos na fita dupla face, adesão de uma das faces da fita ao filme moldado e, por último, a adesão do filme plano à outra face da fita.

O passo de criação de furos na fita adesiva dupla face é semelhante ao procedimento para realizar furos em couro, onde os furos são feitos por vazadores. Dessa forma, centrandose a fita, ainda com a película protetora, entre uma base fixa contendo um furo e uma matriz, semelhante àquela para efetuar a moldagem do filme, com o pressionar do vazador tem-se a película vazada e pronta para receber o filme moldado. Neste trabalho, empregou-se, como vazador, uma furadeira, ilustrada na Figura 3.8.
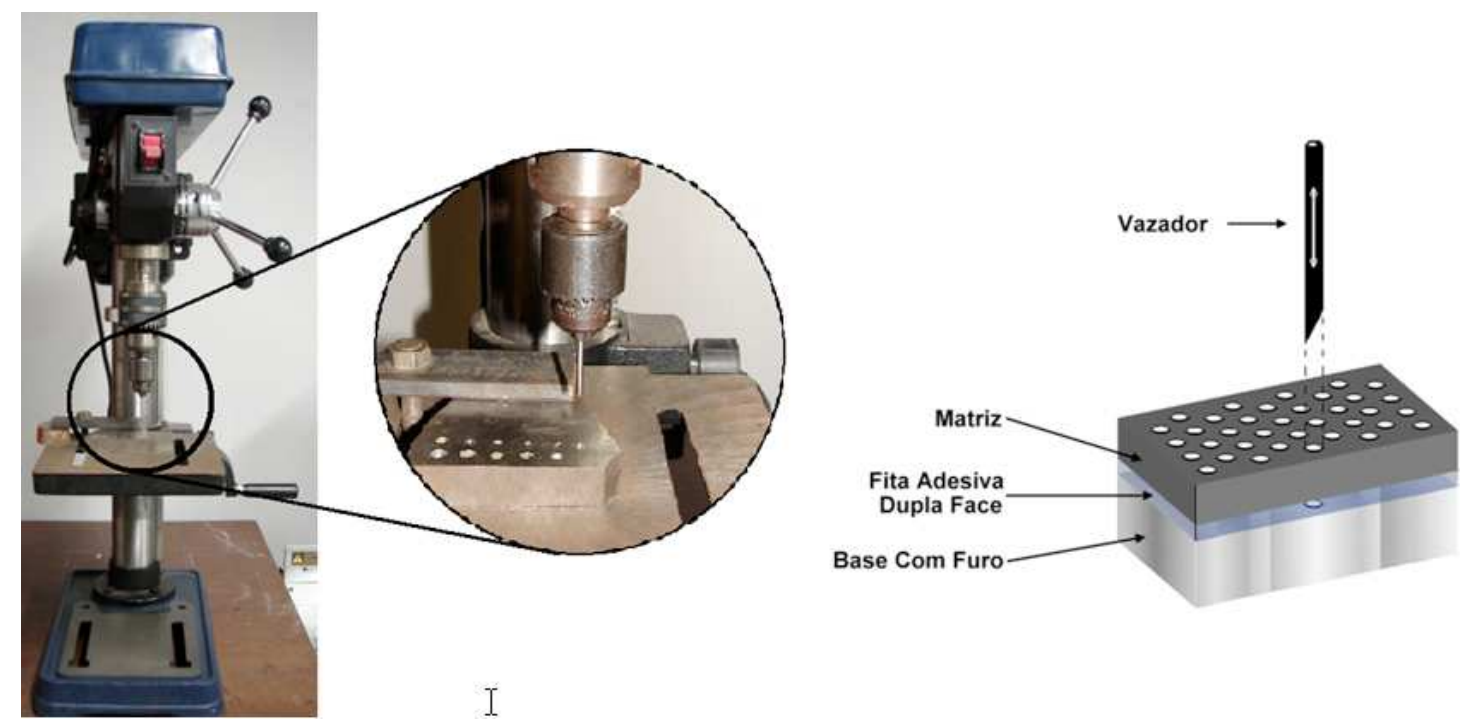

Figura 3.8 À esquerda, imagem da furadeira utilizada para gerar furos na fita adesiva dupla face e à direita, representação esquemática do passo de criação de furos na fita adesiva dupla face. 


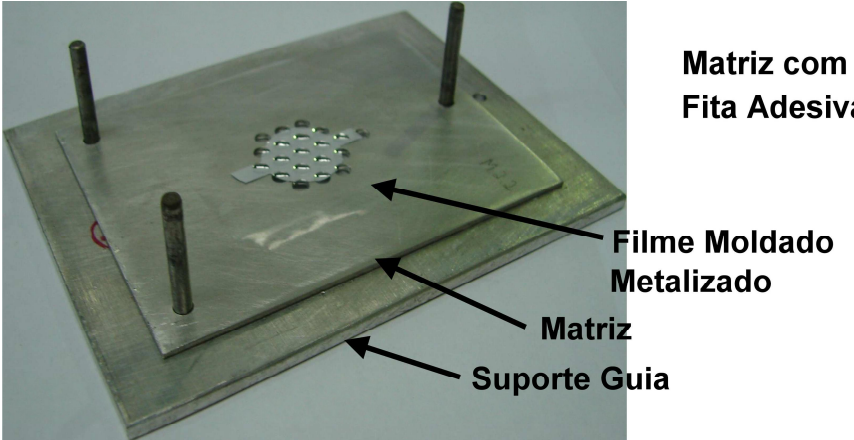

a)

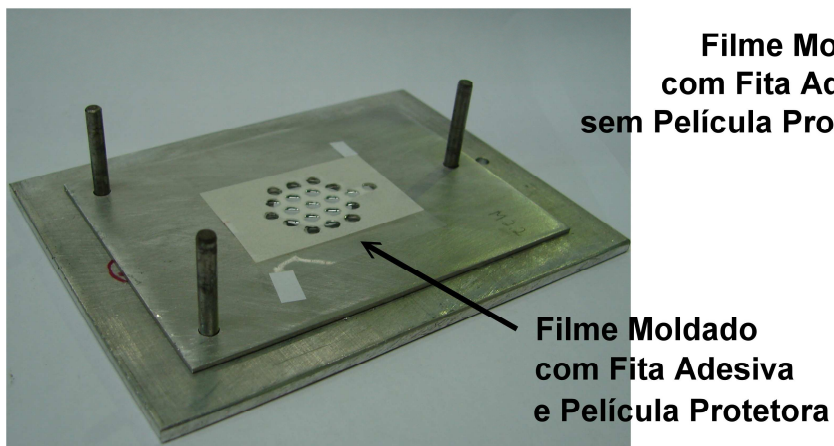

c)

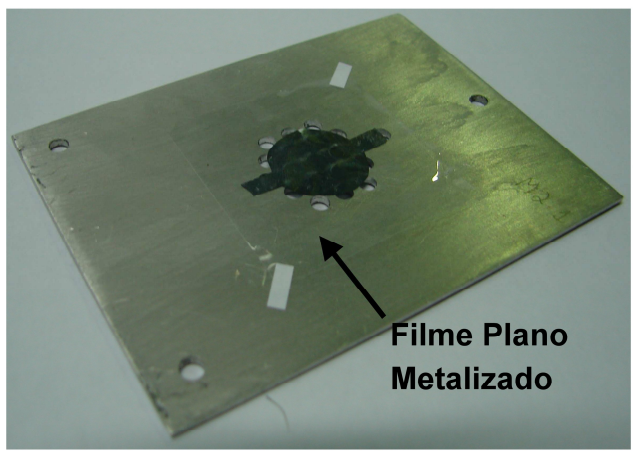

e)

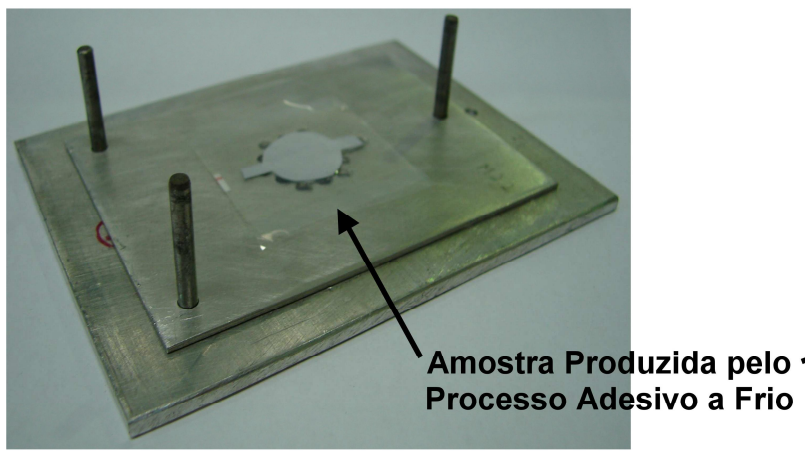

g)

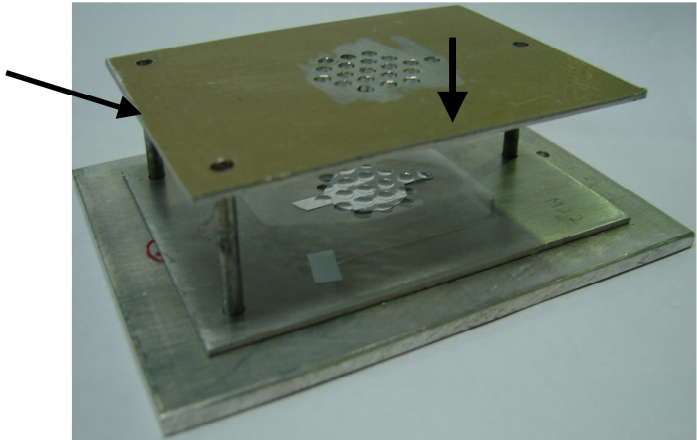

b)

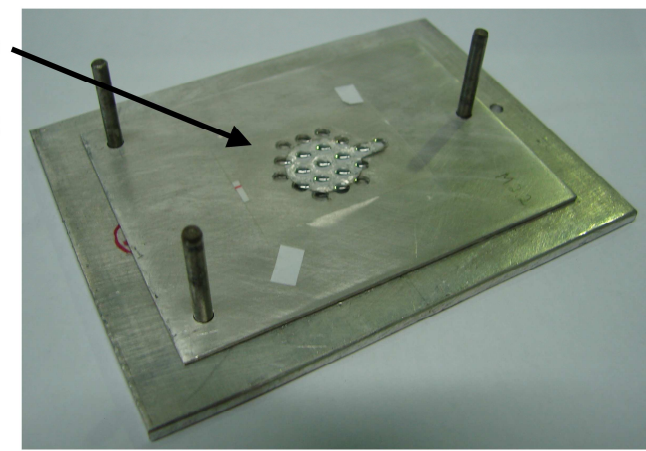

d)

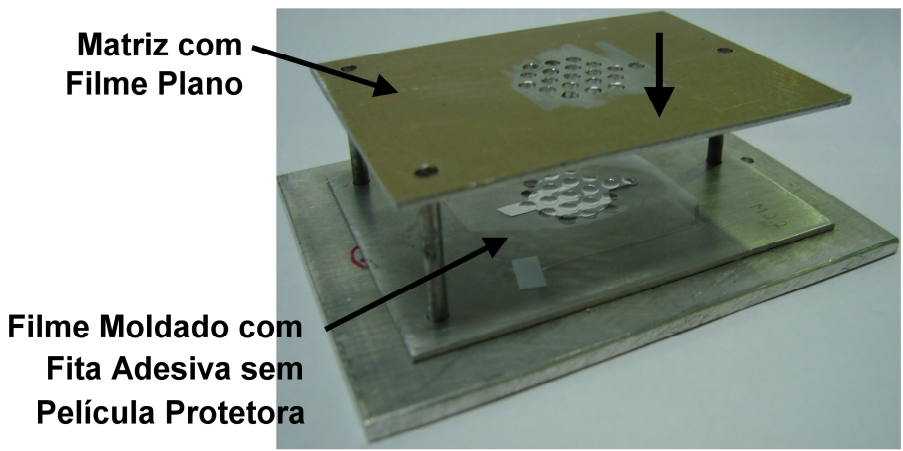

f)

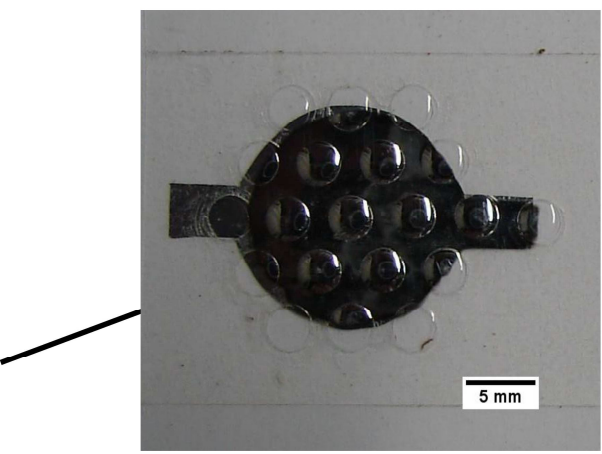

h)

Figura 3.9 Processo adesivo a frio. (a) A matriz com o filme moldado é colocada no suporte guia, (b) a matriz com adesivo é colocada no suporte e pressionada contra o filme moldado, ficando agora com (c) a fita adesiva e sua película protetora (d) que, em seguida, é retirada. O próximo passo é colocar a (e) matriz com filme plano no suporte e $(f)$ pressioná-la contra o filme moldado e com adesivo, originando, assim, (g) (h) uma amostra pelo processo adesivo a frio. 
$\mathrm{Na}$ adesão, foi construído um suporte guia. Nesse suporte, primeiramente, é colocada a matriz com o filme moldado, conforme mostra a Figura 3.9a, e, na sequência, a matriz contendo a fita adesiva é colocada com a face voltada para baixo, sem a película protetora, e pressionada contra o filme moldado (Figura 3.9b).

Após a retirada da película protetora do adesivo aderido ao filme moldado (Figura 3.9d), a matriz contendo o filme plano é colocada no suporte guia e pressionada contra o filme moldado (Figura 3.9f), originando, assim, uma amostra por meio do processo adesivo a frio (Figura 3.9h).

Neste trabalho, foram feitas amostras com três diâmetros diferentes de bolhas: 2,5 $\mathrm{mm}, 3,0 \mathrm{~mm}$ e $3,5 \mathrm{~mm}$. Uma imagem de cada uma, juntamente com a seção transversal de uma de suas bolhas, são mostradas na Figura 3.10.

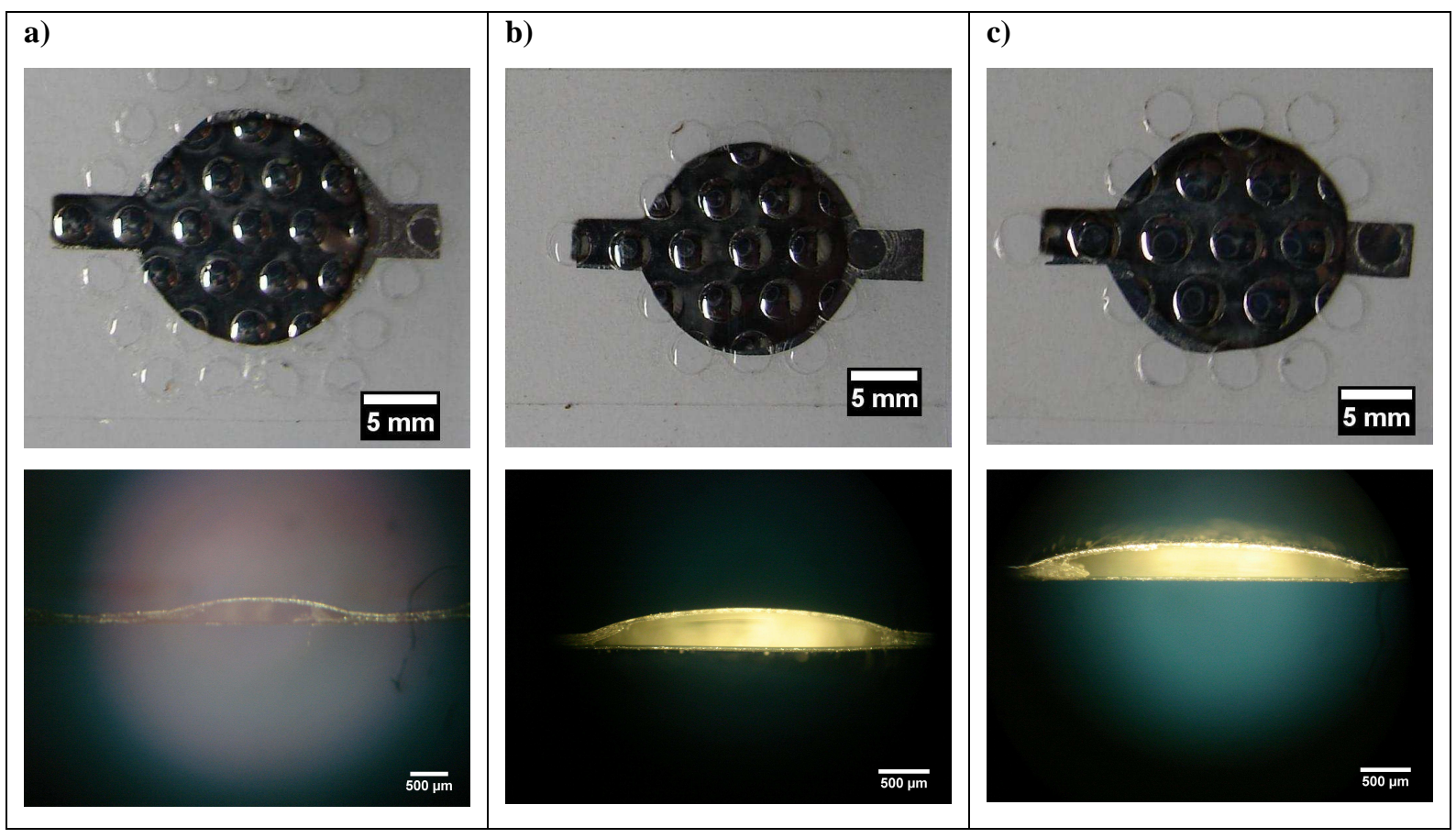

Figura 3.10 Imagem da vista superior e seção transversal das amostras com bolhas de a) 2,5 mm de diâmetro e $290 \mu \mathrm{m}$ de altura, b) 3,0 mm de diâmetro e $350 \mu \mathrm{m}$ de altura e c) 3,5 mm de diâmetro e 290 um de altura.

\subsection{Carregamento Elétrico por Tensão Impulsiva}

Para finalizar o processo de produção dos sensores piezelétricos, as amostras - tanto as confeccionadas pelo processo de laminação a quente quanto aquelas feitas pelo processo adesivo a frio, são submetidas ao carregamento elétrico por tensão impulsiva. Como discutido na Seção 2.2.7, o circuito elétrico para o carregamento por esse método é composto por um capacitor $\mathrm{C}_{1}$ de $1,35 \mathrm{mF}$, conectado em série com o centelhador de $\mathrm{G}$ e o resistor $\mathrm{R}_{2}$ de $44 \Omega$. 
Paralelo ao resistor $\mathrm{R}_{2}$ e em série com o capacitor $\mathrm{C}_{2}$ de $11 \mathrm{nF}$, está conectado o resistor $\mathrm{R}_{1}$, de $72 \Omega$. Uma representação desse circuito é mostrada na Figura 2.11.

Os capacitores são carregados negativamente pela fonte de tensão Spellmam High Voltage DC Suply $20 \mathrm{kV}$. Os valores de pico da tensão impulsiva são estabelecidos por meio do ajustamento manual da distância entre as esferas do centelhador. A câmara de carregamento é composta por um tubo cilíndrico de alumínio onde estão conectados os dois eletrodos eletricamente isolados, sendo o eletrodo inferior devidamente aterrado e o superior conectado à fonte de alta tensão. Completa o circuito um divisor de tensão Tektronix 605 (1000:1) conectado ao eletrodo superior e a um osciloscópio digital TDS 210. Esses elementos fornecem condições para que as tensões impulsivas sejam medidas.

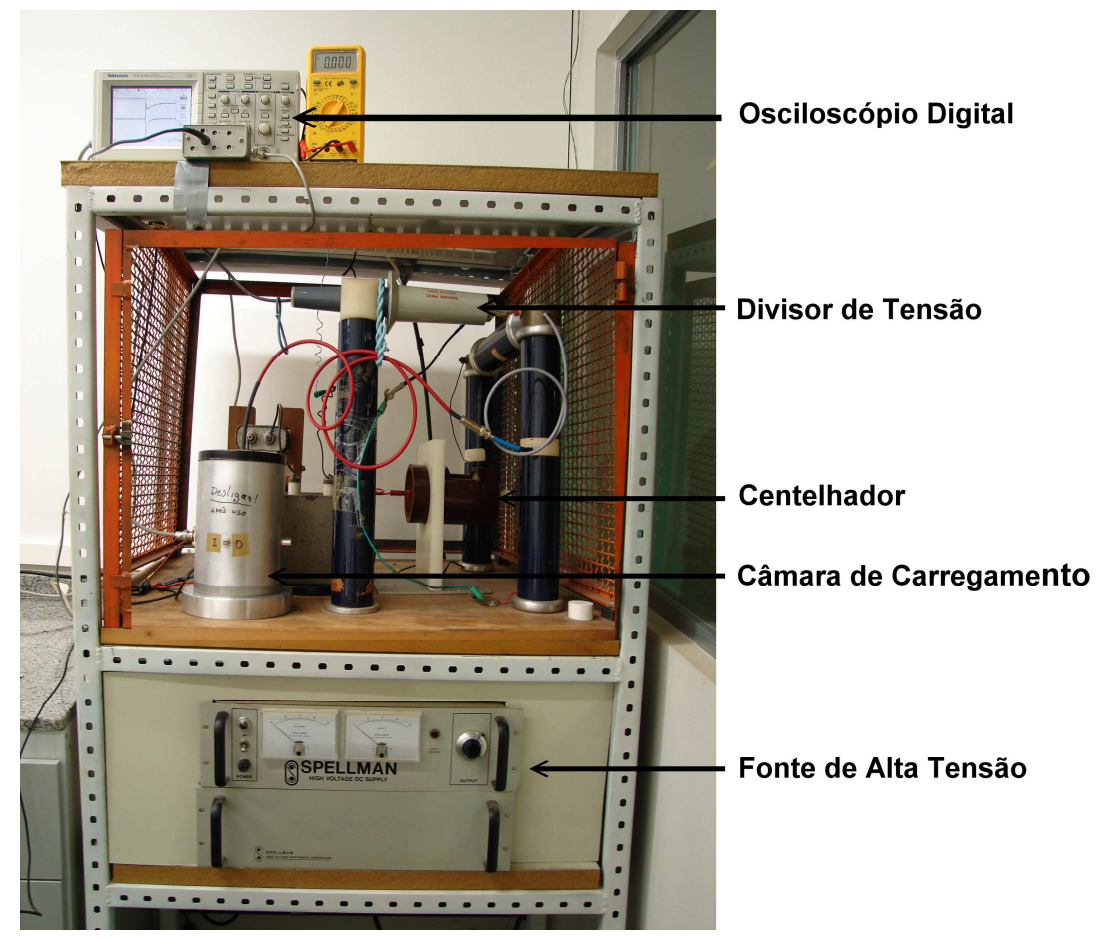

Figura 3.11 Circuito utilizado para o carregamento das amostras por tensão impulsiva.

Assim, o pico de tensão negativa de curta duração aplicada sobre a amostra produz uma descarga elétrica no interior das bolhas e cargas elétricas são aprisionadas nas suas superfícies internas, conforme ilustrado na Figura 3.12. Cada amostra deste trabalho foi submetida a três descargas impulsivas, para assegurar o carregamento elétrico. 


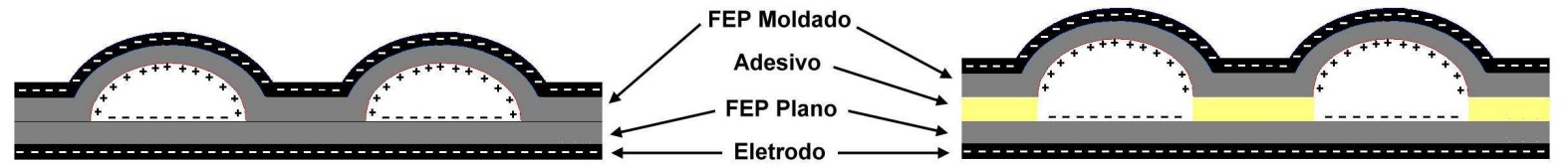

a)

b)

Figura 3.12 Representação esquemática da distribuição de cargas elétricas nas amostras produzidas pelos processos a) de laminação a quente e b) adesivo a frio após o carregamento elétrico. 



\section{Sistema de Medida do Coeficiente Piezelétrico}

Diversas técnicas de medida dinâmicas ou estáticas, diretas ou inversas, eletromecânica, ótica ou acústica foram propostas para determinar o coeficiente piezelétrico. Um resumo dessas técnicas pode ser encontrado em Hillenbrand e Sessler (2004). Nenhuma, entretanto, encontrava-se disponível nos laboratórios do Departamento de Engenharia Elétrica da Escola de Engenharia de São Carlos; assim, foi construído o dispositivo que permite medir o coeficiente piezelétrico de forma direta e quase estática. Por meio desse método, $c p$ é determinado a partir do efeito piezelétrico direto aplicando-se sobre uma área definida da amostra uma força em baixa frequência (abaixo de qualquer frequência de ressonância) e analisando-se sua resposta elétrica. Nas seções seguintes, serão descritas a composição e a configuração desse dispositivo, bem como sua conexão com os demais equipamentos necessários à medição da carga elétrica, ao registro e à análise dos dados coletados.

\subsection{Sistema de Medidas}

O sistema de medidas (Figura 4.1) compõe-se dos seguintes dispositivos e equipamentos:

- dispositivo para solicitação mecânica,

- balança digital Marconi MA-BS 5500,

- gerador de função Tektronix CFG253,

- eletrômetro digital Keithley 617,

- multímetro digital Minipa ET-2076,

- computador do tipo PC,

- aplicativo Multi Meter Interface (Build 07.12.05_1339). 


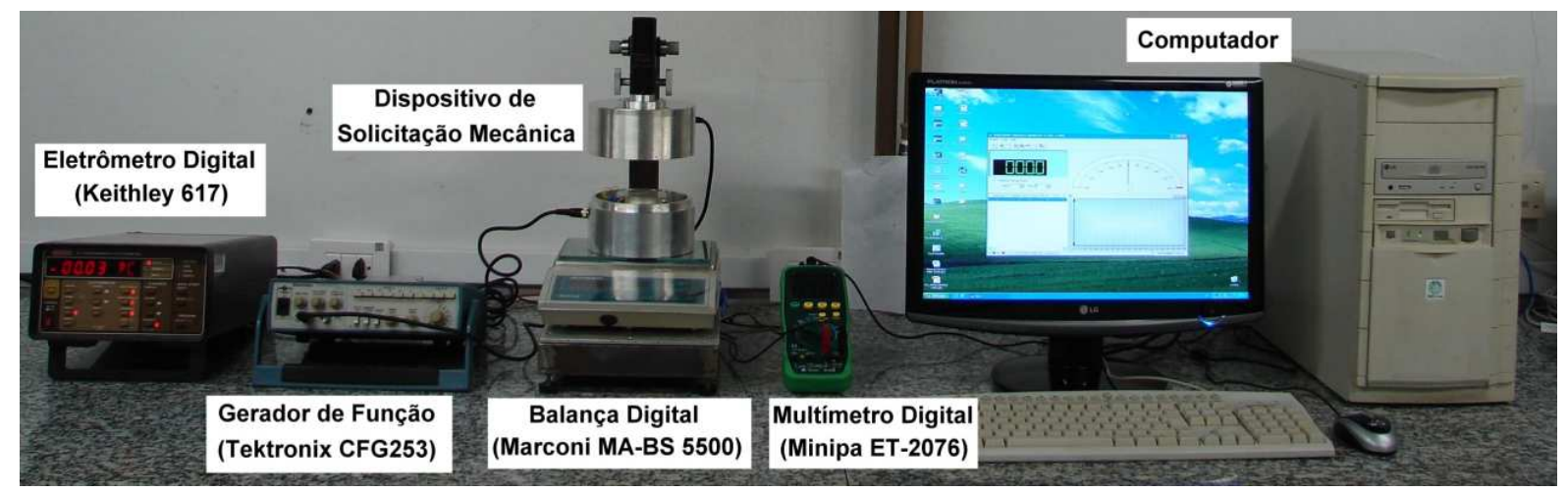

Figura 4.1 Imagem do sistema de medidas do coeficiente piezelétrico cp.

O dispositivo dedicado à solicitação mecânica - único equipamento desenvolvido no Laboratório de Alta Tensão - é composto por:

- uma base superior, que é presa a um suporte, com regulagem de altura, contendo, em seu interior, uma bobina circular com $2 \mathrm{~cm}$ de diâmetro interno e 2000 voltas de fio galvanizado padrão AWG 26;

- um eletrodo cilíndrico vazado (eletrodo superior) de alumínio, contendo, em seu interior, 3 pastilhas de imãs de neodímio, tendo uma massa de 23,3 g, e

- uma base inferior, contendo um eletrodo (eletrodo inferior) e um elemento fixador, entre os quais a amostra é fixada para a realização das medidas.

Todo este conjunto pode ser visto na Figura 4.2.

Este dispositivo encontra-se conectado aos demais equipamentos, como mostrado pela Figura 4.2. O gerador de função fornece à bobina um sinal elétrico quadrático com pico de tensão de até 13,2 V e forma de onda mostrada no gráfico da Figura 4.3. Este sinal gera uma corrente elétrica que flui pela bobina e cria um campo magnético, também variável, que atrai e repele as pastilhas de ímãs que se encontram no interior eletrodo superior. Assim, quando o eletrodo superior estiver apoiado sobre a amostra fixada na base inferior, ela experimentará uma força variável diretamente proporcional ao sinal elétrico. Para a tensão máxima de 13,2 $\mathrm{V}$ aplicada a bobina foi provocada sobre a amostra uma força de aproximadamente $400 \mathrm{mN}$, força suficiente para gerar deformações nas bolhas sem colapsálas. Diferentemente ocorreria se fossem aplicadas as mesmas forças empregadas por sistemas utilizados em outros trabalhos (SESSLER; HILLENBRAND, 1999a, 1999b; HILLENBRAND, SESSLER, 2000; PISANI ALTAFIM et al., 2009), que foram da ordem de $1 \mathrm{a} 4 \mathrm{~N}$. A base superior não deve apoiar-se à base inferior para evitar problemas com as 


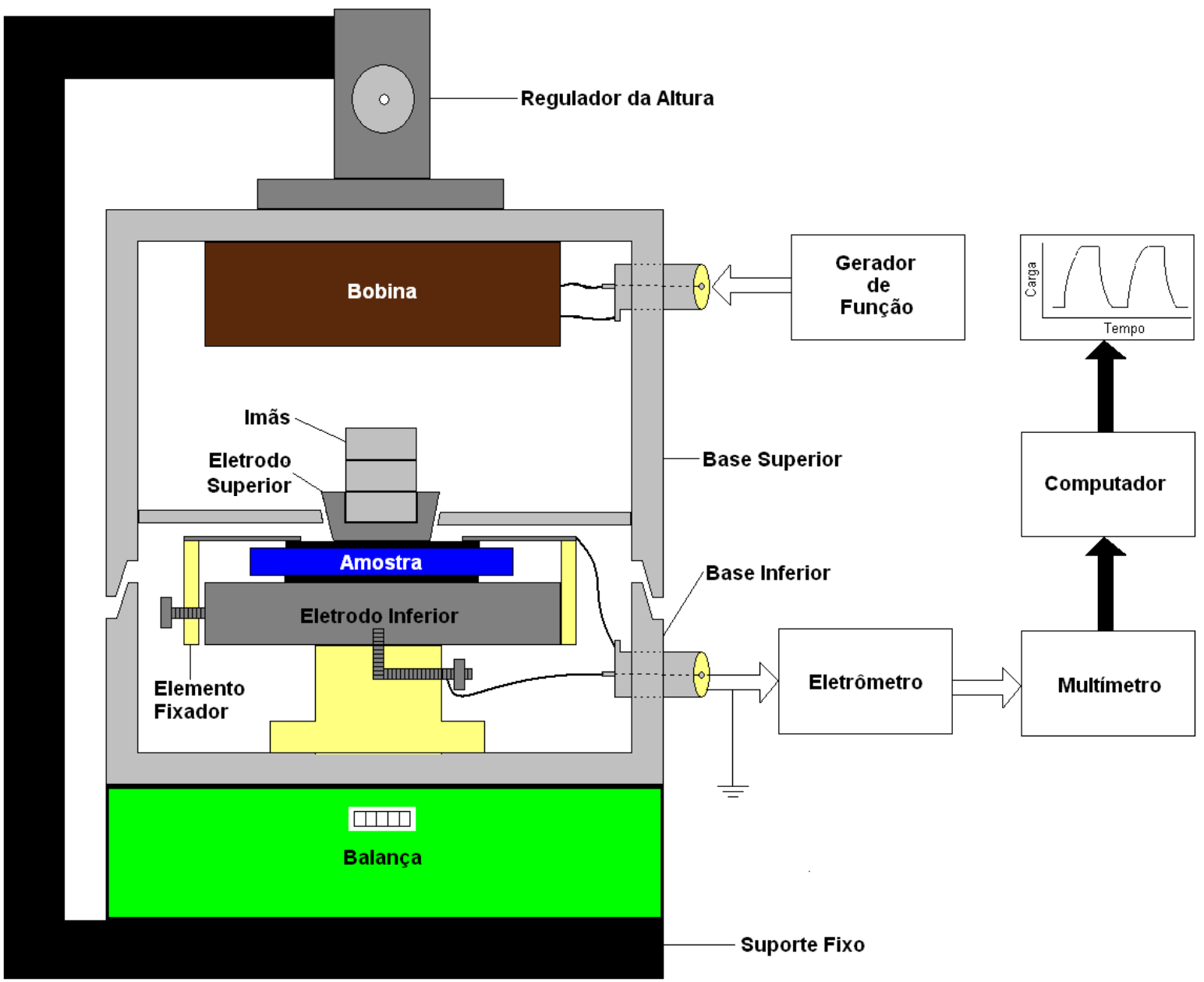

Figura 4.2 Representação esquemática do sistema para medição do coeficiente piezelétrico cp e suas conexões.

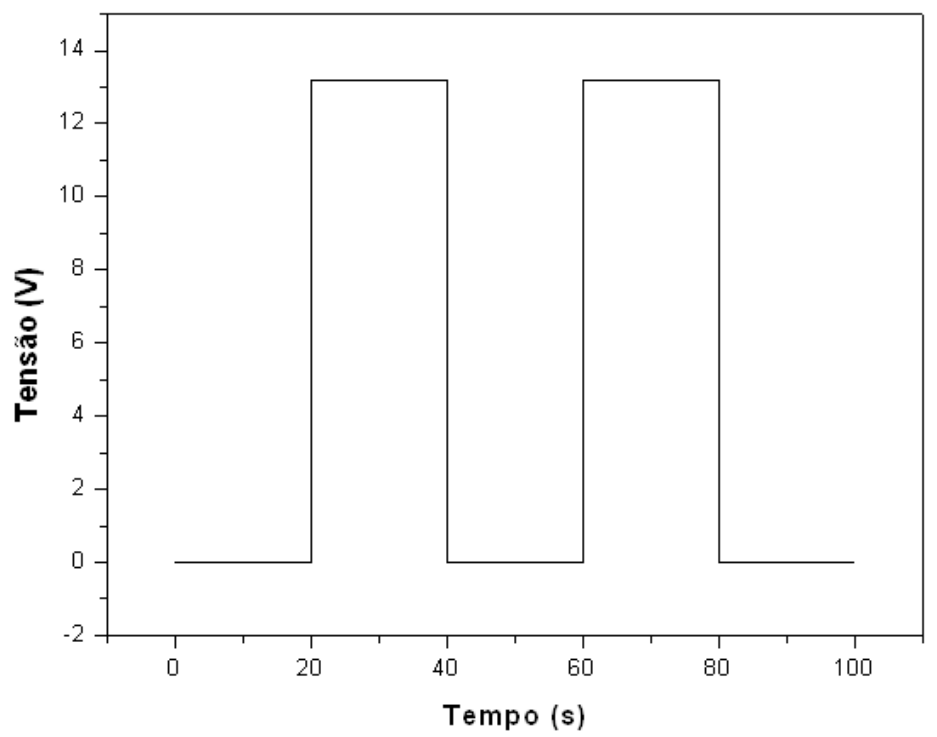

Figura 4.3 Forma de onda da tensão elétrica aplicada a bobina pelo gerador de funções Tektronix CFG253 (tensão de pico de 13,2 V e período de $40 \mathrm{~s}$ ). 
medições da força aplicada. $\mathrm{O}$ valor da força aplicada é medido pela balança digital, que possui uma sensibilidade de 0,01 gramas. O valor da massa correspondente é medido visualmente e registrado manualmente. $\mathrm{O}$ elemento fixador, além de fixar a amostra logo abaixo do eletrodo superior, faz também o contato elétrico entre a superfície superior da amostra metalizada e o contato aterrado. $\mathrm{O}$ eletrodo inferior apoia a amostra e faz o contato elétrico entre a superfície inferior da amostra metalizada e o eletrômetro.

O eletrômetro, habilitado na função amplificador de carga, realiza a integração no tempo da corrente elétrica gerada pela amostra sob solicitação mecânica. Como o eletrômetro, aqui usado, possui uma saída analógica de tensão em $m V$, numericamente igual ao valor da carga medida em $p C$, pode ser conectado ao multímetro que envia as leituras digitalmente para o computador por uma conexão RS-232.

Um aplicativo fornecido pelo fabricante do multímetro - Multi Meter Interface - e instalado no computador adquire os sinais digitais e os disponibiliza para que sejam processados em aplicativos do tipo Excel, da Microsoft. A Figura 4.4 ilustra um exemplo da tela principal desse aplicativo, que possui uma excelente interface com o usuário.

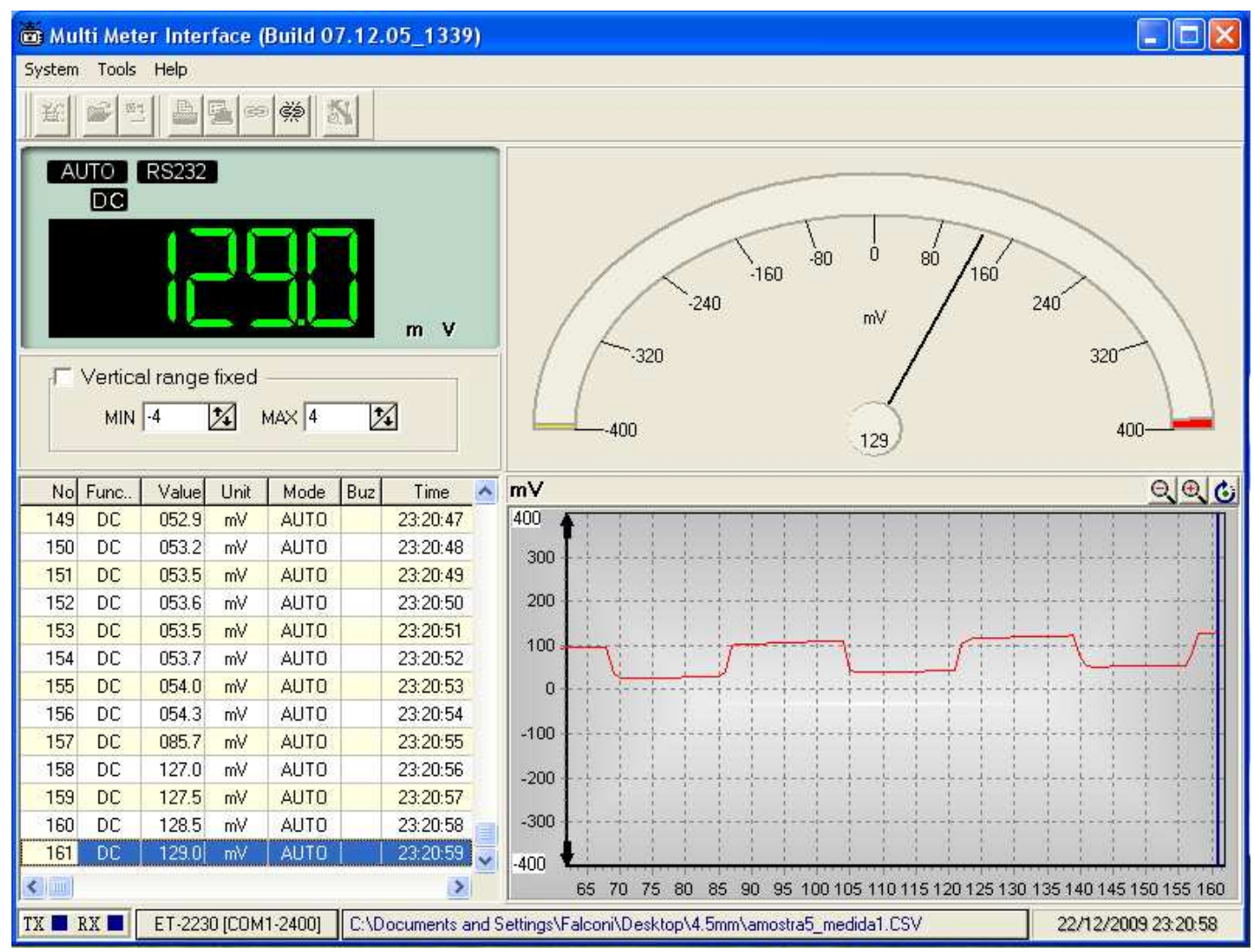

Figura 4.4 Interface do aplicativo para comunicação com o multímetro digital por meio da porta serial, aquisição e registro dos dados. 


\subsection{Cálculo do Coeficiente Piezelétrico}

Após a aquisição dos dados, o valor de $c p$ pode ser calculado pela equação

$$
c p=\frac{\Delta Q}{F}
$$

onde $\Delta Q$ é a diferença entre o valor da carga no instante da aplicação da força e o valor no instante da sua remoção e $F$ o valor da força aplicada, obtido por meio do valor de massa $m$ medido pela balança (descontando o valor da massa do conjunto eletrodo superior e ímãs), multiplicado pela aceleração da gravidade $g$, que aqui é usado igual a $9,8 \mathrm{~m} / \mathrm{s}^{2}$. Substituindo a equação 5.1, o coeficiente piezelétrico $c p$ é então dado por

$$
c p=\frac{\Delta Q}{m \cdot g}
$$

Para uma medida mais precisa de $c p$, o seu cálculo aqui é realizado por uma média da variação da carga nos cinco primeiros ciclos de solicitação mecânica. Assim, o valor de $c p$ obtido para cada amostra é calculado por

$$
c p=\frac{\sum_{i=1}^{5} \Delta Q_{i}}{5 . m \cdot g}
$$

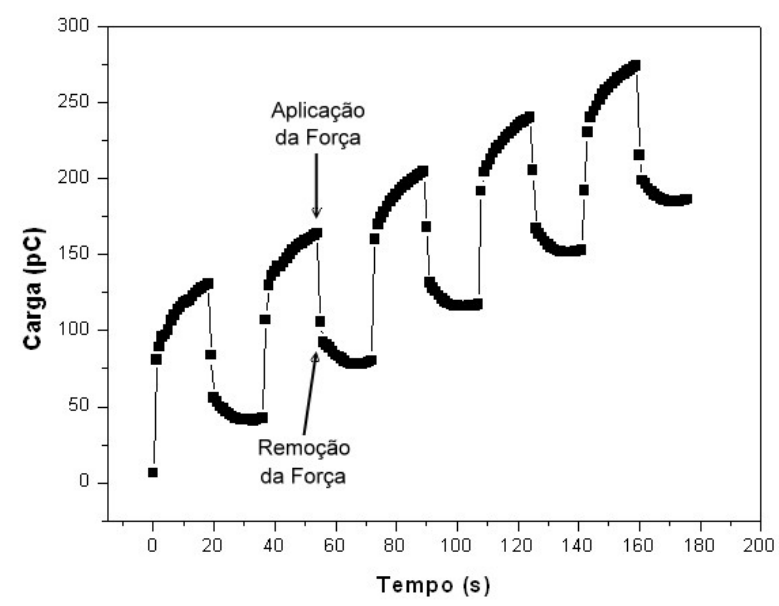

Figura 4.5 Gráfico típico da medida de carga elétrica de uma amostra piezelétrica sob solicitação mecânica periódica por meio do sistema desenvolvido neste trabalho.

No entanto, como se pode notar na Figura 4.5, há uma função crescente somando-se ao valor da carga gerada, o que acarretaria um cálculo incorreto de $c p$. Para corrigir esta 
distorção, é calculada a reta de regressão e realizada sua subtração da curva, como mostrado nas Figuras 4.6 e 4.7; assim, o cálculo de $c p$ pode ser feito com as variações reais de carga.

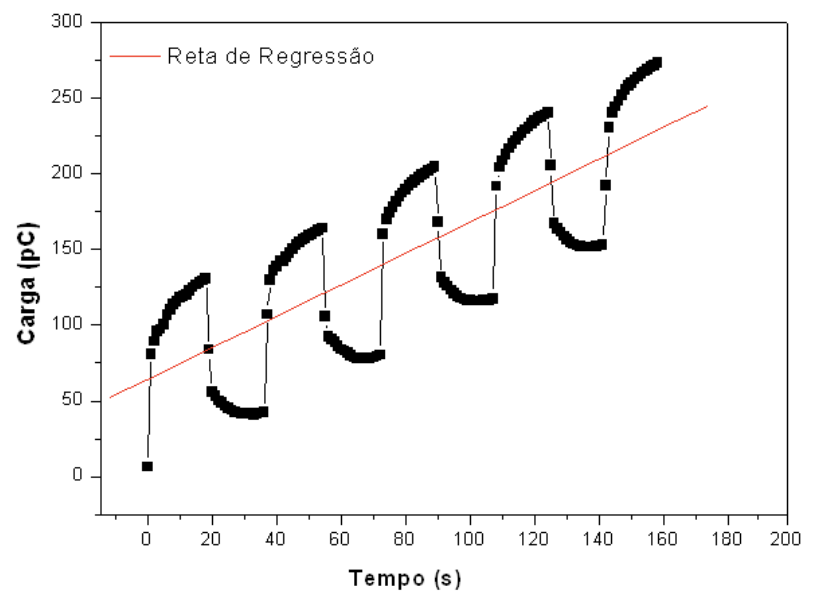

Figura 4.6 Gráfico da medida de carga elétrica juntamente com sua reta de regressão.

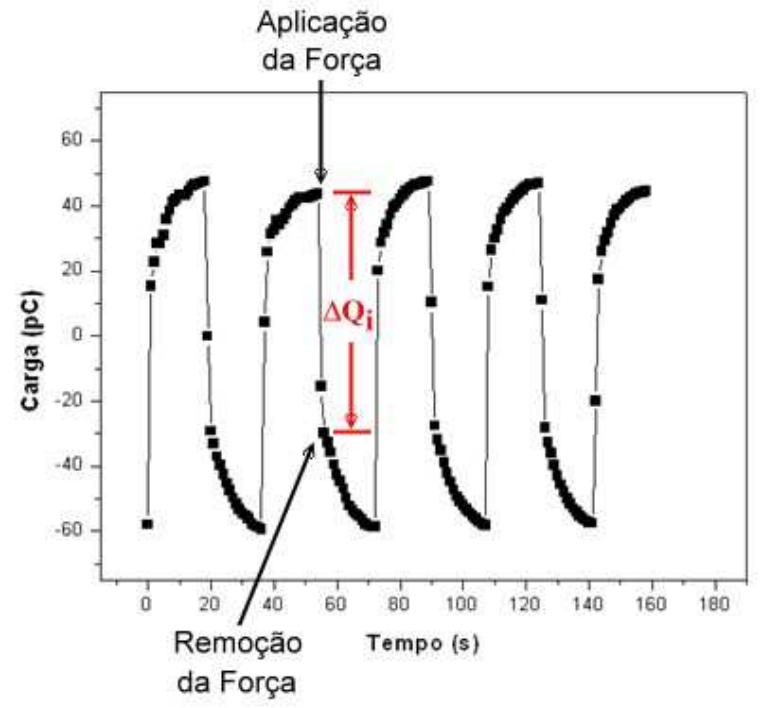

Figura 4.7 Gráfico da medida de carga elétrica com a reta de regressão subtraída.

\subsection{Atividade Piezelétrica das Amostras}

Para confirmar a funcionalidade das amostras produzidas pelos processos descritos, elas foram submetidas a medições de sua piezeletricidade com o sistema de medições desenvolvido e descrito anteriormente.

Foram produzidos três tipos de amostras em cada processo, variando-se o diâmetro das bolhas e empregando-se, nos testes, cinco amostras de cada tipo.

Com o processo de laminação a quente, foram produzidas amostras com diâmetros de bolhas de 3,2 $\mathrm{mm}, 3,8 \mathrm{~mm}$ e 4,5 $\mathrm{mm}$. E com o processo adesivo a frio, foram produzidas amostras com bolhas de 2,5 mm, 3,0 mm e 3,5 mm de diâmetro.

Após o carregamento elétrico por tensão impulsiva, com valor de pico de $5,6 \mathrm{kV}$, foram feitas as medições e o cálculo do coeficiente piezelétrico $c p$, de acordo com a equação 5.3. A seguir, são apresentados os resultados dessas medições e os resultados para cada processo. 


\subsubsection{Amostras: Processo de Laminação a Quente}

Tabela 4.1 Coeficiente piezelétrico cp das amostras com bolhas de 3,2 mm de diâmetro e 230 pm de altura produzidas pelo processo de laminação a quente e carregadas por três descargas impulsivas com pico de 5,6 kV (desvio padrão dos valores de cp igual a 4,98).

\begin{tabular}{|c|c|c|c|c|c|c|c|}
\hline Amostra & $\begin{array}{c}\text { Força Aplicada } \\
(\mathrm{mN})\end{array}$ & $\begin{array}{c}\Delta \mathrm{Q}_{1} \\
(\mathrm{pC})\end{array}$ & $\begin{array}{c}\Delta \mathrm{Q}_{2} \\
(\mathrm{pC})\end{array}$ & $\begin{array}{c}\Delta \mathrm{Q}_{3} \\
(\mathrm{pC})\end{array}$ & $\begin{array}{c}\Delta \mathrm{Q}_{4} \\
(\mathrm{pC})\end{array}$ & $\begin{array}{c}\Delta \mathrm{Q}_{5} \\
(\mathrm{pC})\end{array}$ & $\begin{array}{c}c p \\
(\mathrm{pC} / \mathrm{N})\end{array}$ \\
\hline 1 & 444,23 & 43,52 & 47,64 & 42,43 & 48,23 & 41,72 & 100,64 \\
\hline 2 & 432,67 & 48,48 & 43,17 & 44,17 & 44,05 & 48,57 & 105,60 \\
\hline 3 & 436,98 & 47,98 & 48,58 & 47,98 & 46,58 & 46,88 & 108,93 \\
\hline 4 & 439,73 & 50,16 & 49,92 & 49,85 & 49,96 & 49,75 & 113,54 \\
\hline 5 & 432,28 & 49,28 & 46,48 & 48,27 & 47,98 & 47,47 & 110,80 \\
\hline \multicolumn{7}{|c}{$c p$ médio } \\
\hline
\end{tabular}

Tabela 4.2 Coeficiente piezelétrico cp das amostras com bolhas de 3,8 mm de diâmetro e 280 pm de altura produzidas pelo processo de laminação a quente e carregadas por três descargas impulsivas com pico de 5,6 kV (desvio padrão dos valores de cp igual a 30,21).

\begin{tabular}{|c|c|c|c|c|c|c|c|}
\hline Amostra & $\begin{array}{c}\text { Força Aplicada } \\
(\mathrm{mN})\end{array}$ & $\begin{array}{c}\Delta \mathrm{Q}_{1} \\
(\mathrm{pC})\end{array}$ & $\begin{array}{c}\Delta \mathrm{Q}_{2} \\
(\mathrm{pC})\end{array}$ & $\begin{array}{c}\Delta \mathrm{Q}_{3} \\
(\mathrm{pC})\end{array}$ & $\begin{array}{c}\Delta \mathrm{Q}_{4} \\
(\mathrm{pC})\end{array}$ & $\begin{array}{c}\Delta \mathrm{Q}_{5} \\
(\mathrm{pC})\end{array}$ & $\begin{array}{c}c p \\
(\mathrm{pC} / \mathrm{N})\end{array}$ \\
\hline 1 & 433,85 & 153,87 & 164,67 & 165,77 & 163,87 & 154,97 & 370,25 \\
\hline 2 & 432,77 & 127,04 & 133,74 & 132,84 & 132,44 & 129,83 & 303,11 \\
\hline 3 & 433,75 & 128,82 & 133,62 & 131,52 & 131,32 & 153,92 & 313,18 \\
\hline 4 & 429,34 & 152,63 & 157,23 & 156,12 & 158,62 & 160,42 & 365,69 \\
\hline 5 & 435,81 & 151,97 & 148,27 & 151,57 & 151,08 & 141,58 & 341,66 \\
\hline \multicolumn{7}{|c|}{$c p$ médio } \\
\hline
\end{tabular}


Tabela 4.3 Coeficiente piezelétrico cp das amostras com bolhas de 4,5 mm de diâmetro e 380 um de altura produzidas pelo processo de laminação a quente e carregadas por três descargas impulsivas com pico de 5,6 kV (desvio padrão dos valores de cp igual a 10,36).

\begin{tabular}{|c|c|c|c|c|c|c|c|}
\hline Amostra & $\begin{array}{c}\text { Força Aplicada } \\
(\mathrm{mN})\end{array}$ & $\begin{array}{c}\Delta \mathrm{Q}_{1} \\
(\mathrm{pC})\end{array}$ & $\begin{array}{c}\Delta \mathrm{Q}_{2} \\
(\mathrm{pC})\end{array}$ & $\begin{array}{c}\Delta \mathrm{Q}_{3} \\
(\mathrm{pC})\end{array}$ & $\begin{array}{c}\Delta \mathrm{Q}_{4} \\
(\mathrm{pC})\end{array}$ & $\begin{array}{c}\Delta \mathrm{Q}_{5} \\
(\mathrm{pC})\end{array}$ & $\begin{array}{c}c p \\
(\mathrm{pC} / \mathrm{N})\end{array}$ \\
\hline 1 & 433,75 & 72,84 & 73,64 & 72,23 & 76,24 & 69,73 & 168,15 \\
\hline 2 & 440,02 & 63,62 & 64,52 & 64,11 & 66,01 & 65,41 & 147,12 \\
\hline 3 & 436,30 & 77,13 & 78,03 & 78,02 & 76,83 & 70,83 & 174,58 \\
\hline 4 & 434,63 & 70,08 & 68,58 & 69,28 & 69,18 & 67,48 & 158,57 \\
\hline 5 & 432,47 & 70,62 & 70,42 & 70,62 & 69,51 & 69,82 & 162,32 \\
\hline \multicolumn{7}{|c|}{$c p$ médio } \\
\hline
\end{tabular}

\subsubsection{Amostras: Processo Adesivo a Frio}

Tabela 4.4 Coeficiente piezelétrico cp das amostras com bolhas de 2,5 $\mathrm{mm}$ de diâmetro e 290 um de altura produzidas pelo processo de laminação a quente e carregadas por três descargas impulsivas com pico de 5,6 kV (desvio padrão dos valores de cp igual a 17,37).

\begin{tabular}{|c|c|c|c|c|c|c|c|}
\hline Amostra & $\begin{array}{c}\text { Força Aplicada } \\
(\mathrm{mN})\end{array}$ & $\begin{array}{c}\Delta \mathrm{Q}_{1} \\
(\mathrm{pC})\end{array}$ & $\begin{array}{c}\Delta \mathrm{Q}_{2} \\
(\mathrm{pC})\end{array}$ & $\begin{array}{c}\Delta \mathrm{Q}_{3} \\
(\mathrm{pC})\end{array}$ & $\begin{array}{c}\Delta \mathrm{Q}_{4} \\
(\mathrm{pC})\end{array}$ & $\begin{array}{c}\Delta \mathrm{Q}_{5} \\
(\mathrm{pC})\end{array}$ & $\begin{array}{c}c p \\
(\mathrm{pC} / \mathrm{N})\end{array}$ \\
\hline 1 & 433,75 & 77,93 & 72,93 & 77,22 & 77,52 & 73,83 & 174,21 \\
\hline 2 & 440,02 & 75,92 & 75,62 & 75,52 & 75,12 & 77,91 & 176,62 \\
\hline 3 & 436,30 & 63,54 & 63,55 & 63,55 & 64,25 & 63,24 & 148,68 \\
\hline 4 & 434,63 & 59,81 & 59,90 & 61,10 & 60,30 & 61,10 & 137,89 \\
\hline 5 & 432,47 & 74,81 & 75,00 & 73,41 & 74,11 & 74,00 & 171,26 \\
\hline \multicolumn{7}{|c|}{$c p$ médio } \\
\hline
\end{tabular}


Tabela 4.5 Coeficiente piezelétrico cp das amostras com bolhas de 3,0 mm de diâmetro e 350 pm de altura produzidas pelo processo de laminação a quente e carregadas por três descargas impulsivas com pico de 5,6 kV (desvio padrão dos valores de cp igual a 21,16).

\begin{tabular}{|c|c|c|c|c|c|c|c|}
\hline Amostra & $\begin{array}{c}\text { Força Aplicada } \\
(\mathrm{mN})\end{array}$ & $\begin{array}{c}\Delta \mathrm{Q}_{1} \\
(\mathrm{pC})\end{array}$ & $\begin{array}{c}\Delta \mathrm{Q}_{2} \\
(\mathrm{pC})\end{array}$ & $\begin{array}{c}\Delta \mathrm{Q}_{3} \\
(\mathrm{pC})\end{array}$ & $\begin{array}{c}\Delta \mathrm{Q}_{4} \\
(\mathrm{pC})\end{array}$ & $\begin{array}{c}\Delta \mathrm{Q}_{5} \\
(\mathrm{pC})\end{array}$ & $\begin{array}{c}c p \\
(\mathrm{pC} / \mathrm{N})\end{array}$ \\
\hline 1 & 435,61 & 101,31 & 103,37 & 104,07 & 104,72 & 105,27 & 237,42 \\
\hline 2 & 430,42 & 94,94 & 99,24 & 100,74 & 101,50 & 102,80 & 229,98 \\
\hline 3 & 427,97 & 135,09 & 135,89 & 136,89 & 134,61 & 137,03 & 313,96 \\
\hline 4 & 438,35 & 167,27 & 169,57 & 170,25 & 170,87 & 172,35 & 392,70 \\
\hline 5 & 433,65 & 170,02 & 168,61 & 167,22 & 165,52 & 163,72 & 385,49 \\
\hline \multicolumn{7}{|c|}{$c p$ médio } \\
\hline
\end{tabular}

Tabela 4.6 Coeficiente piezelétrico cp das amostras com bolhas de 3,5 mm de diâmetro e 290 um de altura produzidas pelo processo de laminação a quente e carregadas por três descargas impulsivas com pico de 5,6 kV (desvio padrão dos valores de cp igual a 53,81).

\begin{tabular}{|c|c|c|c|c|c|c|c|}
\hline Amostra & $\begin{array}{c}\text { Força Aplicada } \\
(\mathrm{mN})\end{array}$ & $\begin{array}{c}\Delta \mathrm{Q}_{1} \\
(\mathrm{pC})\end{array}$ & $\begin{array}{c}\Delta \mathrm{Q}_{2} \\
(\mathrm{pC})\end{array}$ & $\begin{array}{c}\Delta \mathrm{Q}_{3} \\
(\mathrm{pC})\end{array}$ & $\begin{array}{c}\Delta \mathrm{Q}_{4} \\
(\mathrm{pC})\end{array}$ & $\begin{array}{c}\Delta \mathrm{Q}_{5} \\
(\mathrm{pC})\end{array}$ & $\begin{array}{c}c p \\
(\mathrm{pC} / \mathrm{N})\end{array}$ \\
\hline 1 & 436,20 & 91,21 & 89,61 & 91,21 & 92,61 & 92,41 & 209,56 \\
\hline 2 & 435,90 & 88,91 & 90,81 & 90,31 & 90,71 & 89,71 & 206,67 \\
\hline 3 & 434,83 & 48,46 & 47,47 & 49,06 & 48,77 & 48,66 & 111,50 \\
\hline 4 & 433,75 & 42,78 & 42,38 & 43,88 & 44,48 & 43,58 & 100,10 \\
\hline 5 & 432,18 & 58,84 & 49,54 & 49,84 & 52,55 & 50,24 & 120,79 \\
\hline \multicolumn{7}{|c|}{$c p$ médio } \\
\hline
\end{tabular}




\subsubsection{Discussão: Atividade Piezelétrica}

As amostras produzidas com os novos aprimoramentos exibiram atividade piezelétrica com coeficientes superiores aos dos filmes de PVDF e apresentou valores comparáveis aos das espumas poliméricas e dos ferroeletretos de estruturas homogêneas. Seu coeficiente piezelétrico apresentou valores entre 110 e $340 \mathrm{pC} / \mathrm{N}$ por meio do processo de laminação a quente, e entre 160 e 240 pC/N por meio do processo adesivo a frio, dependendo do diâmetro de suas bolhas.

Tabela 4.7 Resumo dos valores dos coeficientes piezelétricos médios das amostras produzidas pelos processos laminação a quente e adesivo a frio.

\begin{tabular}{|c|c|c|c|c|c|c|}
\cline { 2 - 7 } \multicolumn{1}{c|}{} & \multicolumn{3}{c|}{ Laminação a Quente } & \multicolumn{3}{c|}{ Adesivo a Frio } \\
\hline Diâmetro $(\mathrm{mm})$ & 3,2 & 3,8 & 4,5 & 2,5 & 3,0 & 3,5 \\
\hline Altura $(\mu \mathrm{m})$ & 230 & 280 & 380 & 290 & 350 & 290 \\
\hline$c p$ médio $(\mathrm{pC} / \mathrm{N})$ & 110 & 340 & 160 & 160 & 240 & 160 \\
\hline
\end{tabular}

Também é possível notar que a atividade piezelétrica tanto para as amostras produzidas pelo processo laminação a quente, quanto naquelas produzidas pelo processo adesivo a frio possui um limiar de saturação. No entanto essa verificação torna-se inconclusiva, pois as amostras produzidas não possuem as mesmas alturas de bolhas, propriedade de suma importância durante o carregamento elétrico que é regido pela lei de Paschen e, consequêntemente, intimamente ligada ao processo de aprisionamento de cargas elétricas nas superfícies internas das bolhas.

Além disso, outra similaridade notada é uma possível correspondência entre a altura das bolhas e a correspondente atividade piezelétrica das amostras produzidas por meio do processo adesivo a frio, como pode ser visto para o caso de amostras com bolhas de $290 \mu \mathrm{m}$ de altura. Entretanto, o mesmo não pode ser constatado com as amostras produzidas pelo processo laminação a quente devido à indisponibilidade de amostras com tal altura de bolhas. 
Contudo, ressalta-se a necessidade de estudos aprofundados com amostras com uma maior variedade de diâmetros e alturas de bolhas para relacioná-las à correspondente atividade piezelétrica. 



\section{Conclusão}

Os aprimoramentos aqui implementados possibilitam um maior controle da distribuição, altura e diâmetro das bolhas de ar. Ressalta-se que suas principais contribuições relativas aos processos existentes foram a moldagem prévia do filme de uma das camadas e os novos processos de colagem, laminação a quente e utilizando filme adesivo. Assim, estes aprimoramentos têm permitido um melhor controle das dimensões das bolhas e facilitado sobremaneira sua implementação em escala industrial. Desta forma, vislumbra-se que com o controle proporcionado pelos aprimoramentos desenvolvidos possa permitir o projeto de transdutores piezelétricos, conforme sua aplicação, e, consequentemente, ampliar significativamente a gama de aplicações comerciais, a exemplo dos sensores de presença, teclados finos, balanças dinâmicas e sensores de pressão.

Outra importante contribuição deste trabalho foi o desenvolvimento de um sistema quase estático para a medida do coeficiente piezelétrico que possibilita a aplicação de forças de poucos miliNewtons, da ordem de $400 \mathrm{mN}$, força suficiente para provocar deformações nas bolhas sem colapsá-las, diferentemente dos sistemas de medidas empregados em outros trabalhos que aplicam forças da ordem de 1 a $3 \mathrm{~N}$.

As amostras produzidas com os novos aprimoramentos exibiram atividade piezelétrica com coeficientes superiores aos dos filmes de PVDF e apresentou valores comparáveis aos das espumas poliméricas e dos ferroeletretos de estruturas homogêneas. Seu coeficiente piezelétrico apresentou valores entre 110 e $340 \mathrm{pC} / \mathrm{N}$ por meio do processo de laminação a quente, e entre 160 e 240 pC/N por meio do processo adesivo a frio, dependendo do diâmetro de suas bolhas. No entanto, devido à reduzida variedade de tamanhos de bolhas apresentadas não foi ainda possível estabelecer uma relação entre a atividade piezelétrica e as dimensões das bolhas.

Neste contexto, ainda é necessária um estudo mais aprofundado desses sensores para possibilitar um melhor entendimento das suas características eletromecânicas. Assim, propõese para trabalhos futuros: 
- caracterização de sensores com bolhas de uma variedade maior de diâmetros e alturas para tentar estabelecer uma relação entre os parâmetros das bolhas e a atividade piezelétrica,

- caracterização da atividade piezelétrica direta com variação da força aplicada para verificar a região de linearidade da resposta elétrica,

- caracterização dinâmica para verificar sua resposta em frequência,

- caracterização piezelétrica de sensores carregados eletricamente com diferentes tensões e sob diferentes temperaturas,

- caracterização temporal para se verificar a perda da atividade piezelétrica com o tempo de carregamento, e

- caracterização térmica para verificar a resposta elétrica com a variação de temperatura.

Além disso, também é possível desenvolver estudos com amostras produzidas com outros filmes poliméricos e com diferentes gases no interior das bolhas, para que se verifique a alteração da quantidade de cargas elétricas aprisionadas e, consequentemente, a variação do coeficiente piezelétrico. 


\section{Referências Bibliográficas}

ADAMS, E. P. On electrets. Journal of the Franklin Institute, Philadelphia, v. 204, n. 4, p. 469-486, 1927.

ALTAFIM, R. A. C.; GIACOMETTI, J. A.; JANISZEWSKI, J. M. A novel method for electret production using impulse voltages. IEEE Transactions on Dielectrics and Electrical Insulation, New York, v. 27, n. 4, p. 739-743, 1992.

ALTAFIM, R. A. C.; LEAL FERREIRA, G. F.; GIACOMETTI, J. A. Self-controlled prebreakdown discharges in planar symmetry. IEEE Transactions on Dielectrics and Electrical Insulation, New York, v. 5, n. 1, p. 77-81, 1998.

ALTAFIM, R. A. C. et al. Piezoelectricity of multi-layers space-charge electrets from Teflon FEP with homogeneous voids distributed on its surface. In: IEEE ANNUAL REPORT CONFERENCE ON ELECTRICAL INSULATION AND DIELECTRIC PHENOMENA, 2003, Albuquerque. Proceedings... Piscataway: IEEE Service Center, 2003. p. 225-228.

. Piezoelectricity in Multi-Air Voids Electrets. In: IEEE ANNUAL REPORT CONFERENCE ON ELECTRICAL INSULATION AND DIELECTRIC PHENOMENA, 2005, Nashville. Proceedings... Piscataway: IEEE Service Center, 2005. p. 669-672.

. Piezoelectrets from thermo-formed bubble structures of fluoropolymer-electret films. IEEE Transactions on Dielectrics and Electrical Insulation, New York, v. 13, n. 5, 2006.

BACKMAN, J.; KARJALAINEN, M. Audio and ultrasonic transducers based on electromechanical film (ETMF). In: IEEE INTERNATIONAL CONFERENCE ON ACOUSTICS, SPEECH AND SIGNAL, 1990, Albuquerque. Proceedings... Piscataway: IEEE Service Center, 1990. v. 2, p. 1173-1176.

BALLATO, A. Piezoelectricity: History and New Thrusts. In: IEEE ULTRASONICS SYMPOSIUM, 1996, San Antonio. Proceedings... Piscataway: IEEE Service Center, 1996. v. 1, p. 575-583. 
BAUER, S. et al. Modern electrets. In: IEEE SYMPOSIUM ON ULTRASONICS, 2003, Honolulu. Proceedings... Piscataway: IEEE Service Center, 2003. v. 1, p. 370-276.

BEHRENDT, N. et al. Development of porous polypropylene blends with NA11 particles and glass hollow spheres by biaxial stretching for electret applications. IEEE Transactions on Dielectrics and Electrical Insulation, New York, v. 13, n. 5, p. 992-1000, 2006.

BOTTOM, V. E. The theory and design of quartz crystal units: an introduction to the basic principles of piezoelectricity and their application to the design of quartz. Texas: Mcmurry, 1968.

BRUNO, W. Reproduction of Sound. United States Patent 2024705, 16 jul. 1940, 26 mai. 1942.

CRESWELL, R. A.; PERLMAN, M. M. Thermal currents from corona charged mylar. Journal of Applied Physics, Menasha, v. 41, p. 2365-2375, 1970.

CRICHTON, G. C.; KARLSSON, P. W.; PEDERSEN, A. Partial discharges in ellipsoidal and spherical voids. IEEE Transactions on Electrical Insulation, New York, v. 24, p. 335342, 1989.

EGUCHI, M. On dielectric polarization. Physico-Mathematical Society of Japan, Tokyo, ser. 3, v. 1, p. 326-331, 1919.

- Further researches on permanently polarized dielectric. Physico-Mathematical Society of Japan, Tokyo, ser. 3, v. 2, p. 169-176, 1920.

. Some experimental studies on the nature of the internal electrical charge of the electret. Physico-Mathematical Society of Japan, Tokyo, ser. 3, v. 5, p. 107-113, 1923. 182,1925

On the permanent electret. Philosophical Magazine, London, ser. 6, v. 49, p. 178-

FARADAY, M. Experimental Researches in Electricity. Philosophical Transactions of the Royal Society, London, ser. 11, v. 128, p. 1-40, 1838.

FUKADA, E. History and recent progress in piezoelectric polymers. IEEE Transaction on Ultrasonic Ferroelectrics and Frequency Control, New York, v. 47, n. 6, p. 1277-1290, 2000.

GEMANT, A. Recent investigations on electrets. Philosophical Magazine, London, ser. 7, n. 136, v. 20, p. 929-952, 1935. 
GERHARD-MULTHAUPT, R. Electrets: dielectrics with quasi-permanent charge or polarization. IEEE Transactions on Electrical Insulation, New York, v. EI-22, n. 5, p. 531554, 1987.

Less can be more: holes in polymers lead to a new paradigm of piezoelectric materials for electret transducers. IEEE Transactions on Dielectrics and Electrical Insulation, New York, v. 9, n. 5, p. 850-859, 2002.

GERHARD-MULTHAUPT, R. et al. Preliminary study of multi-layer space-charge electrets with (quasi-)piezoelectric properties from porous and non-porous Teflon films. In: IEEE INTERNATIONAL SYMPOSIUM ON ELECTRETS, 10., 1999, Delphi. Proceedings... Piscataway: IEEE Service Center, 1999. p. 273-276.

Porous polytetrafluoroethylene space-charge electrets for piezoelectrical applications. IEEE Transactions on Dielectrics and Electrical Insulation, New York, v. 7, p. 480-488, 2000.

Electrode poling of cellular polypropylene films with short high-voltage pulses. In: IEEE ANNUAL REPORT CONFERENCE ON ELECTRICAL INSULATION AND DIELECTRIC PHENOMENA, 2002, Cancun. Proceedings... Piscataway: IEEE Service Center, 2002. p. 299-302.

GRAY, S. A Letter from Mr. Stephen Gray to Dr. Mortimer, Secr. R. S. Containing a Farther Account of His Experiments concerning Electricity. Philosophical Transactions of the Royal Society, London, v. 37, p. 285-291, 1732.

GROSS, B. Experiments on electrets. Physical Review, Woodbury, v. 66, n. 1 e 2, p. 26-28, 1944. $143,1958$.

Irradiation effects in plexiglas. Journal of Polymer Science, Easton, v. 27, p. 135Charge storage in solid dielectrics. Amsterdan: Elsevier, 1964.

GUARROTXENA, N. et al. Charge decay properties of poly (propylene) samples (PP) with various stereochemical compositions. Macromolecular Rapid Communications, Basel, v. 21, p. 691-696, 2000.

GUTMAN, F. The Electret. Review of Modern Physics, Minneapolis, v. 20, n. 3, p. 457-472, 1948. 
HILKZER, B.; MALECKI, J. Electrets. Traduzido por Jerzy Tomaszczyk. Amsterdam: Elsevier; Warszawa: PWN-Polish Scientific, 1986.

HILLENBRAND, J.; SESSLER, G. M. Mechanical and electrical response of charged polymers with cellular structure. In: IEEE ANNUAL REPORT CONFERENCE ON ELECTRICAL INSULATION AND DIELECTRIC PHENOMENA, 1999, Austin. Proceedings... Piscataway: IEEE Service Center, 1999. p. 43-46.

Piezoelectricity in cellular electret films. IEEE Transactions on Dielectrics and Electrical Insulation, New York, v. 7, n. 4, p. 537-542, 2000.

Quasistatic and Dynamic Piezoelectric Coefficients of Polymer Foams and Polymer Film Systems. IEEE Transactions on Dielectrics and Electrical Insulation, New York, v. 11, n. 1, p. 72-79, 2004.

KACPRZYK, R.; MOTYL, E. Properties of PP-PS Double layer electrets. In: IEEE INTERNATIONAL SYMPOSIUM ON ELECTRETS, 8., 1994, Paris. Proceedings... Piscataway: IEEE Service Center, 1994. p. 703-708.

KACPRZYK, R.; DOBRUCKI, A.; GAJEWSKI, J. B. Double-layer electrets transducer. Journal of Electrostatics, Amsterdam, v. 39, p. 33-40, Jan. 1997.

KACPRZYK, R. et al. Piezoelectric Properties of nonuniform electrets. Journal of Electrostatics, Amsterdam, v. 35, n. 2/3, p. 161-166, Aug. 1995.

KAWAI, H. The Piezoelectricity of Poly (vinylidene Fluoride). Japanese Journal of Applied Physics, Tokyo, v. 8, n. 7, p. 975-976, 1969.

KRESSMANN, R. Linear and nonlinear piezoelectric response of charged cellular polypropylene. Journal of Applied Physics, Menasha, v. 90, p. 3489-3496, Oct. 2001a.

New piezoelectric polymer for air-borne and water-borne sound transducers. Journal of the Acoustical Society of America, New York, v. 109, p. 1412-1416, Apr. 2001b.

KÜNSTLER, W. et al. Piezoelectricity of porous polytetrafluoroethylene single and multiplefilm electrets containing high charge densities of both polarities. Applied Physics A, Dordrecht, v. 70, p. 5-8, 2000.

LEKKALA, J.; PAAJANEN, M. EMFi - New electrets material for sensors and actuators. In: IEEE INTERNATIONAL SYMPOSIUM ON ELECTRETS, 10., 1999, Delphi. Proceedings... Piscataway: IEEE Service Center, 1999. p. 743-746. 
LINDNER, M. et al. Dielectric barrier microdischarges: mechanism for the charging of cellular piezoelectric polymers. Journal of Applied Physics, Menasha, v. 91, p. 5283-5287, Apr. 2002.

Charged cellular polymers with "ferroelectretic" behavior. IEEE Transactions on Electrical Insulation, New York, v. 11, p. 255-263, 2004.

MCALLISTER, L. W. Decay of charge deposited on the wall of gaseous void. IEEE Transactions on Electrical Insulation, New York, v. 27, p. 1202-1207, 1992.

Partial discharges in spheroidal voids: void orientation. IEEE Transactions on Dielectrics and Electrical Insulation, New York, v. 4, p. 456-461, 1997.

MEDYCKI, W.; HILCZER, B. An efficient method of production of high charge density electrets. Journal of Electrostatics, Amsterdan, v. 19, n. 2, p. 205-207, May 1987.

MELLINGER, A. et al. Thermally stable dynamic piezoelectricity in sandwich films of porous and nonporous amorphous fluoropolymer. Applied Physics Letters, Woodbury, v. 79, p. 1852-1854, 2001.

MORENO, R. A.; GROSS B. Measurement of potential building and decay, surface charge density, and charging currents of corona-charged polymer foil electrets. Journal of Applied Physics, Menasha, v. 47, n. 8, p. 3397-3402, 1976.

MURPHY, P. V. Method of making an electret. United States Patent 3702493, 4 mar. 1971, 14 nov. 1972.

NEUGESCHWANDTNER, G. S. et al. Large and broadband piezoelectricity in smart polymer-foam space-charge electrets. Applied Physics Letters, Woodbury, v. 77, p. 38273829, 2000.

Large piezoelectric effects in charged, heterogeneous fluoropolymer electrets. Applied Physics A, Dordrecht, v. 70, p. 1-4, 2000.

Piezo and pyroelectricity of a polymer-foam space-charge electrets. Journal of Applied Physics, Menasha, v. 89, p. 4503-4511, Apr. 2001.

NEWNHAM, R. E. et al. Electrostriction: Nonlinear electromechanical coupling in solid dielectrics. Journal of Physical Chemistry, Washington, v. 101, p. 10141-10150, 1997. 
PAAJANEN, M.; LEKKALA, J.; KIRJAVAINEN, K. Electromechanical film (EMFi) - A new multipurpose electret material. Sensors and Actuators, Lausanne, v. 84, n. 1/2, p. 95-102, Aug. 2000.

PAAJANEN, M.; LEKKALA, J.; VÄLIMÄKI, H. Electromechanical modeling and properties of the electrets film EMFi. IEEE Transactions on Dielectrics and Electrical Insulation, New York, v. 8, n. 4, p. 629-636, 2001.

PAAJANEN, M.; VÄLIMÄKI, H.; LEKKALA, J. Modeling the sensor and actuator operations of the Electro-Mechanical Film EMFi. In: IEEE INTERNATIONAL SYMPOSIUM ON ELECTRETS, 10., 1999, Delphi. Proceedings... Piscataway: IEEE Service Center, 1999. p. 735-738.

Modeling the electromechanical film (EMFi). Journal of Electrostatics, Amsterdam, v. 48, n. 3-4, p. 193-203, Mar. 2000.

PAAJANEN, M.; WEGENER, M.; GERHARD-MULTHAUPT, R. Understanding the role of gas in the voids during corona charging of cellular electrets films - A way to enhance their piezoelectricity. Journal of Physics D: applied physics, Bristol, v. 34, n. 16, p. 2482-2488, Aug. 2001a.

Charging of cellular space charge electrets films in various gas atmospheres. In: IEEE ANNUAL REPORT CONFERENCE ON ELECTRICAL INSULATION AND DIELECTRIC PHENOMENA, 2001, Kitchener. Proceedings... Piscataway: IEEE Service Center, 2001b. p. 24-27.

PELTONEN, J.; PAAJANEN, M.; LEKKALA, J. Determination of the actuator sensitivity of electromechanical polypropylene films by atomic force microscopy. Journal of Applied Physics, Menasha, v. 88, n. 8, p. 4789-4793, 2000.

PILLAI, P. K. C.; ARYA, S. K. Photoelectret state formation and its temperature dependence thin-films of CdS. Solid State Electronics, London, v. 15, n. 11, p. 1245-1251, 1972.

PISANI ALTAFIM, R. A. Análise e implementação de métodos para a caracterização de eletretos termo-formados. 2006. 63 f. Dissertação (Mestrado em Engenharia Elétrica) Escola de Engenharia de São Carlos, Universidade de São Paulo, São Carlos, 2006.

PISANI ALTAFIM, R. A. et al. Template-based fluorethylenepropylene piezoelectrets with tubular channels for transducer applications. Journal of Applied Physics, Menasha, v. 106, p. 014106-1-5, 2009.

POUNDER, C. The quest for a charging mechanism to the end of the 19th century. Journal of Electrostatics, London, v. 3, n. 4, p. 389-394, Nov. 1977. 
QIU, X. et al. Barrier discharges in cellular polypropylene ferroelectrets: how do they influence the electromechanical properties? Journal of Applied Physics, Menasha, 101, n. 10, p. 104112-1-7, 2007a.

Spectroscopic study of dielectric barrier discharges in cellular polypropylene ferroelectrets. Applied Physics Letters, Woodbury, v. 91, n. 13, p. 132905-1320907, 2007b.

RUTHERFORD, R. T. Microphone. United States Patent 2024705, 11 nov. 1931, 17 dez. 1935.

SAWA, G; LEE, D. C.; IEDA, M. Discharge current on corona charged polyethylene. Japanese Journal Applied Physics, Tokyo, v. 14, n. 5, p. 643-649, 1975.

SAVOLAINEN, A. Biaxially oriented polypropylene blown films. I: Morphological analysis of orientation in the machine direction, Polymer Engineering and Science, Easton, v. 30, p. 1258-1264, 1990.

SCHWÖDIAUER, R. et al. Low-dielectric-constant cross-linking polymers: Film electrets with excellent charge stability. Applied Physics Letters, Woodbury, v. 75, n. 25, p. 39984000, 1999a.

. Dielectric and electret properties of novel Teflon PTFE and PTFE-like polymers. In: IEEE INTERNATIONAL SYMPOSIUM ON ELECTRETS, 10., 1999, Delphi. Proceedings... Piscataway: IEEE Service Center, 1999b. p. 313-316.

Preparation and characterization of novel piezoelectric and pyroelectric polymer electrets. IEEE Transactions on Dielectrics and Electrical Insulation, New York, v. 7, n. 4, p. 578-586, 2000.

SESSLER, G. M. Polymeric Electrets. In: SEANOR, D. A. (Ed.). Electrical Properties of Polymers. New York: Academic Press, 1982. Cap. 6, p. 241-284.

Electrets. Morgan Hill: Laplacian, 1998. v. 1.

SESSLER, G. M.; HILLENBRAND, J. Electromechanical response equations of cellular electret films. In: IEEE INTERNATIONAL SYMPOSIUM ON ELECTRETS, 10., 1999, Delphi. Proceedings... Piscataway: IEEE Service Center, 1999a. p. 261-264.

Electromechanical response of cellular electret films. Applied Physics Letters, Woodbury, v. 75, n. 21, p. 3405-3407, 1999b. 
SESSLER, G. M.; WEST, J. E. Self-Biased Condenser Microphone with High Capacitance. Journal of the Acoustical Society of America, New York, v. 34, n. 11, p. 17871788, Nov. 1962.

Foil-Electret Microphones. Journal of the Acoustical Society of America, New York, v. 40, n. 6, p. 1433-1440, 1966.

Production of high quasipermanent charge densities on polymer foils by application of breakdown fields. Journal of Applied Physics, Menasha, v. 43, n. 3, p. 922-926, 1972.

Electret transducers: a review. Journal of the Acoustical Society of America, New York, v. 53, n. 6, p. 1589-1600, June 1973.

SHAHIN, M. M. Nature of charge carriers in positive and negative corona discharges. In: IEEE ANNUAL REPORT CONFERENCE ON ELECTRICAL INSULATION AND DIELECTRIC PHENOMENA, 1968. Proceedings... Piscataway: IEEE Service Center, 1968. p. 85-89.

Nature of charge carriers in negative coronas. Applied Optics, Easton, v. 8, n. S1, p. 106-110, 1969.

TUNCER, E.; WEGENER, M. Elastic properties of highly anisotropic thin poly(propylene) foams. Materials Letter, Menasha, v. 58, n. 22/23, p. 2815-2818, Sept. 2004.

URAYAMA, K. et al. Investigations of ferroelectric-to-paraelectric phase transition of vinylidenefluoride trifluoroethylene copolymer thin films by electromechanical interferometry. Journal of Applied Physics, Menasha, v. 86, p. 6367-6375, 1999.

VAN TURNHOUT, J. et al. Distribution and stability of charges in porous polypropylene films. In: IEEE INTERNATIONAL SYMPOSIUM ON ELECTRETS, 10., 1999, Delphi. Proceedings... Piscataway: IEEE Service Center, 1999. p. 785-788.

VON SEGGERN, H. Identification of TSC peaks and surface-voltage stability in Teflon FEP. Journal of Applied Physics, Menasha, v. 50, n. 4, 2817-2821, 1979.

WEGENER, M. et al. Coating of porous polyfluoroethylene films with other polymers for electrets applications. In: IEEE ANNUL REPORT CONFERENCE ON ELECTRICAL INSULATION AND DIELECTRIC PHENOMENA, 2001, Kitchener. Proceedings... Piscataway: IEEE Service Center, 2001. p. 100-103. 
Ferroelectrets: highly anisotropic electrically charged polymer foams for electromechanical transducer applications. In: IEEE ULTRASONICS SYMPOSIUM, 2004, San Juan. Proceedings... Piscataway: IEEE Service Center, 2004. v. 2, p. 1138-1141.

Polyethylene terephthalate (PETP) foams as ferroelectrets. In: IEEE INTERNATIONAL SYMPOSIUM ON ELECTRETS, 12., 2005, Salvador. Proceedings... Piscataway: IEEE Service Center, 2005. p. 28-30.

WEINHOLD, T. et al. Porous polytetrafluoroethylene (PTFE) single-film space-charge electrets with high piezoelectric coefficients. In: IEEE INTERNATIONAL CONFERENCE ON DIELECTRIC MATERIALS, MEASUREMENTS AND APPLICATIONS, 8., 2000, Edinburgh. Proceedings... Piscataway: IEEE Service Center, 2000. p. 380-385.

WINDMILL, J. F. C. et al. Nanomechanical and electrical characterization of a new cellular electret sensor-actuator. Nanotechnology, New York, v. 19, n. 3, p. 035506-1-7, 2008.

XIA, Z.; WEDEL, A.; DANZ, R. The excellent charge storage stability of porous polytetrafluoroethylene (PTFE) film electrets. In: IEEE INTERNATIONAL SYMPOSIUM ON ELECTRETS, 10., 1999, Delphi. Proceedings... Piscataway: IEEE Service Center, 1999. p. 23-26.

XIA, Z. et al. High surface-charge stability of porous polytetrafluoroethylene electrets films at room and elevated temperatures. Journal of Physics D: applied physics, Bristol, v. 32, n. 17, p. L83-L85, Sept. 1999.

YANG, G. M. Thermally stimulated discharge of electron-beam and corona charged polypropylene films. Journal of Physics D: applied physics, Bristol, v. 26, n. 4, p. 690-693, Apr. 1993.

ZHANG, X.; HILLENBRAND, J.; SESSLER, G. M. Thermally stable fluorocarbon ferroelectrets with high piezoelectric coefficient. Applied Physics A, Dordrecht, v. 84, n. 1/2, p. 139-142, July 2006.

Ferroelectrets with improved thermal stability made from fused fluorocarbon layers. Journal of Applied Physics, Menasha, v. 101, n. 105, p. 054114-1-8, Mar. 2007.

ZHANG, P. et al. Influence of charging parameters on piezoelectricity for cellular polypropylene film electrets. In: IEEE INTERNATIONAL SYMPOSIUM ON ELECTRETS, 12., 2005, Salvador. Proceedings... Piscataway: IEEE Service Center, 2005. p. 39-42. 